درجة تطبيق استزاتيبية التلعيب في تعليه العلوم ومهعوقات

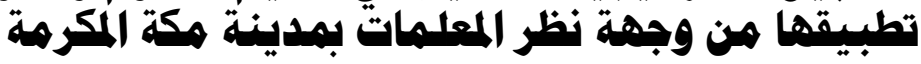

\title{
:
}

أ/منيرة بنت محمد إبراهيم العبدان

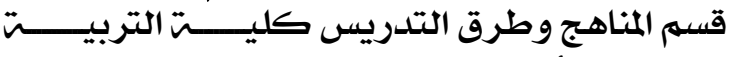

جامعت أم القرى بالمملكت العربيت السعوديت المبرديت

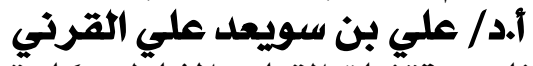

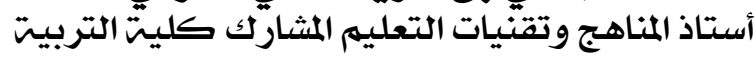

جامعت أم القرى بالمملكت العربيت السعوديتة 



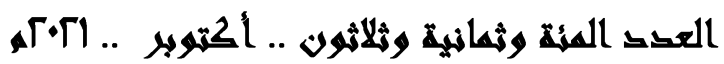

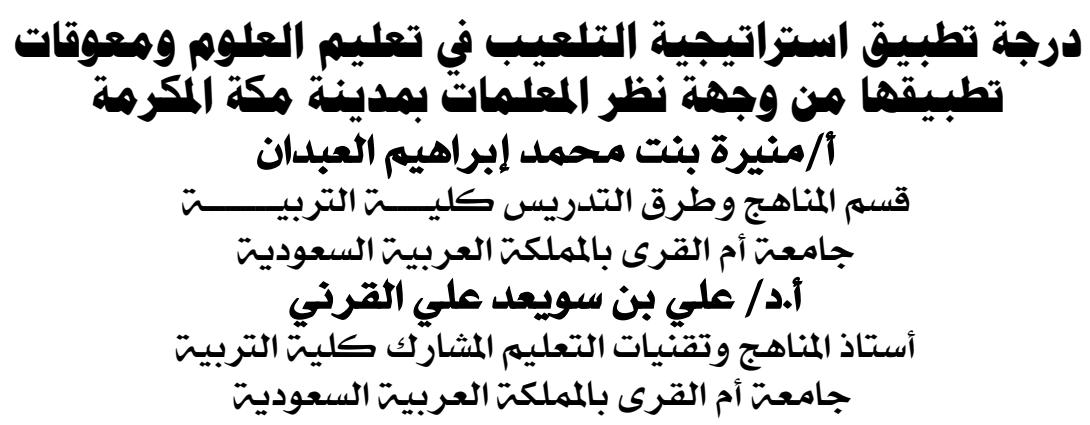

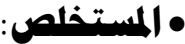

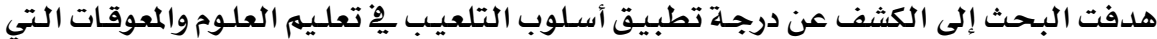

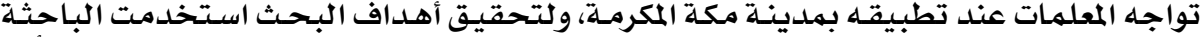

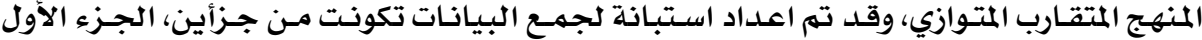

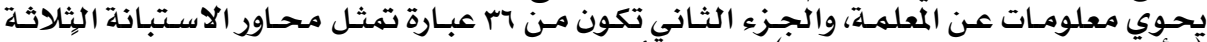

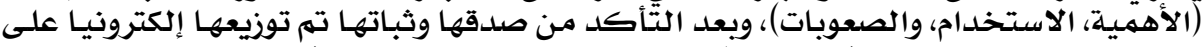

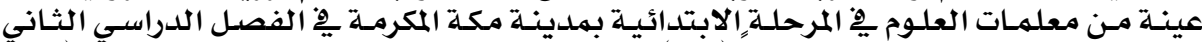

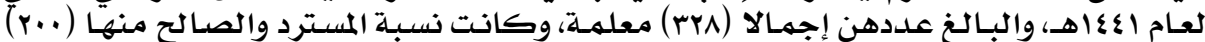

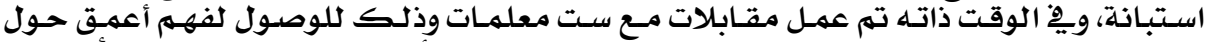

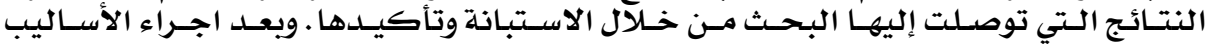

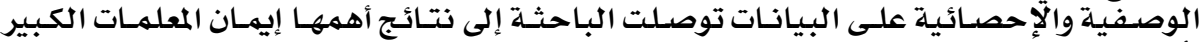

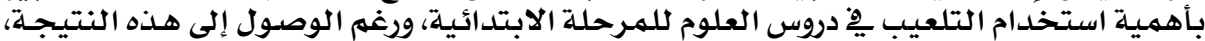

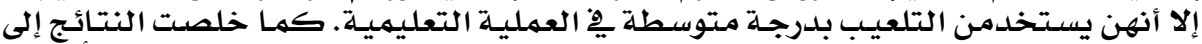

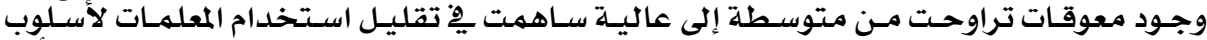

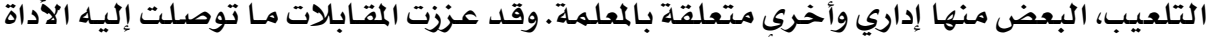

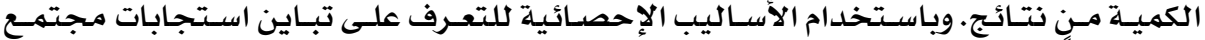

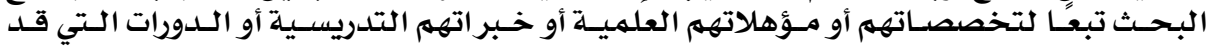

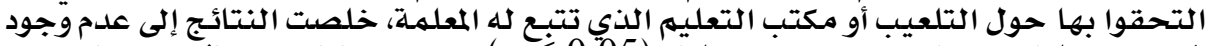

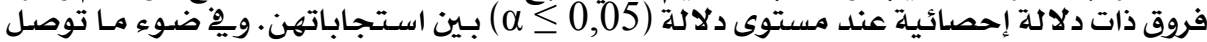

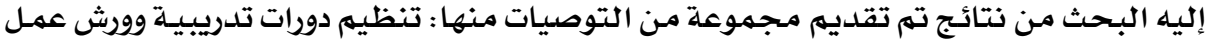

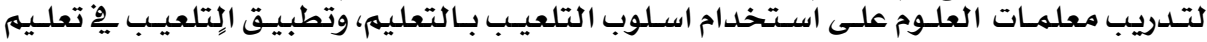

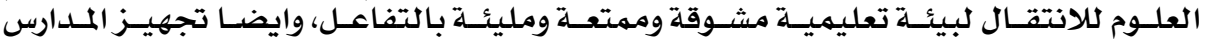

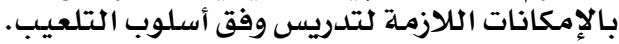

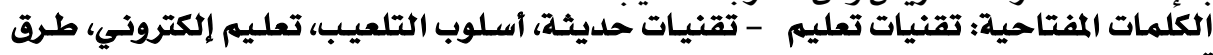

The Degree of Application of the Gamification Strategy in Science Education and the Obstacles to its Application from the Point of View of Teachers in Makkah Al-Mukarramah

Munira bint Muhammad Ibrahim Al-Abdan

Prof. Dr. Ali Bin Suwaid Ali Al-Qarni

$\underline{\text { Abstract }}$

The study aimed to reveal the degree of application of the gamification method in teaching science and the difficulties faced by female teachers when applying it in the city of Makkah Al-Mukarramah, and to achieve the goals of the study the researcher used the parallel converging approach, and a questionnaire was prepared to collect data consisting of two parts, the first 


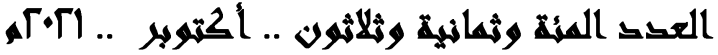

part contains information about the teacher, and the second part consists of 36 phrases that represent the three axes of the questionnaire (importance, use, difficulties), and after confirming their credibility and validity, they were distributed electronically to a sample of science teachers in the primary stage in the city of Makkah Al-Mukarramah in the second semester of the year 1441 $A H$, and their total number was 328 teachers. The percentage of retriever and the valid ones was (200) questionnaires, and at the same time interviews were conducted with six female teachers in order to reach a deeper understanding about the results of the study through the questionnaire and its confirmation. After conducting descriptive and statistical methods on the data, the researcher reached results, the most important of which is the teachers 'great belief in the importance of using gamification in science lessons for the primary stage, and despite reaching this result, they use medium-level gamification in the educational process. The results also concluded that there were obstacles ranging from medium to high, which contributed to reducing the use of parameters for the manipulation method, some of which are administrative and others related to the parameter. The interviews reinforced the findings of the quantitative tool. By using statistical methods to identify the variance of the responses of the study community according to their specializations, educational qualifications, teaching experiences, or courses that they may enroll in on gamification or the education office to which the teacher belongs, the results concluded that there were no statistically significant differences at the level of significance

$(\alpha \leq 0,05)$ Show their responses In light of the results of the research, a set of recommendations was presented, including: organizing training courses and workshops to train science teachers on the use of the gamification method in education, and the application of gamification in science education to move to an interesting, enjoyable and interactive educational environment, and also equipping schools with the necessary capabilities to teach according to a method Gamification.

Key words: teaching techniques, modern techniques, gamification method, e-learning, teaching methods.

• الاقدهمة:

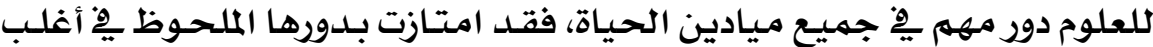

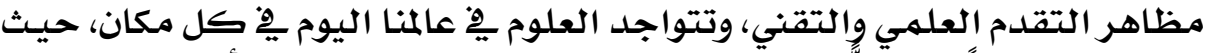

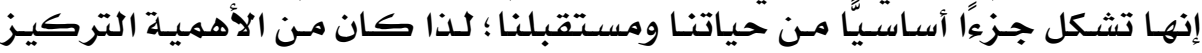

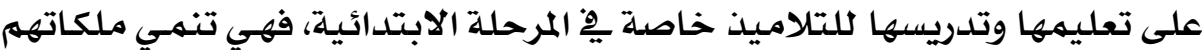

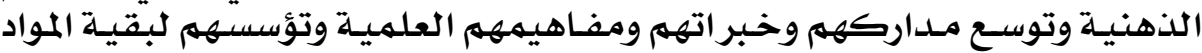

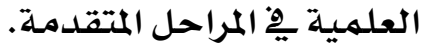

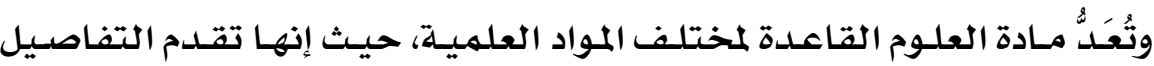

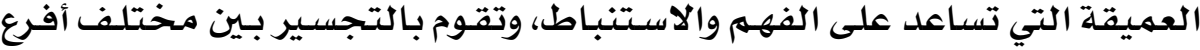

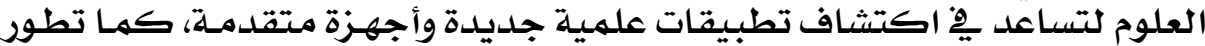

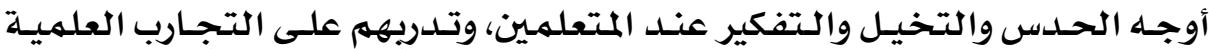

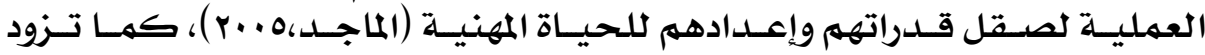

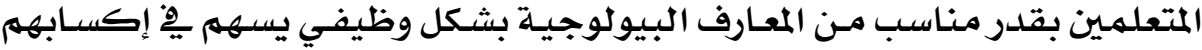

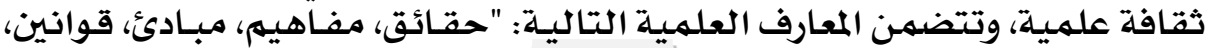




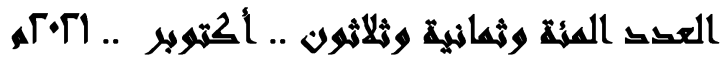

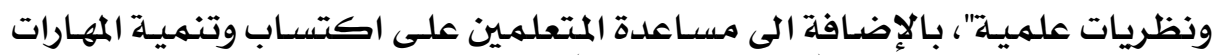

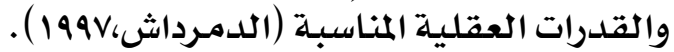

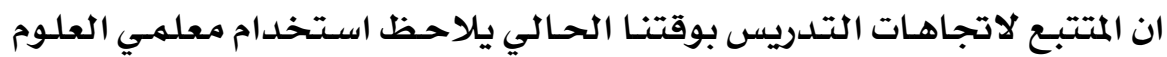

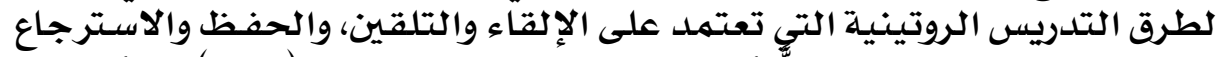

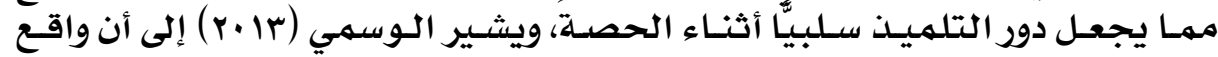

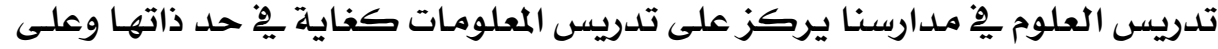

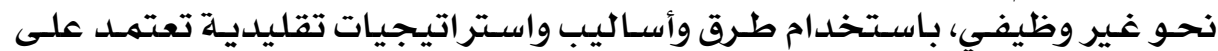

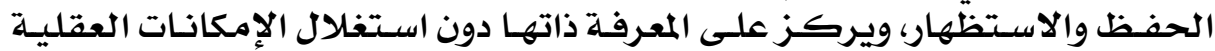

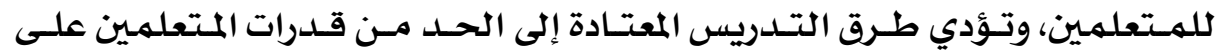

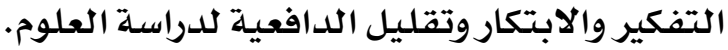

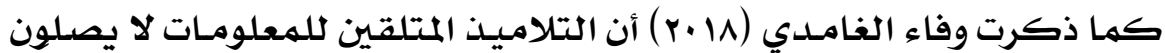

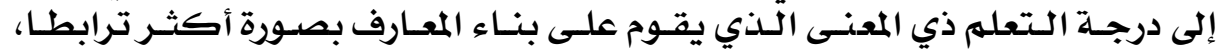

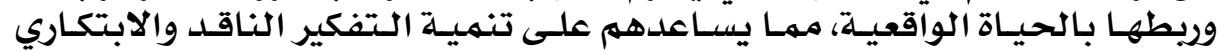

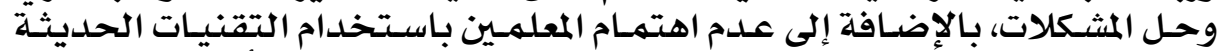

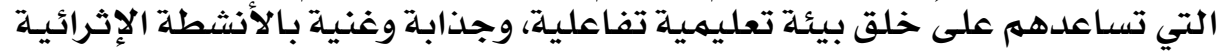

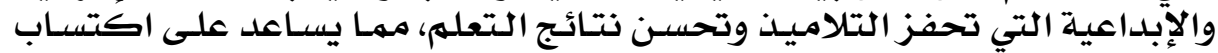

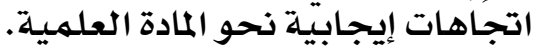

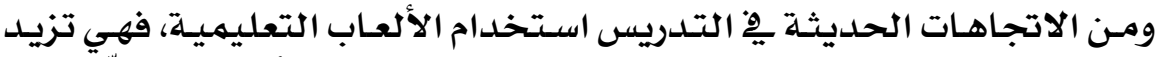

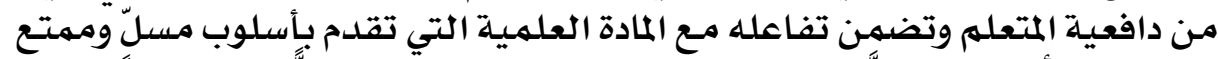

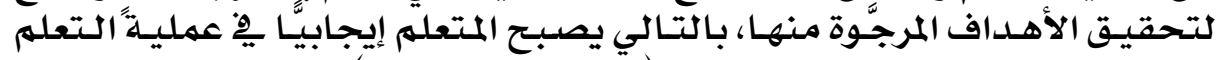

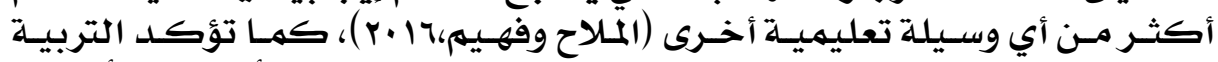

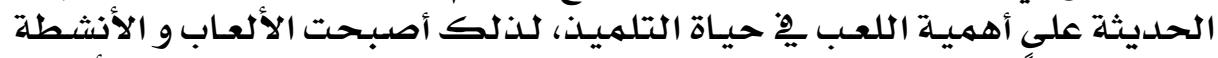

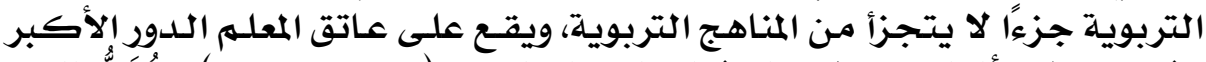

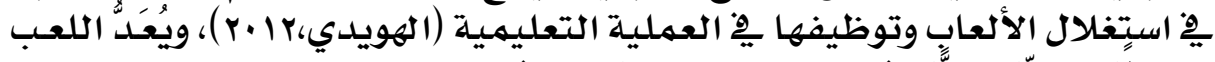

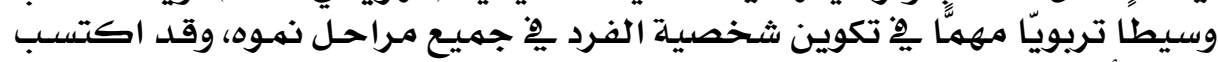

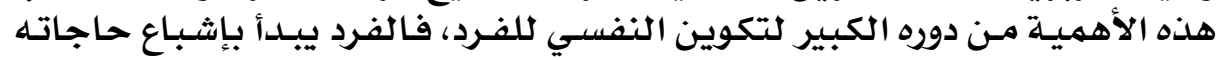

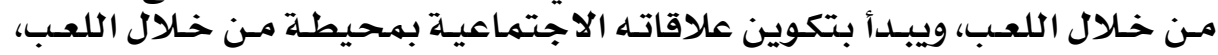

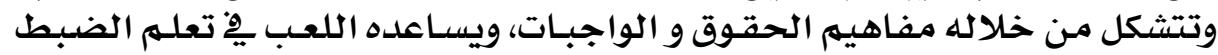

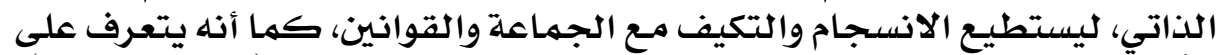

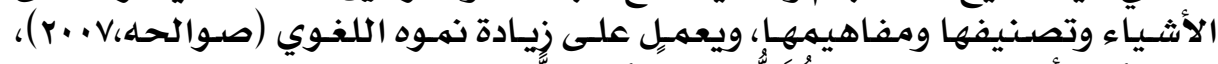

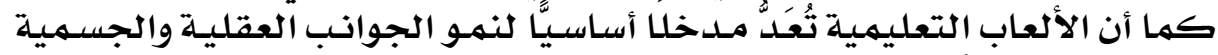

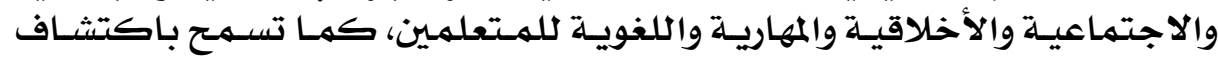

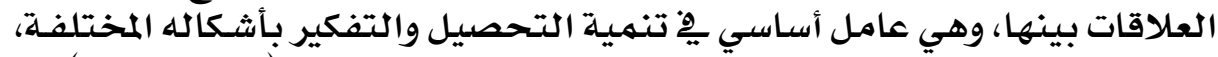

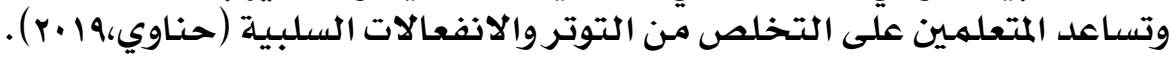

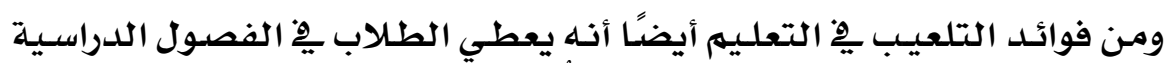

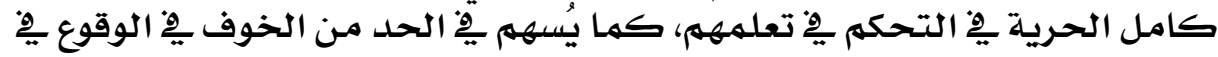




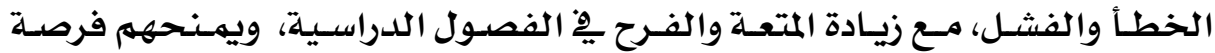

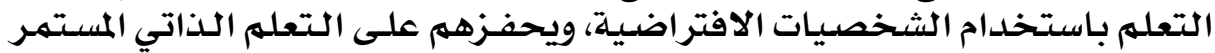

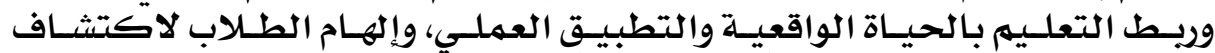

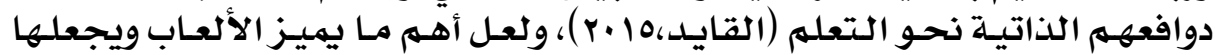

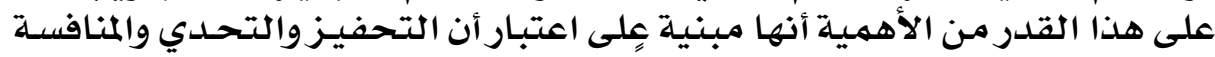

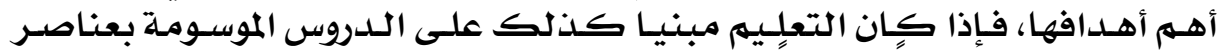

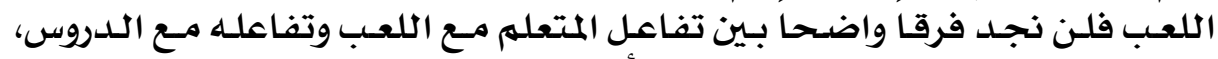

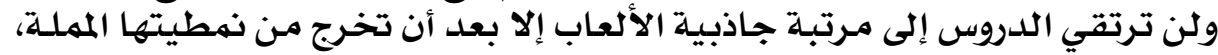

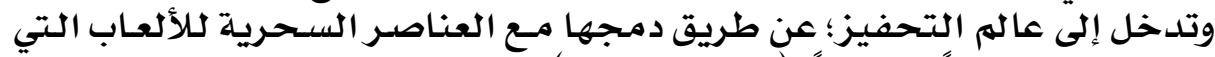

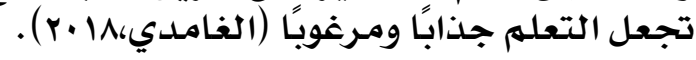

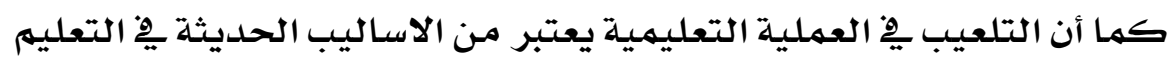

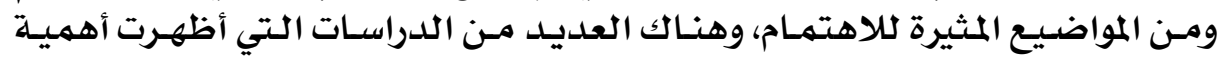

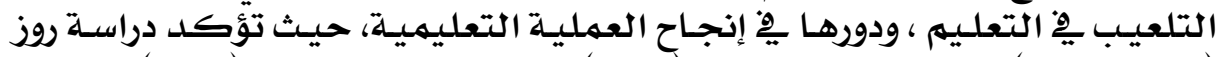

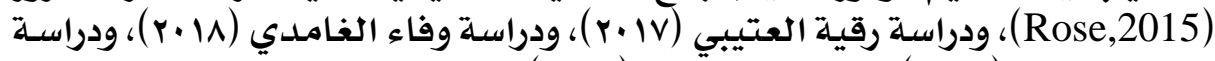

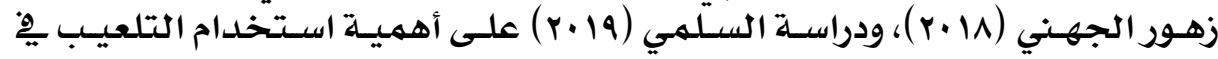

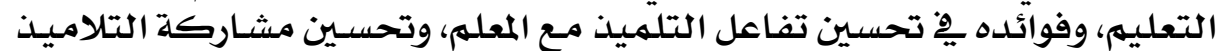

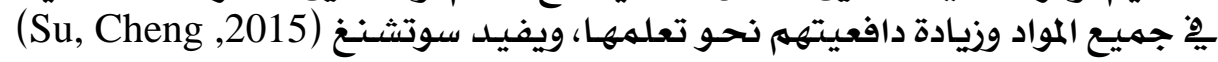

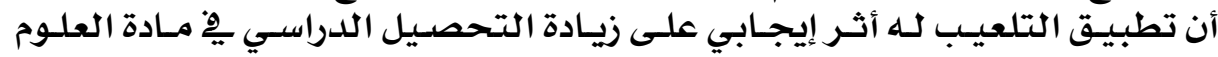
وزيادة الدافعية.

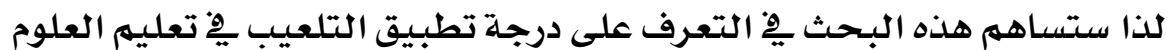

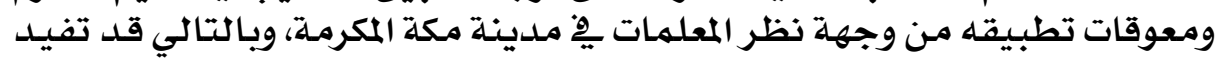

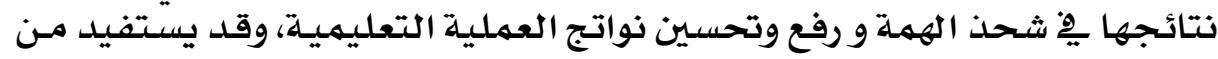

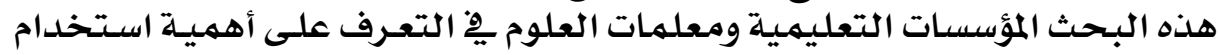

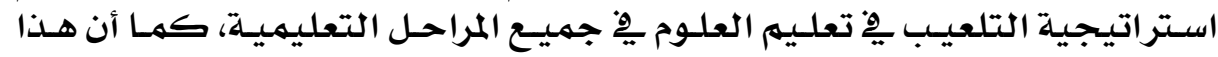

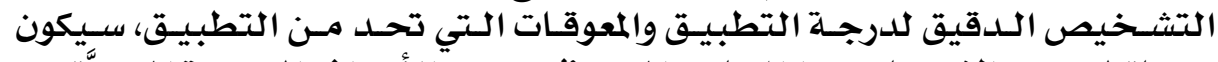

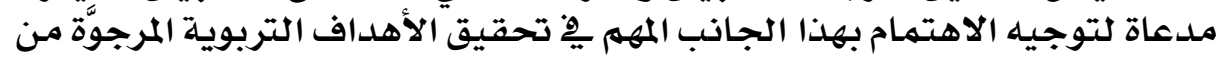

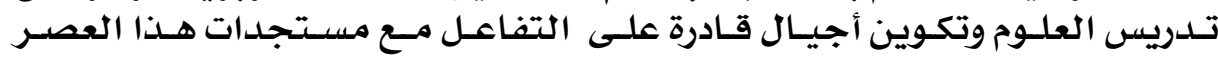

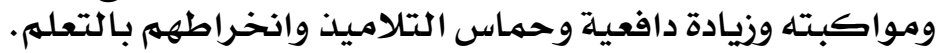

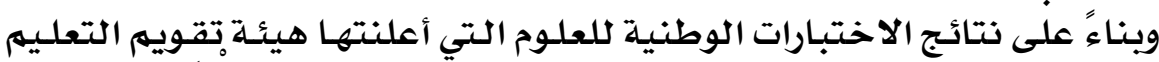

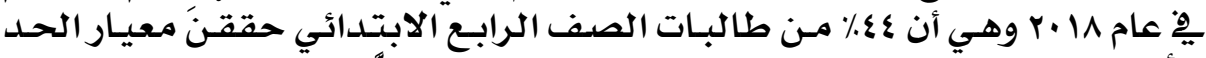

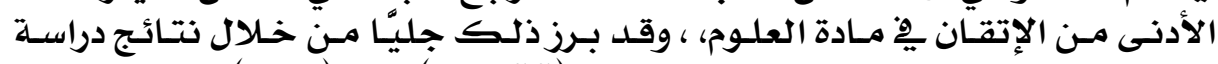

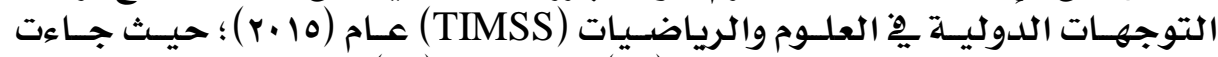

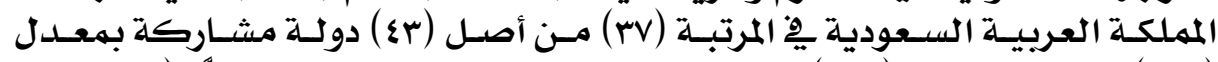

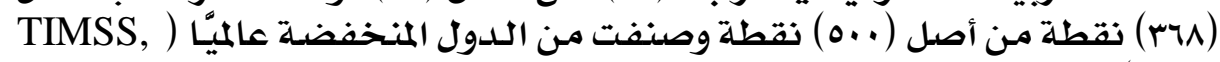

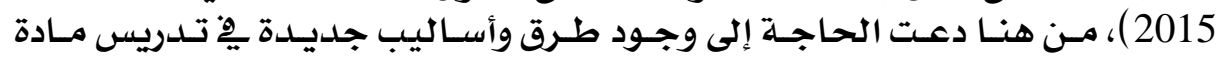

\section{$\varepsilon \Lambda$}




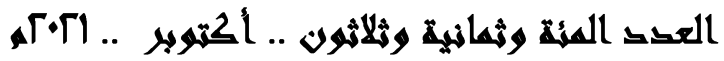

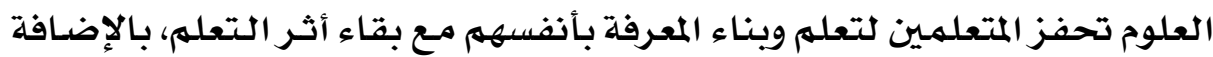

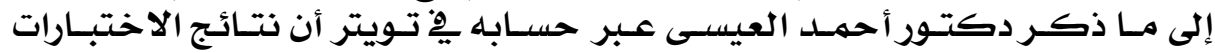

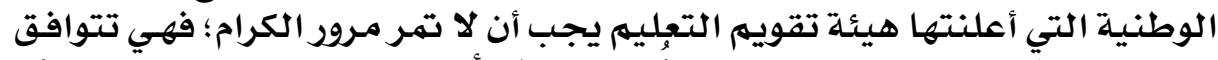

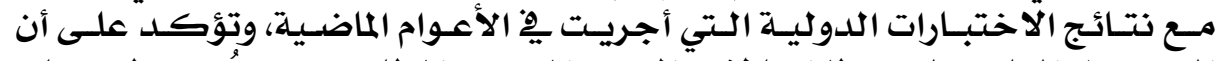

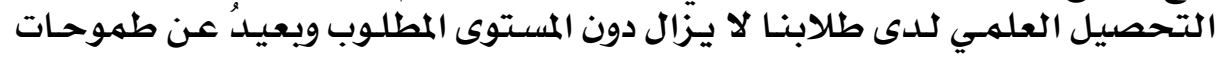

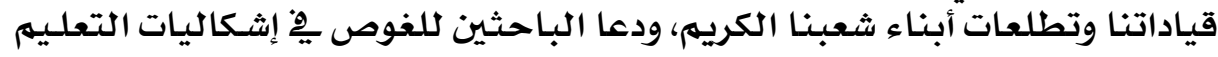
العميقة والمؤثرة يِّة مستوى تحصيل تصعيل أبنائنا وبناتنا.

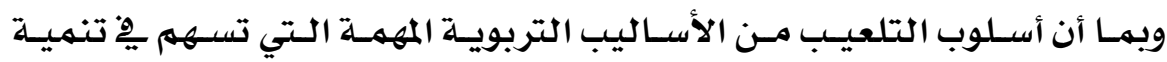

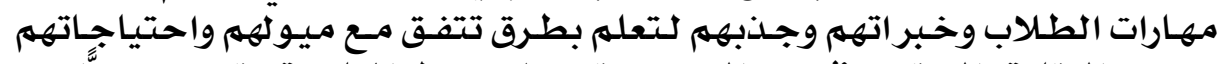

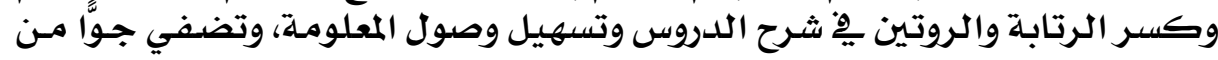

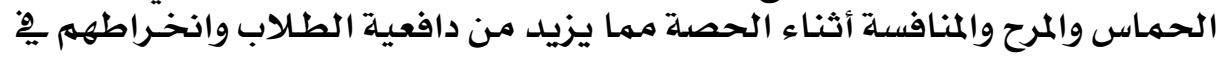

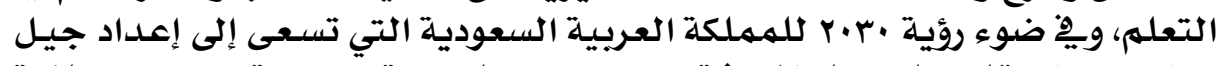

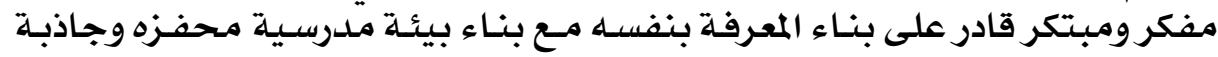

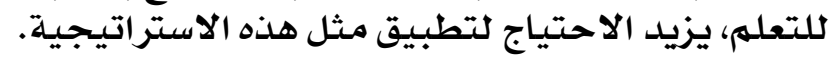

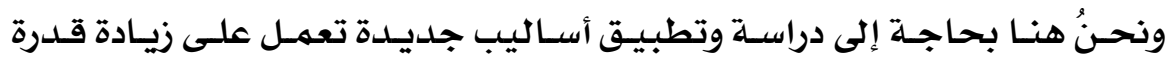

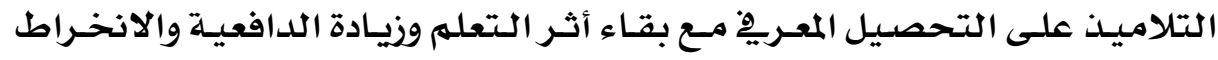
بالتعلهم.

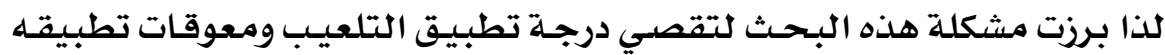

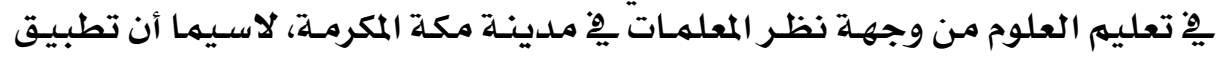

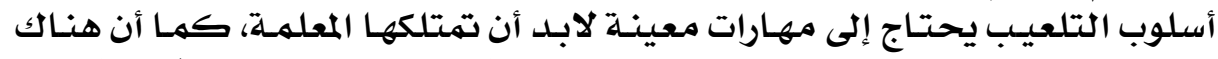

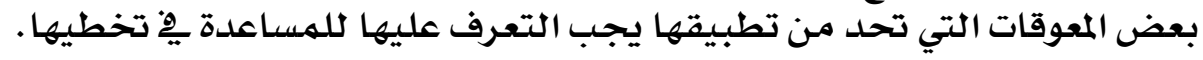

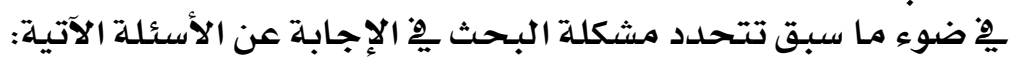

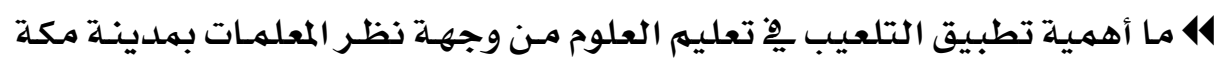

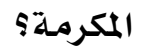
14 ما درجة تطبيق التلعيب يِّ تعليهم العلوم مـن وجهـة نظر المعلمـات بمدينـة مكـة

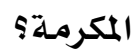
11 ما معوقات تطبيق التلعيب يِّ تعليم العلوم من وجهة نظر المعلمات بمدينة مكة

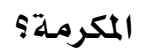

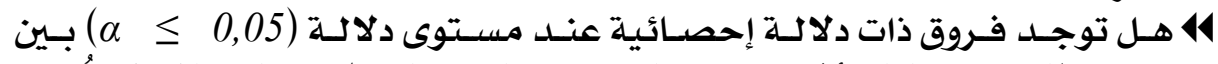

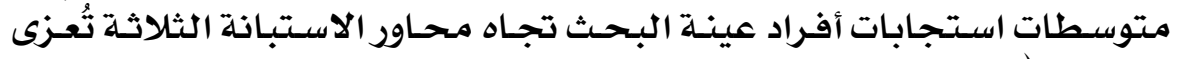

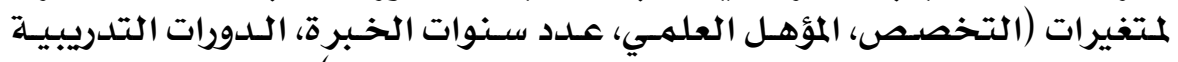

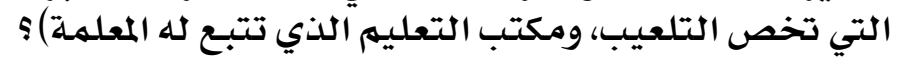

يهدف البحثث الحالي إلى: 


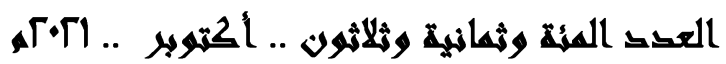

14 الكشـف عـن أهميـة تطبيـق التلعيـب يخ فعلـيهم العلـوم مـن وجهـة نظـر المعلهـات بمدينة مكة المكرومـة.

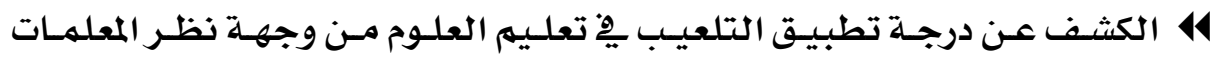
بهلينة مكة المكرمة.

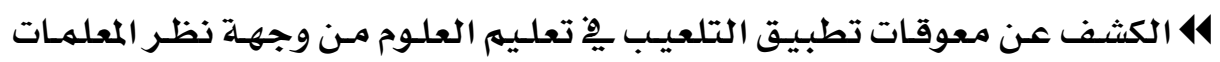
بملدينة مكة المكرمـة.

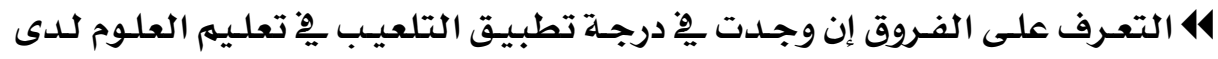

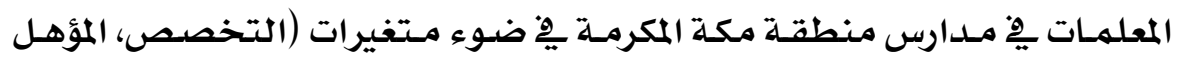

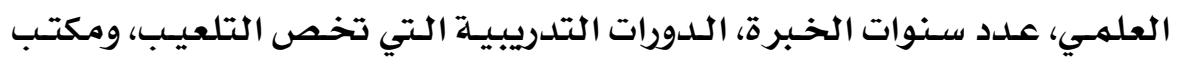
التعليهم الذي تتبـع له المعلهمة ).

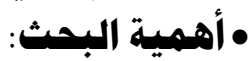

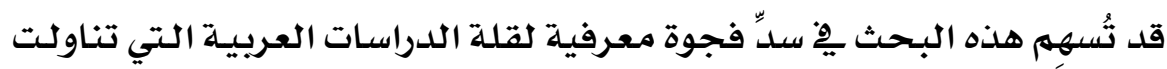

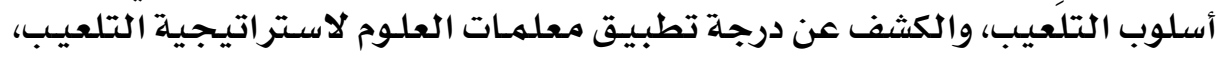

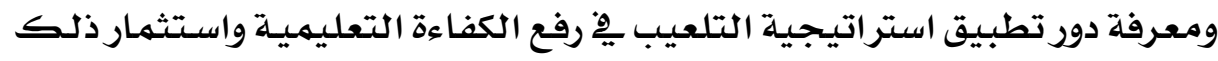

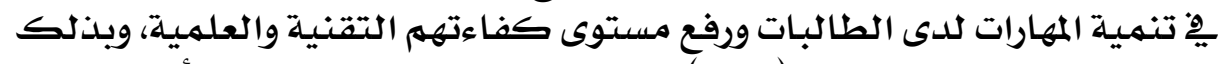

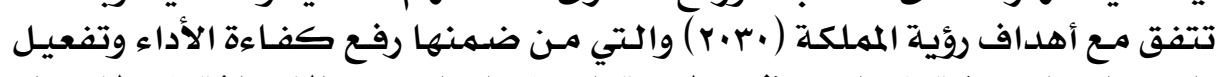

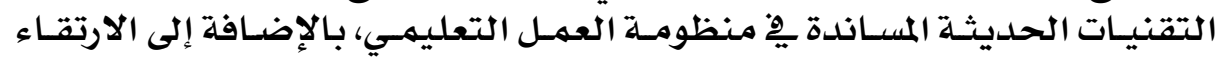

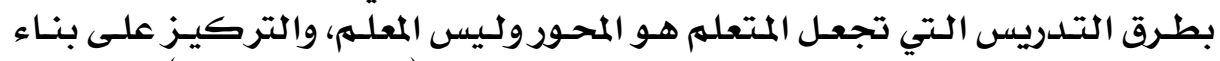

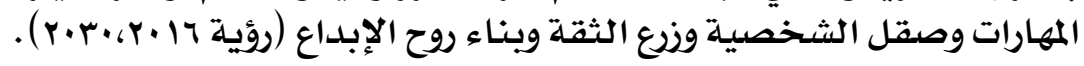

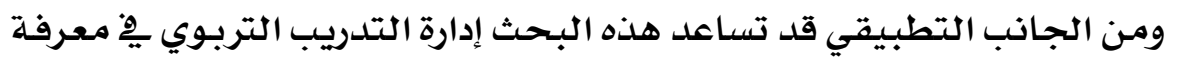

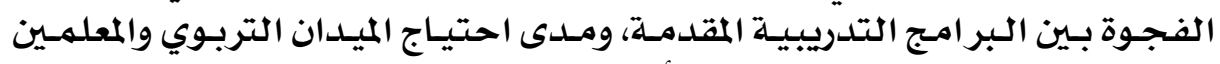

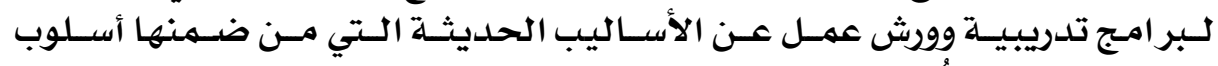

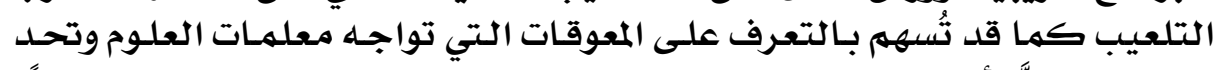

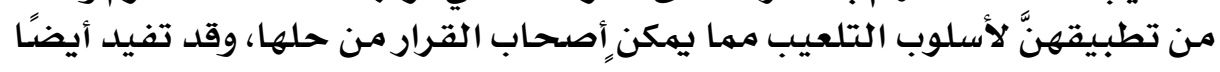

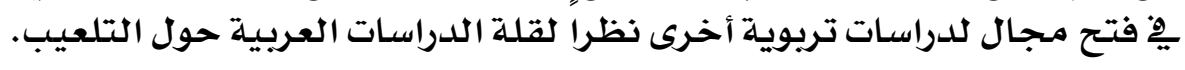

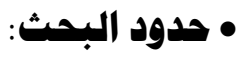

$$
\text { تقتصر البحث على الحدود الآتية: }
$$

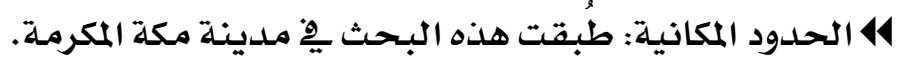

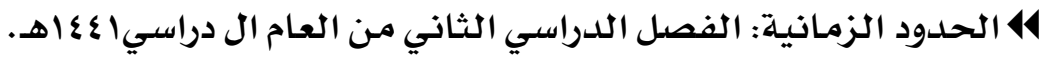

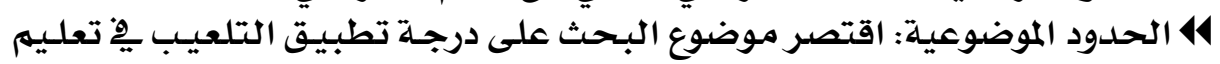

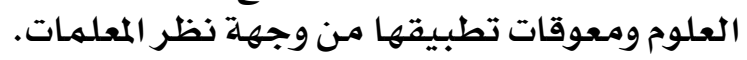

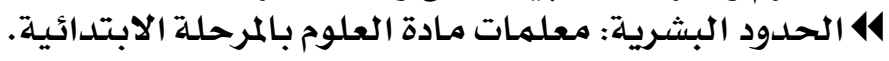




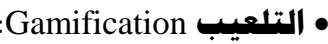

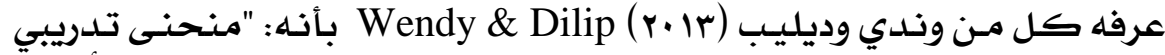

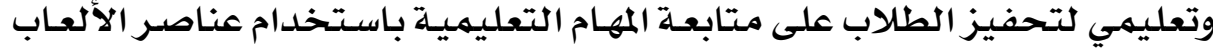

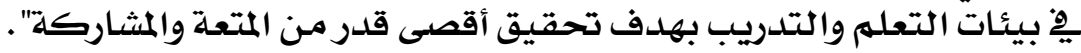

$$
\text { وتعرفه الباحثة إجرائيًا : }
$$

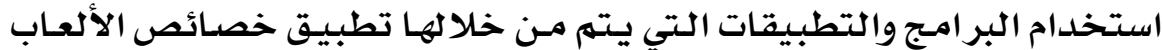

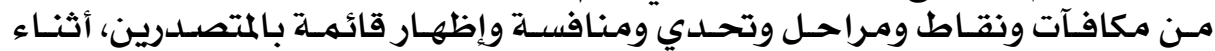

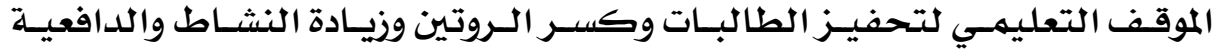

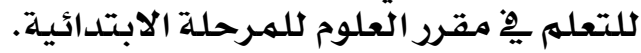

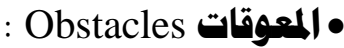

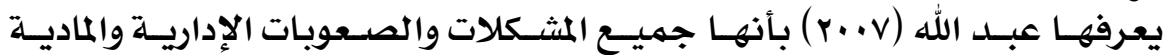

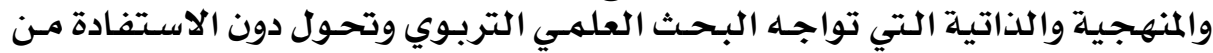

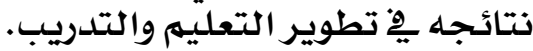

$$
\text { وتعرفه الباحثة إجرائيًا : }
$$

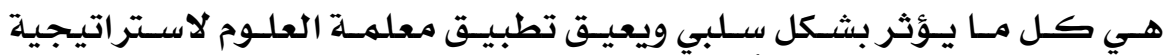

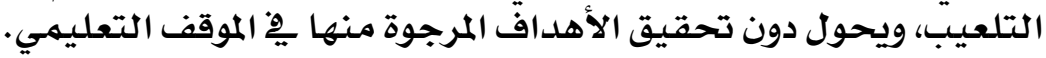

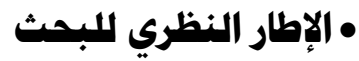

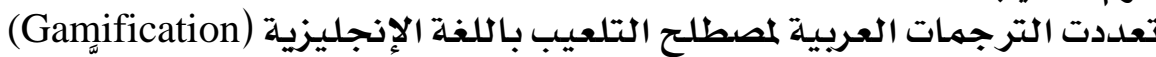

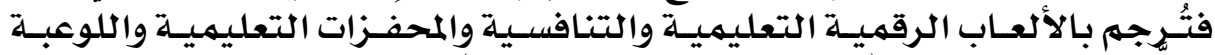

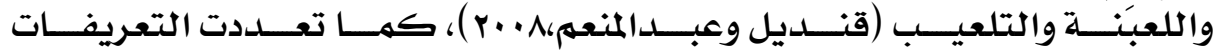

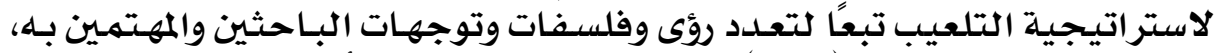

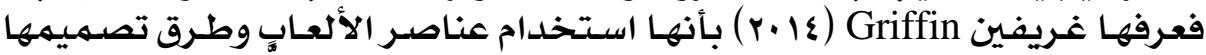

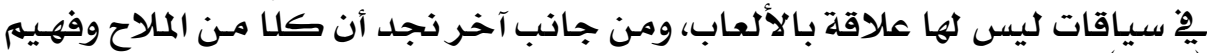

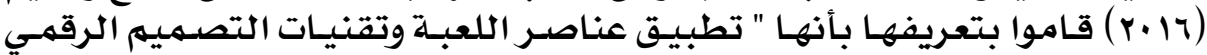

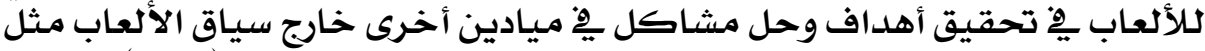

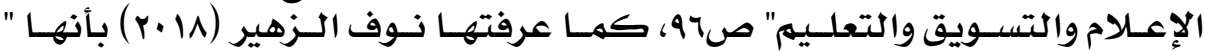

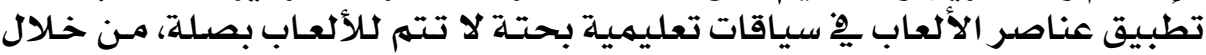

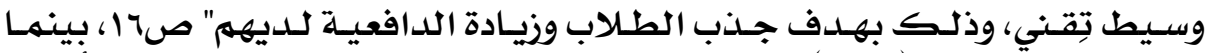

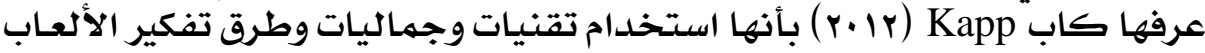

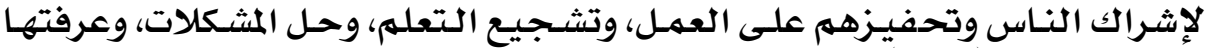

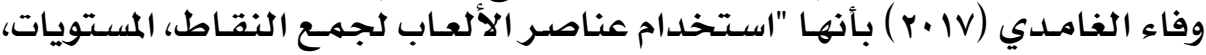

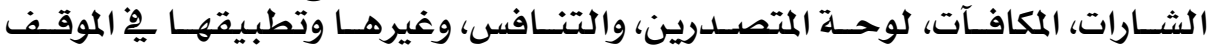

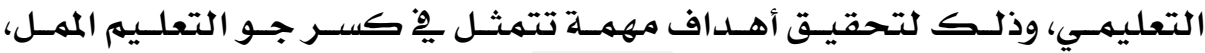

\section{$\varepsilon \wedge \mathrm{r}$}


وتحويلِ المادة الدراسية إلى لعبة مسلية، وجعل عملية التعلم والتعليم أكثر متعـة

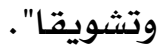

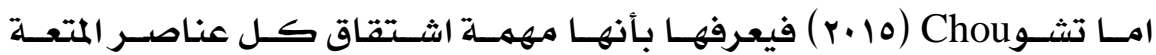

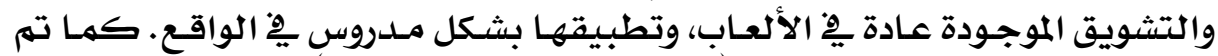

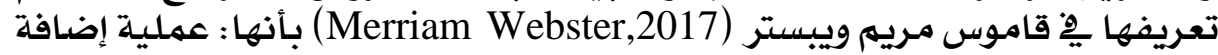

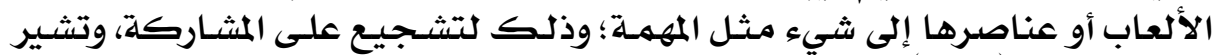

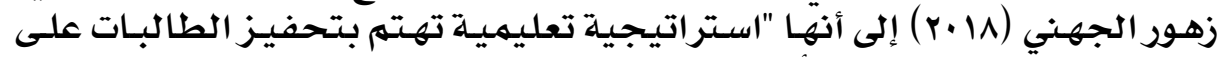

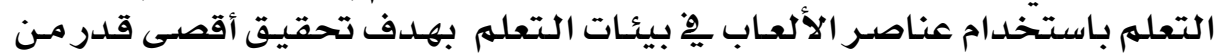

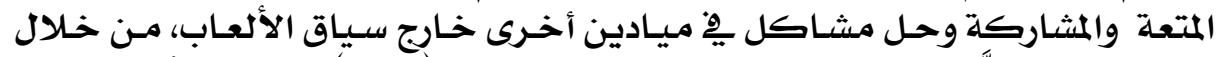

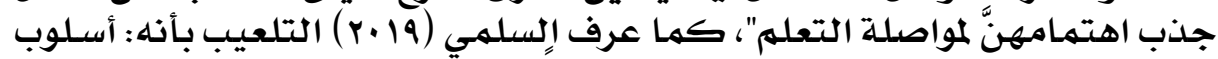

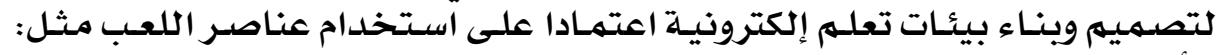

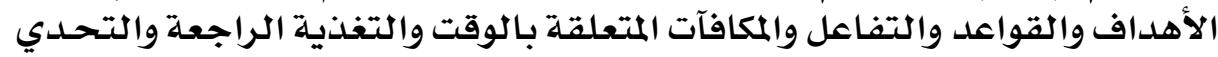

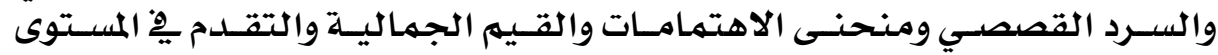

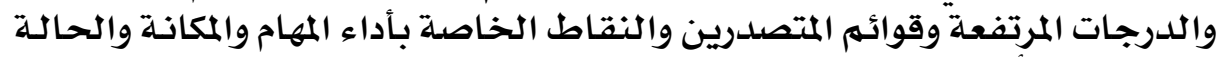

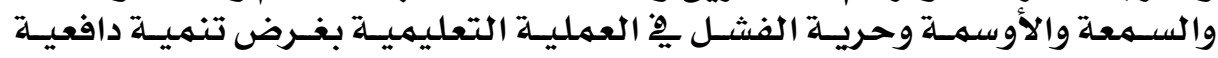

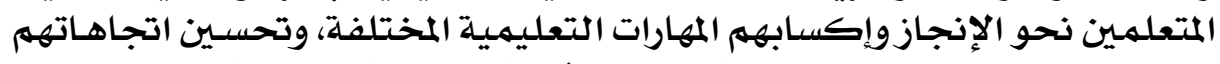

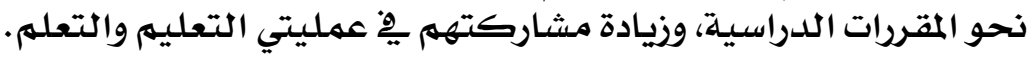

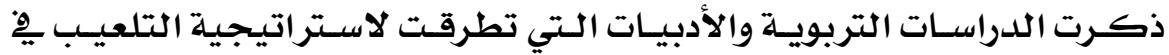

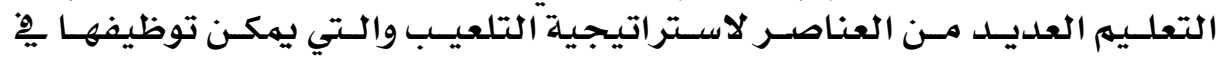

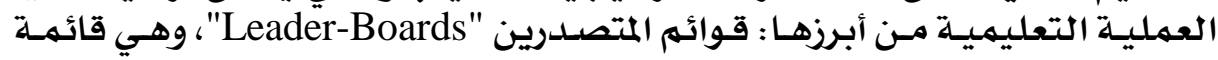

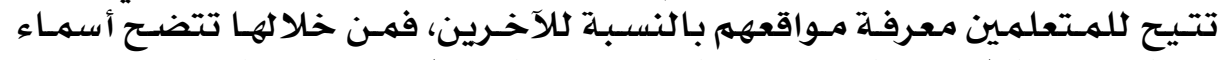

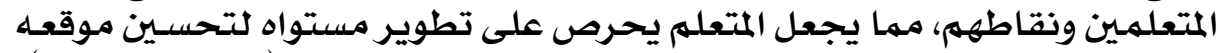

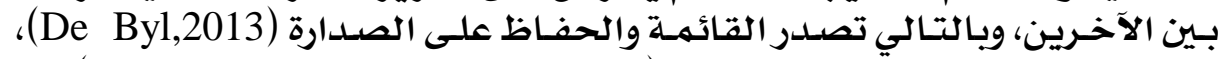

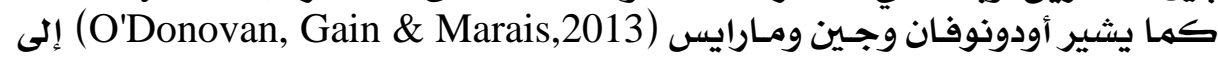

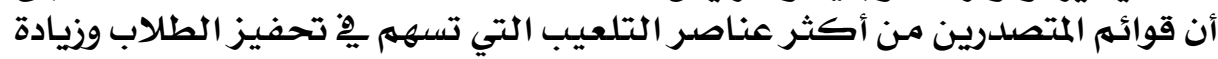

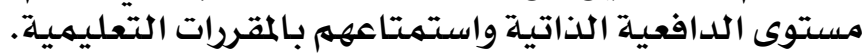

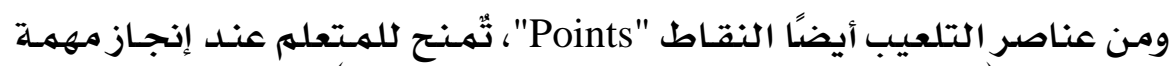

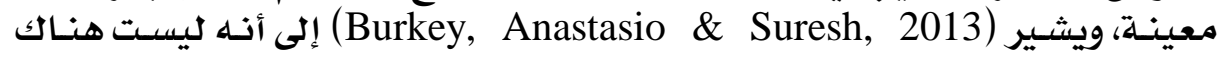

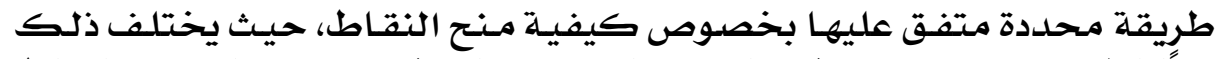

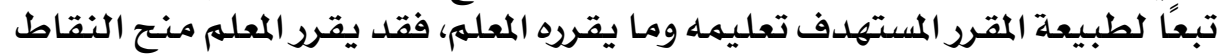

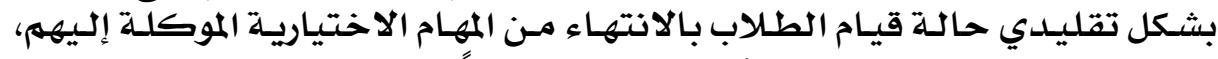

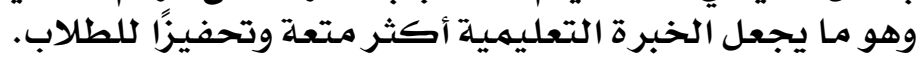

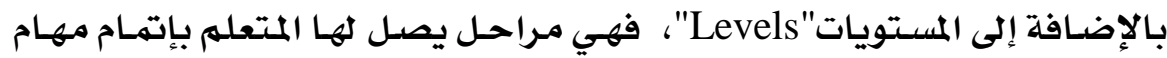

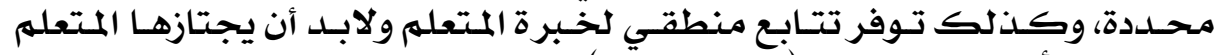

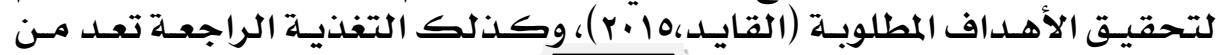

\section{$\varepsilon \wedge \varepsilon$}




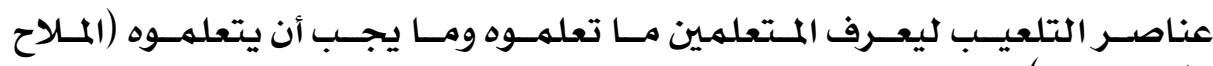

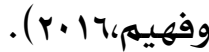

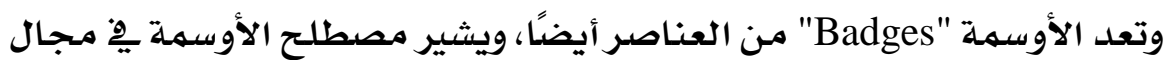

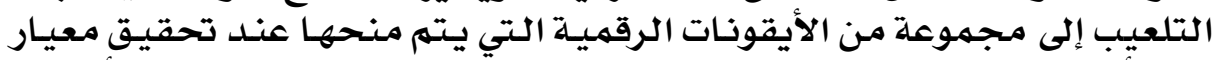

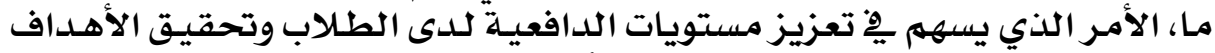

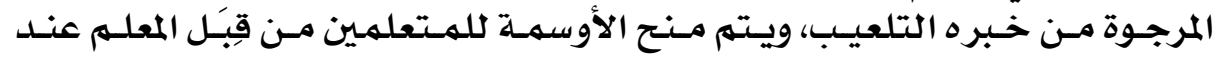

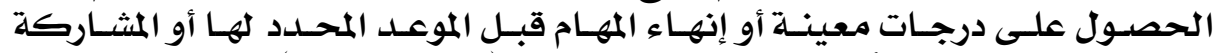

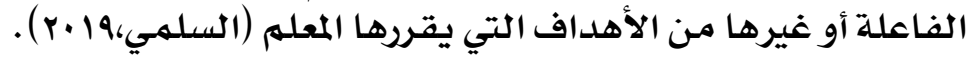

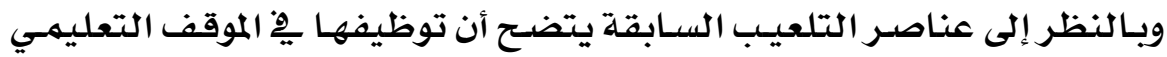

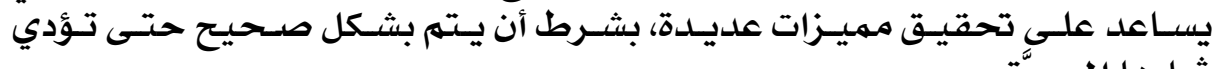
ثمارها المرجوَّة. تصني

\section{• فوائد تطبيق استراتيجية التلعيب في تعليم العلوم: فئوهي}

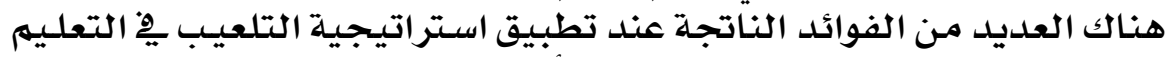

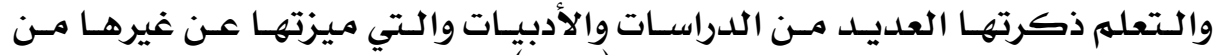

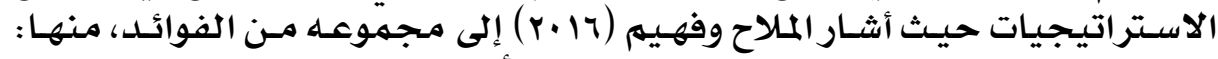

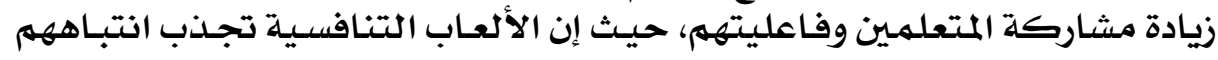

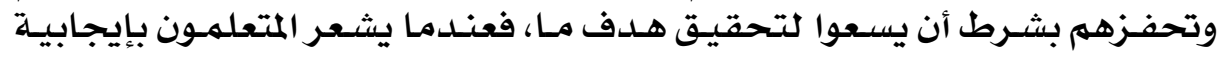

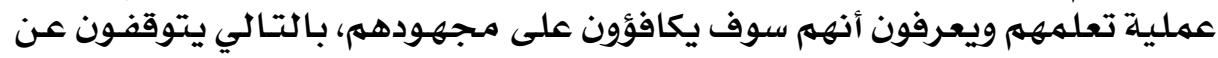

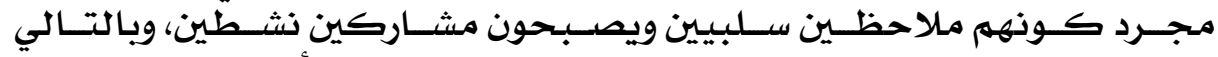

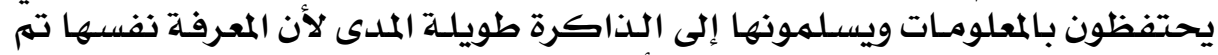

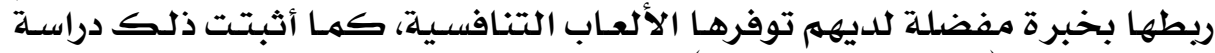

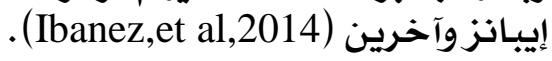

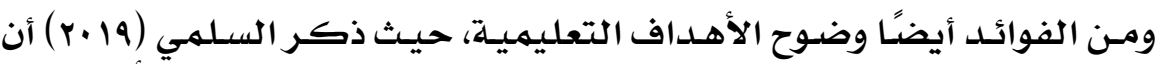

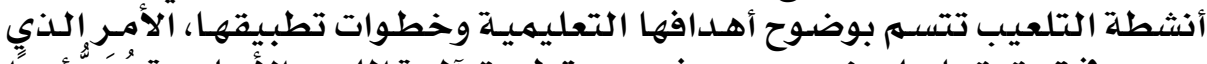

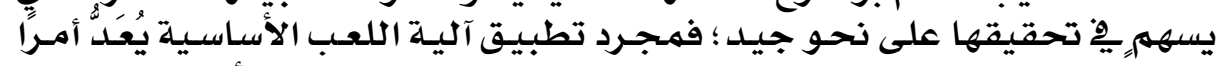

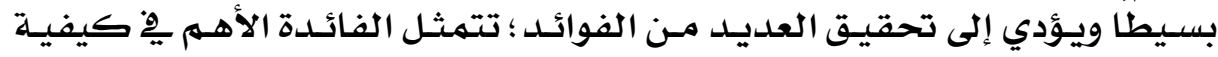

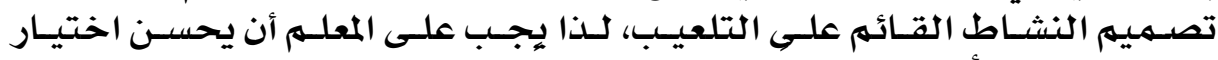

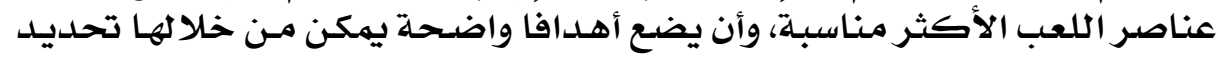

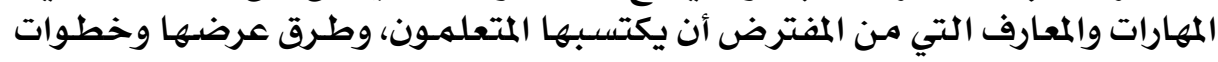

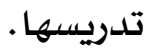

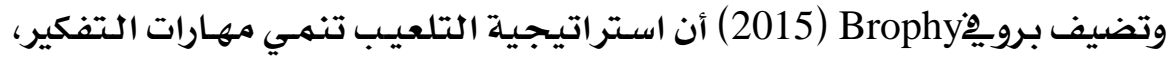

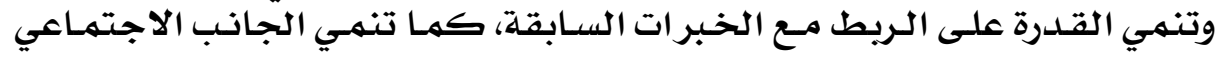

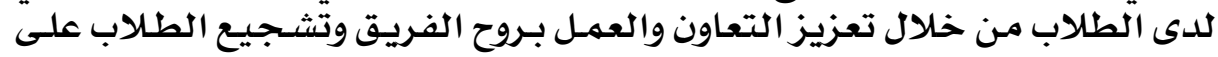

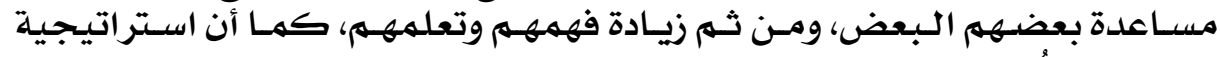

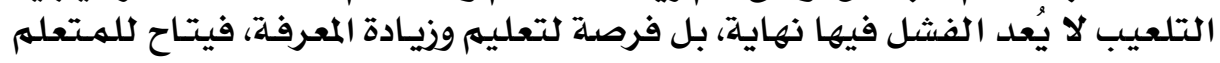

\section{$\varepsilon \wedge \odot$}




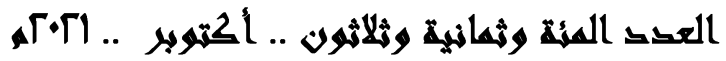

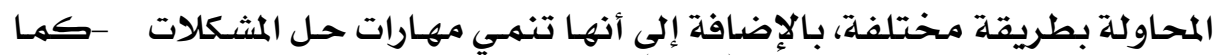

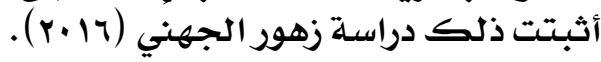

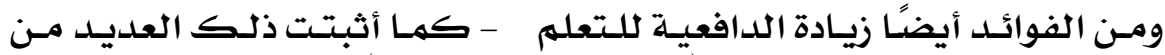

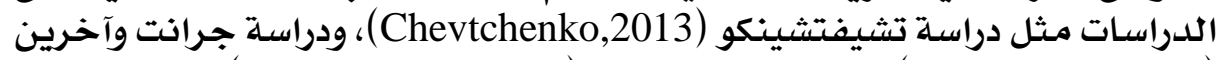

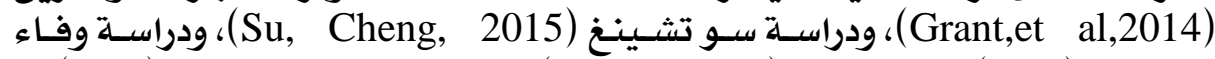

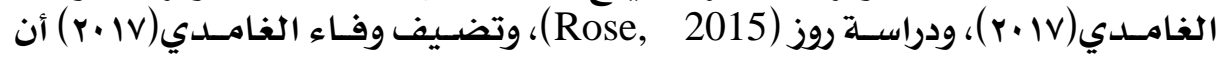

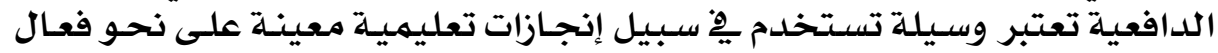

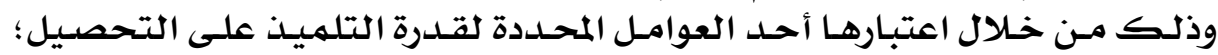

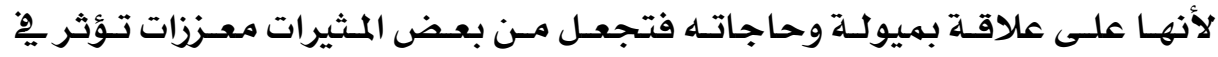

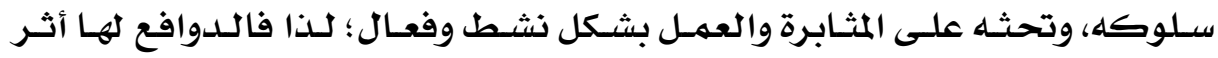

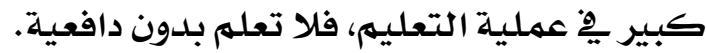

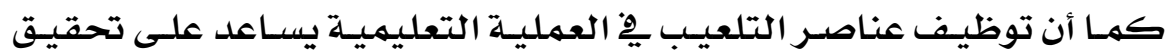

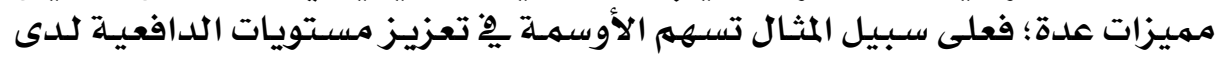

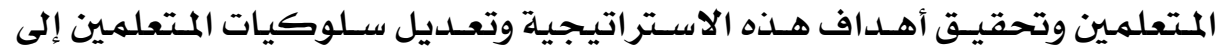

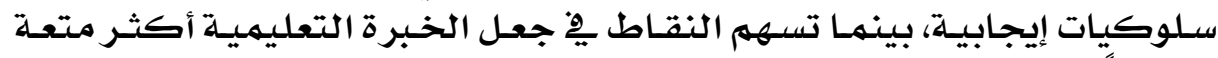

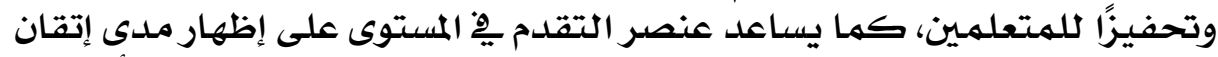

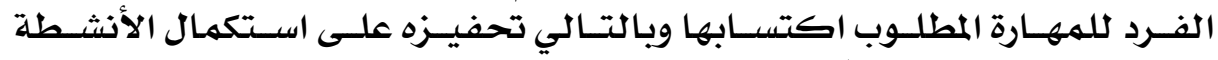

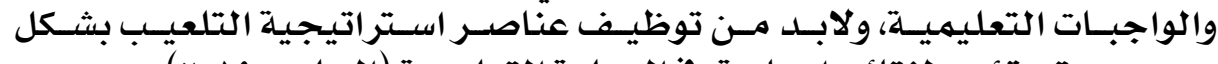

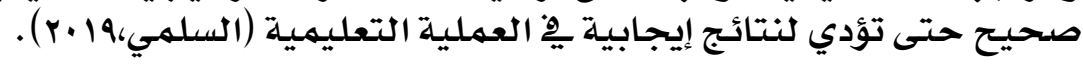

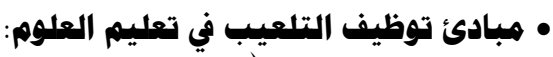

ذور كل مسن: (Wendy,Yuan \& Dilip,2013) و (Huang \& Soman,2013)

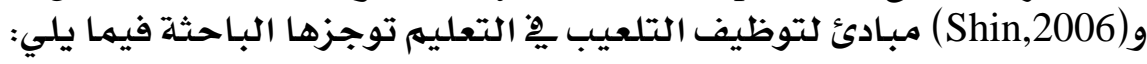

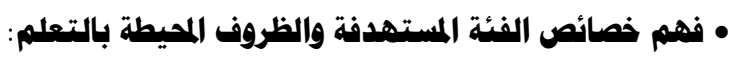

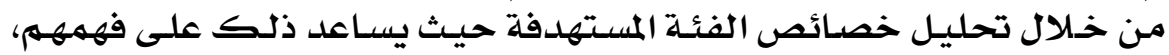

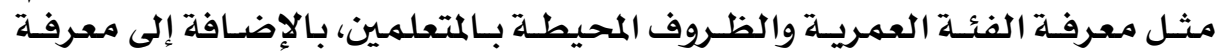

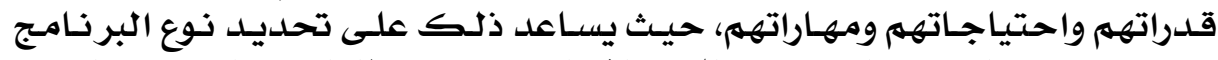

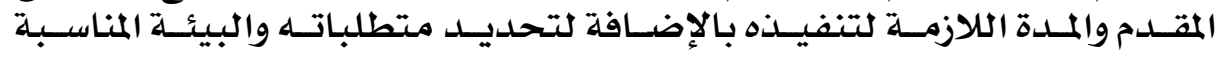
كتقديمة.

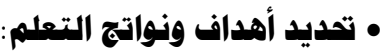

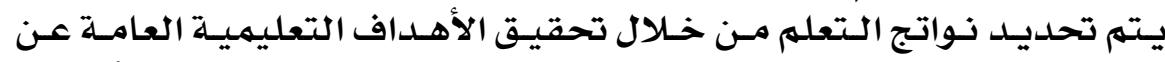

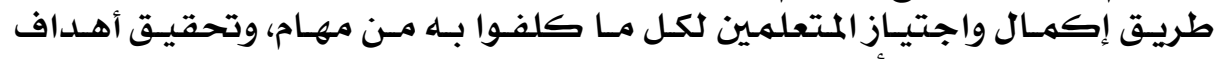

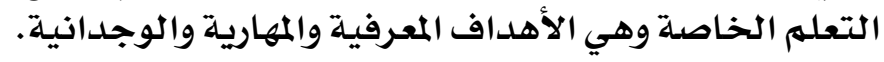

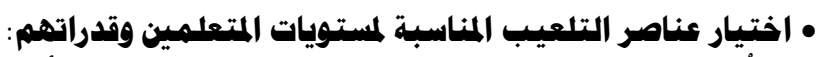

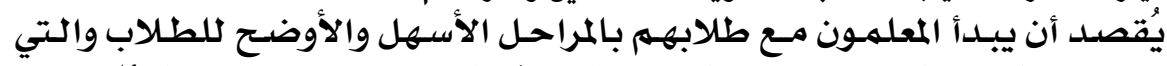

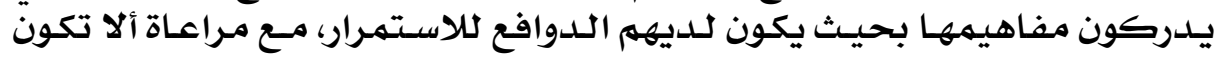




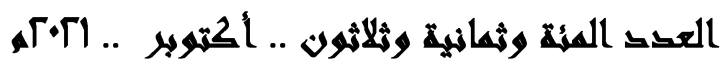

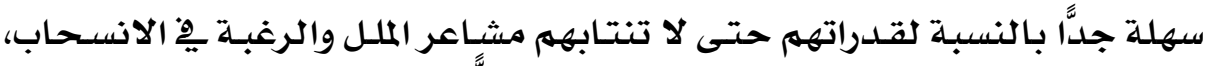

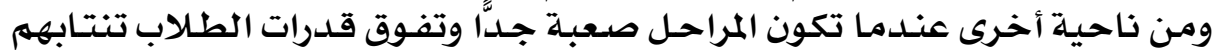

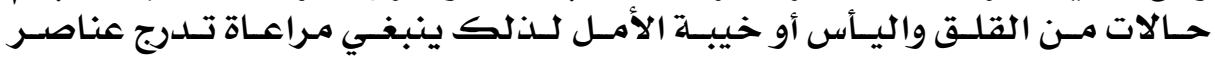

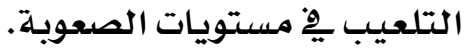

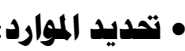

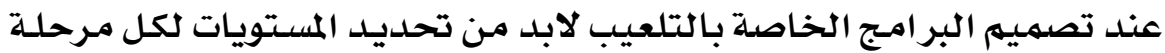

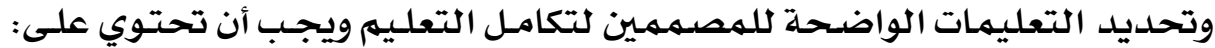

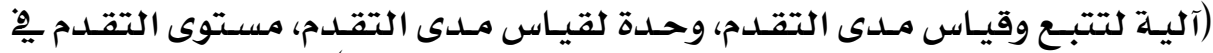

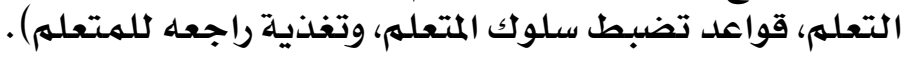

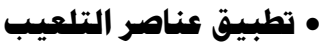

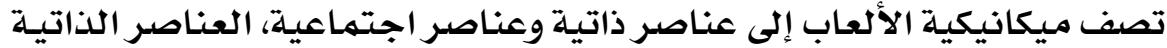

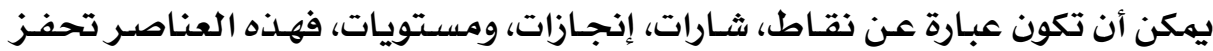

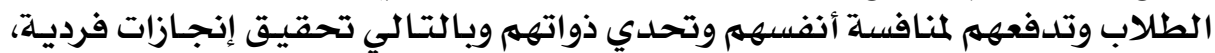

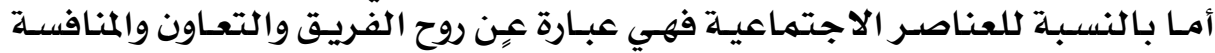

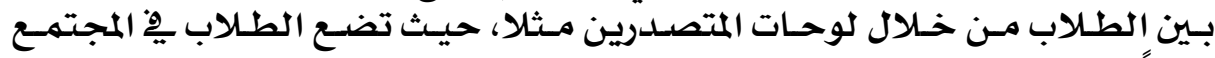

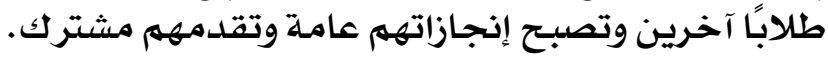

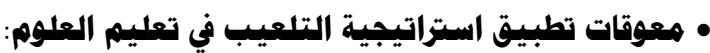

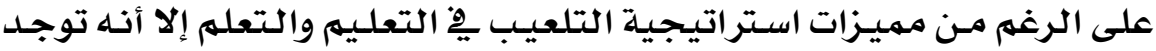

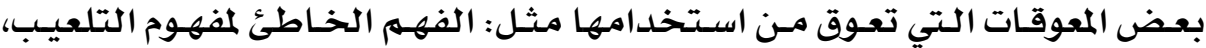

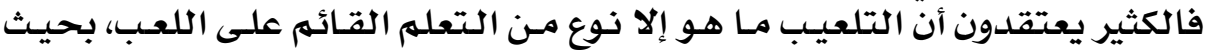

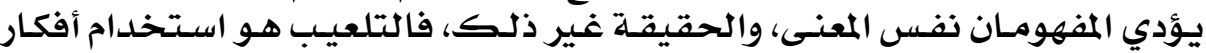

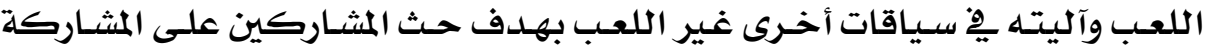

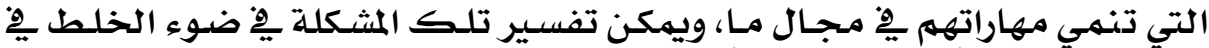
تعريف التلعيب (Jenkins,2016).

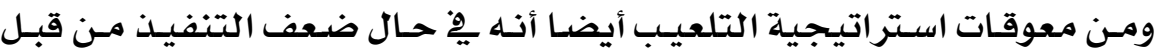

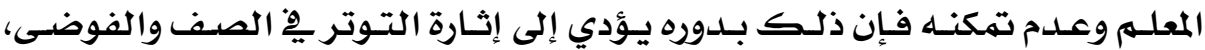

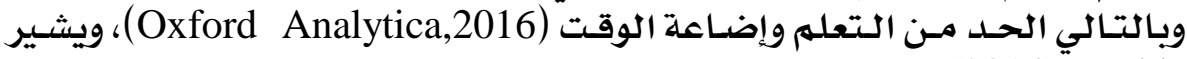

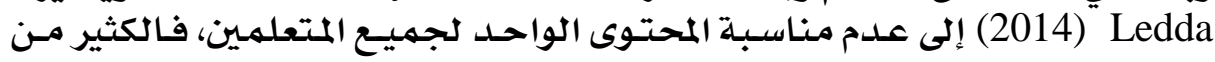

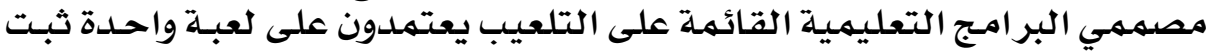

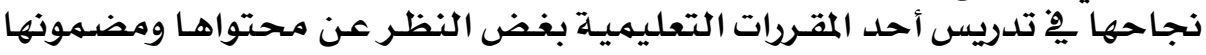

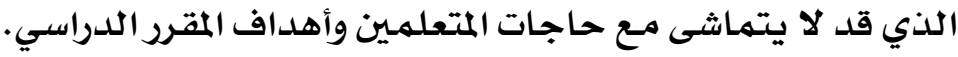

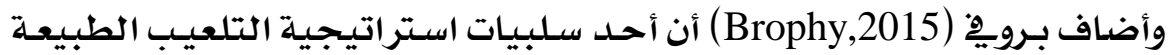

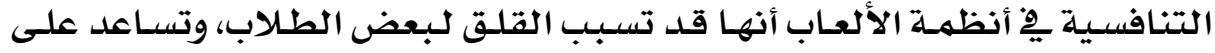

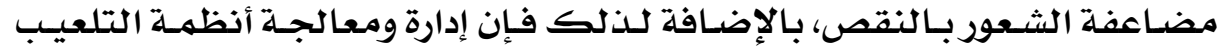

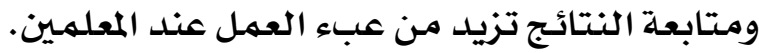




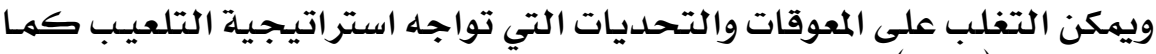

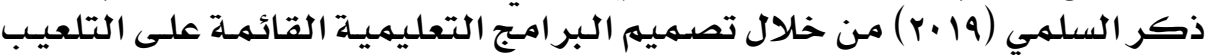

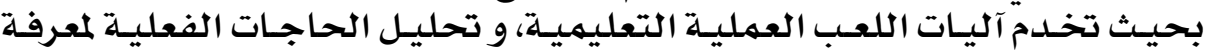

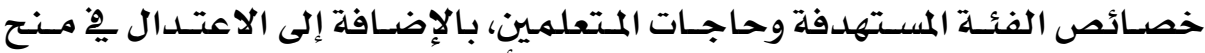

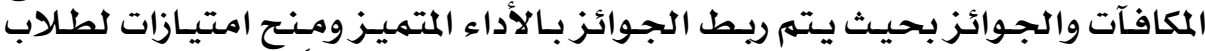

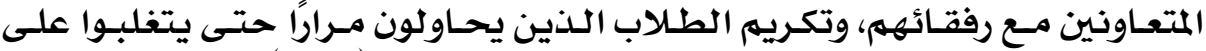

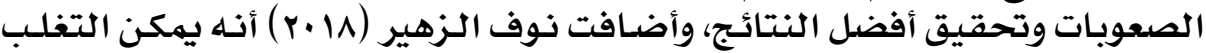

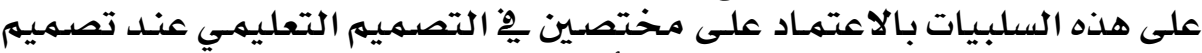

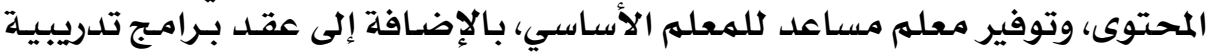

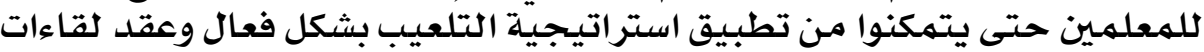

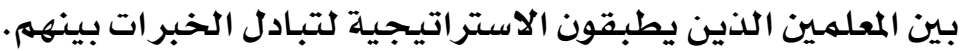

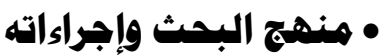

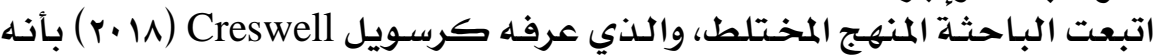

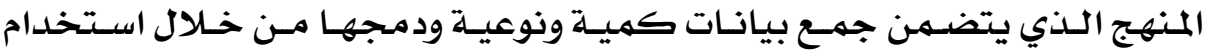

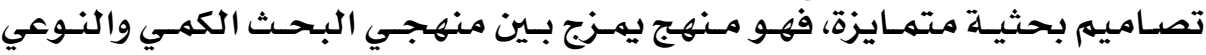

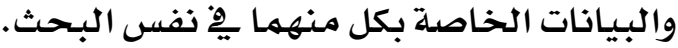

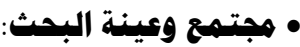

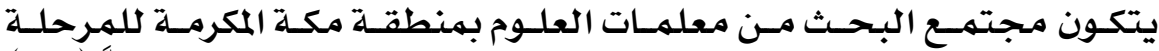

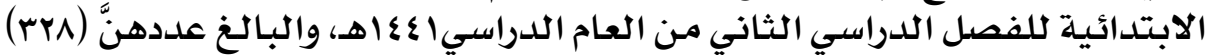

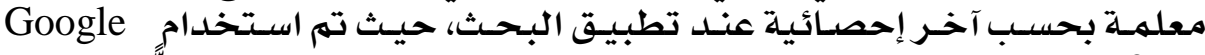

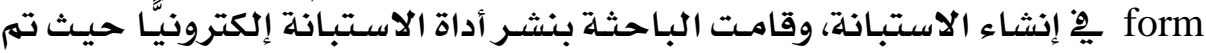

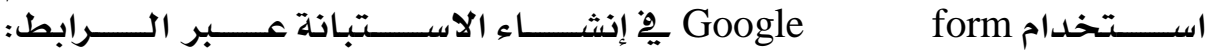

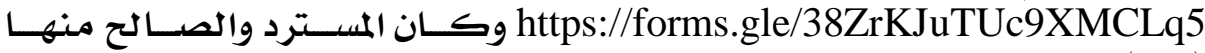

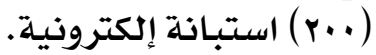

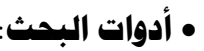

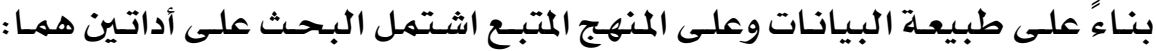

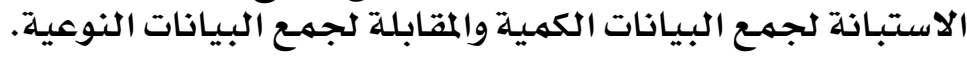

• أولاً: الاستبانة

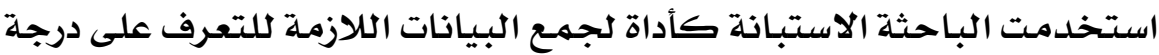

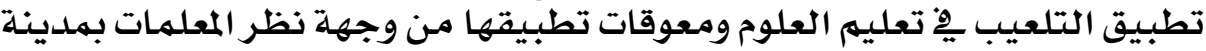

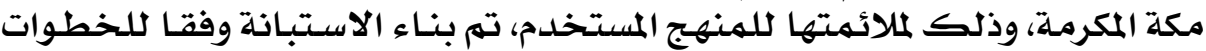

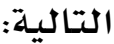

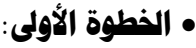

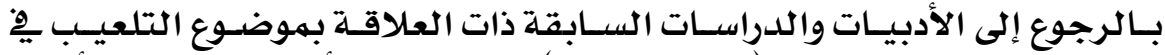

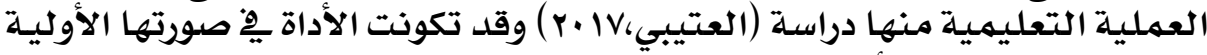

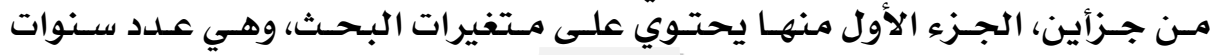




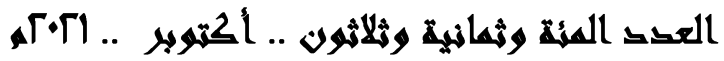

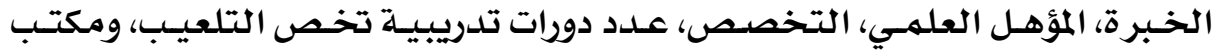

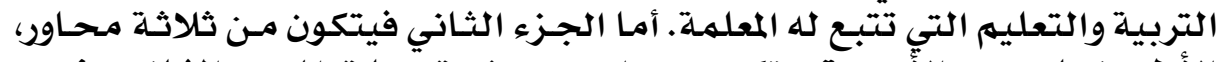

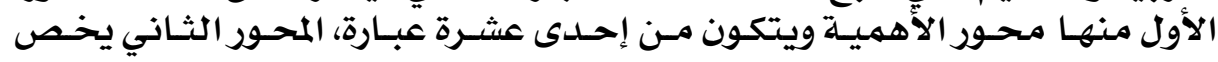

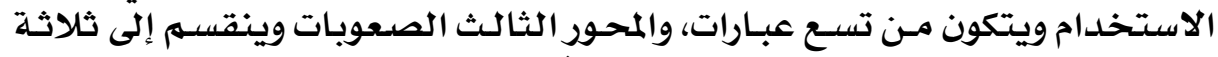

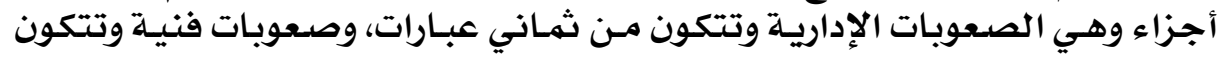

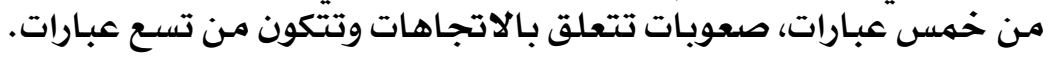

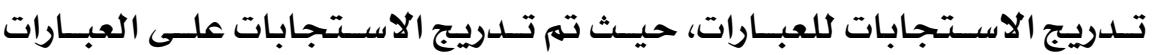

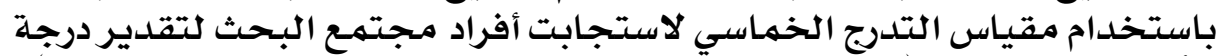

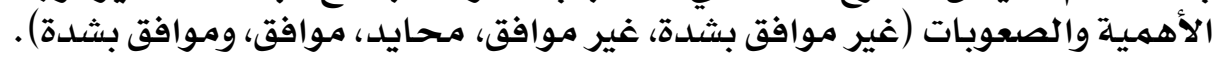
ومقياسِ التدارج الخماسي التتالي لتقدير درجـة الاسـتخدام (أبـدًا، نادرًا، أحيـانًا،

غالبًا، دائمًَا ).

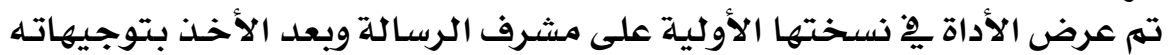

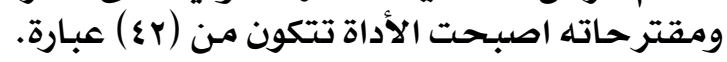

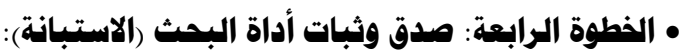
• الصدق الظاهري (الخارجي):

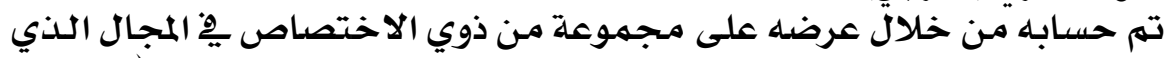

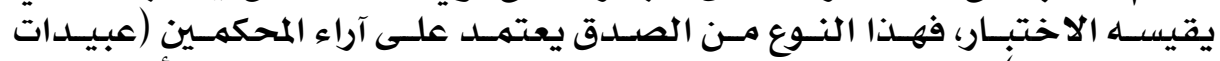

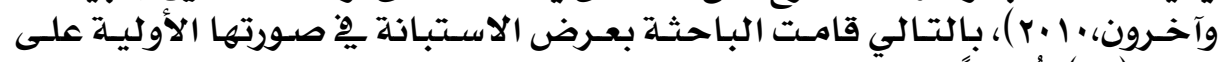

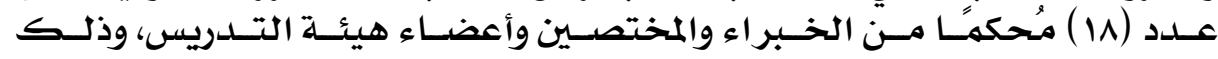

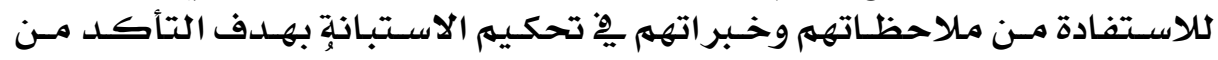

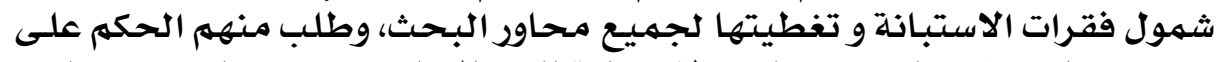

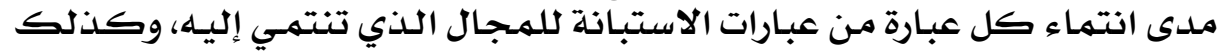

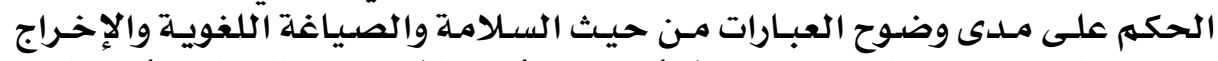

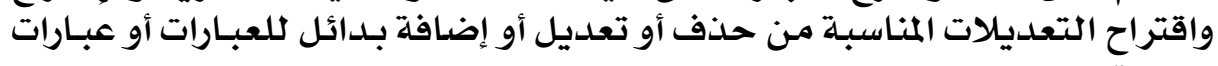

$$
\text { جديدة. }
$$

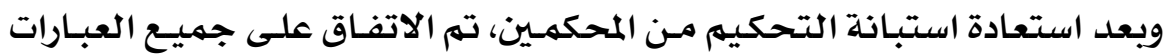

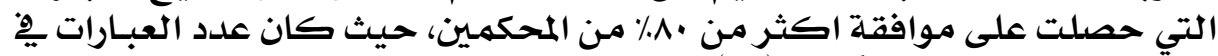

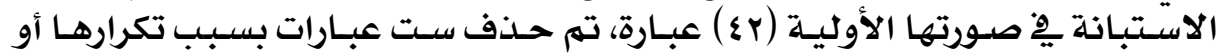

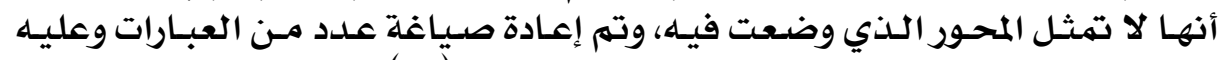

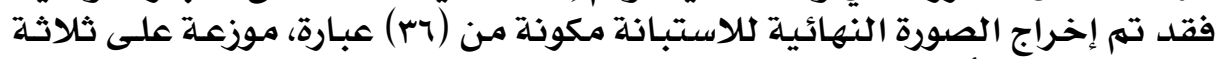

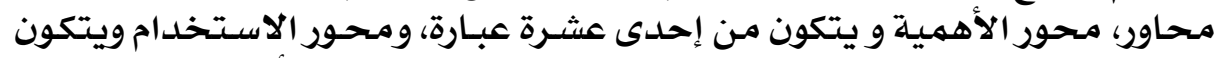

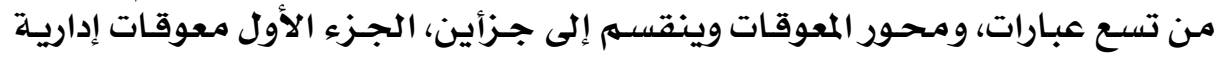

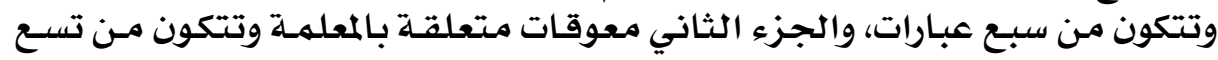

\section{$\varepsilon \wedge q$}




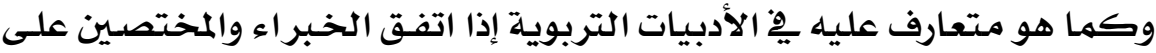

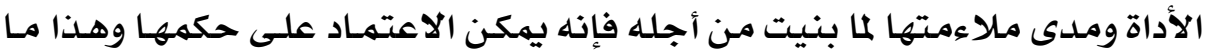

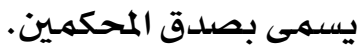

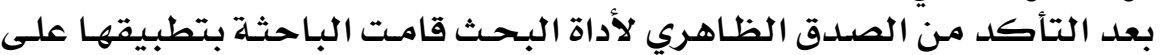

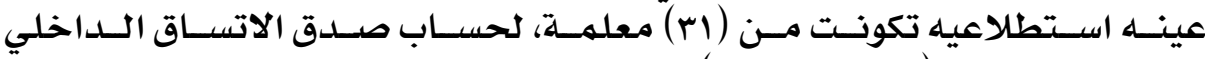
لكلاستبـانة، ويشير (العسـاف،

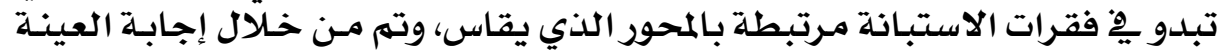

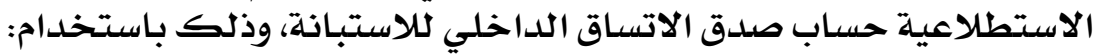

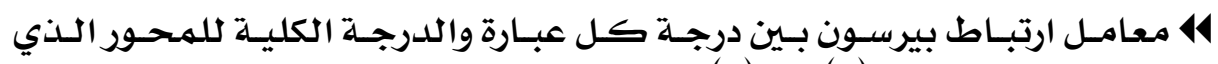

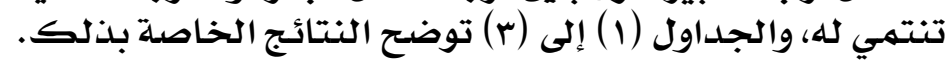

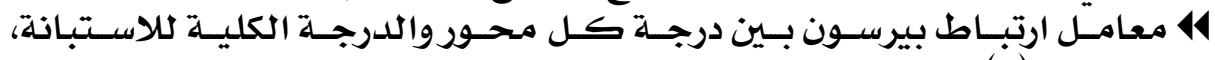

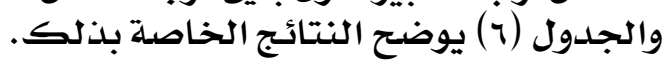

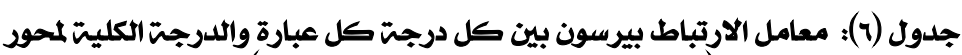
(أهميت استخدام التلعيب في تعليم العلوم)

\begin{tabular}{|c|c|c|}
\hline الارتباط & العبارة & الرقم \\
\hline A10. & يزداد تفاعل الطالبات العلمي اثناء الدرس عند تطبيق التلعيب. & 1 \\
\hline AVo. & يحقق التلعيب المتعت والإثارةً فِ تعلم العلوم. & $\mathbf{Y}$ \\
\hline कalr. & يسهم التلعيب يِ تكرار المحاولتّ والخطأ للى الطالبات دون أي انعكاسات سلبيت. & $r$ \\
\hline "AVI. & تز تزداد المنافست العلميت الشريفت بين الطالبات من خلال استخذام التلعيب & $\varepsilon$ \\
\hline "ANV. & 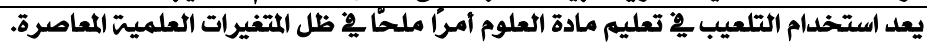 & - \\
\hline ATr. & يسهم التلعيب يِّ مراعاة الفروق الفرديت بين الطالبات. & 7 \\
\hline$\% 901$. & يسهل فهم الطالبات لموضوعات العلوم عند استخدام التلعيب. & $\mathrm{v}$ \\
\hline क91६. & ي ينمي التلعيب الدافعيتً لدى الطالبات اثناء التعلم. & $\mathbf{A}$ \\
\hline "AVr. & يساعِ التلعيب يِ تحقيق أهداف الدرس. & 9 \\
\hline "AE.. & يسهم التلعيب بِّ تبسيط المفاهيم العلميت للطالبات. & 1. \\
\hline "A10. & 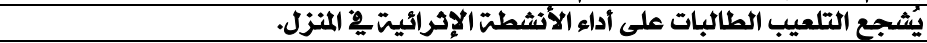 & 11 \\
\hline \multicolumn{3}{|c|}{ هـ دال إحصائيًا عند مستوى دلالت ألل من ا... } \\
\hline
\end{tabular}

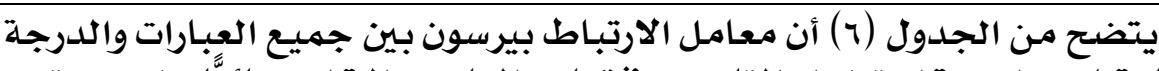

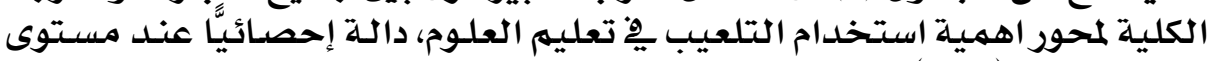

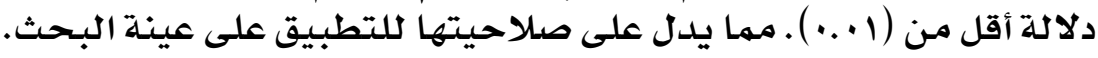

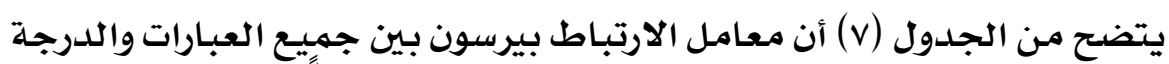

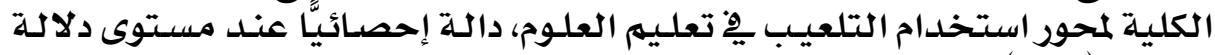

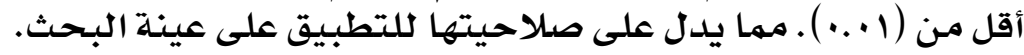

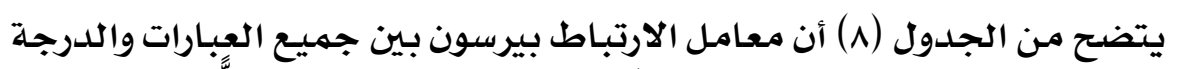

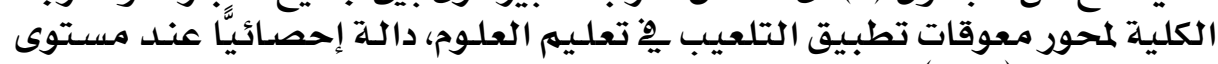

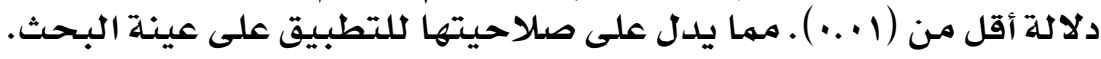

\section{$\varepsilon 9$.}




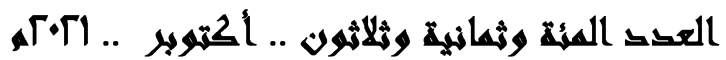

جلدول (V): معامل الارتباط بيرسون بين كل درجت كال عبارة والدرجت الكليت لمحور

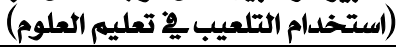

\begin{tabular}{|c|c|c|}
\hline معامل الارتباط & العبارة & 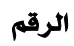 \\
\hline AMl. & أستخلدم التطبيقات التي تتخذ مبدأ التلعيب لتبسيط تعلم العلوم. & ir \\
\hline $91 \cdot$. & 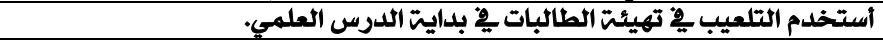 & ir \\
\hline •• १ะฯ. & أستخدم التطبيقات المحققت مبدأ التلعيب لكسر الروتين بالحصتّ وإضفاء النشاط & i\& \\
\hline $90 \mathrm{~V}$. & أستخدم التلعيب لزيادة التنافس الشريف بين الطالبات. & 10 \\
\hline Arr. & أعطي للطالبات أشططت إثرائيت منزليتة هائمت على التلعيب. & 17 \\
\hline$\wedge 91$. & أستخلدم التلعيب لمراعاة الفروق الفرديت بين الطالبات. & IV \\
\hline 9910. & أستخدم التلعيب لجذب انتباه الطالبات للدرس. & M \\
\hline $9+\cdots$ & أعطي للطالبات أنشطت علاجيت منزليت قائمت على التلعيب. & 19 \\
\hline कqदY. & أستخلّم التلعيب كطريقت جديلة من طرق تعليم العلوم. & r. \\
\hline \multicolumn{3}{|c|}{ 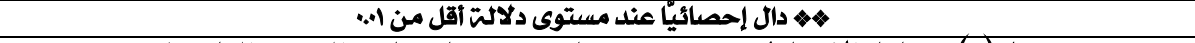 } \\
\hline
\end{tabular}

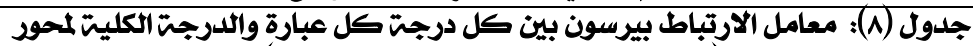

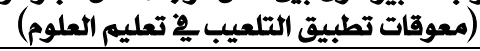

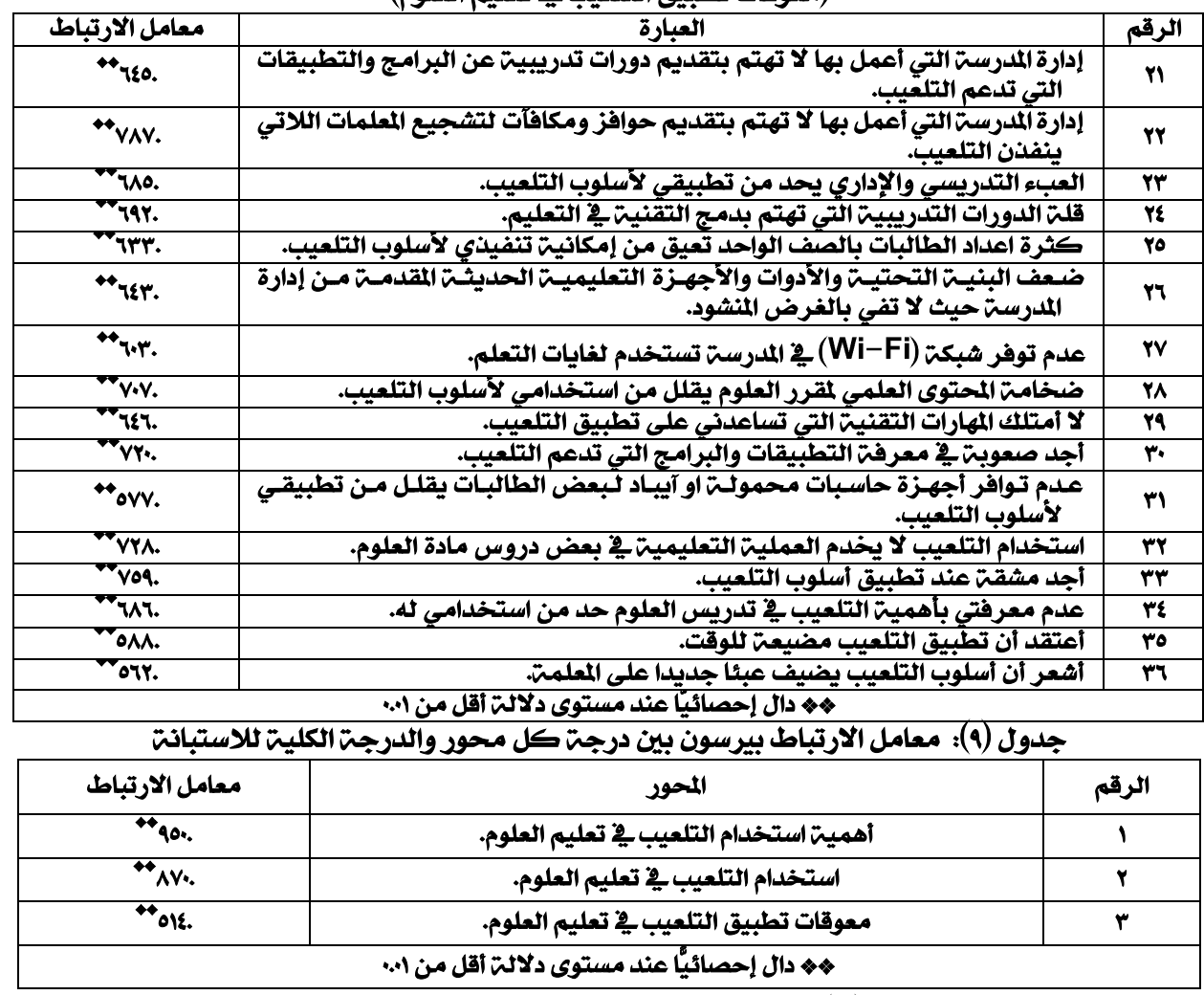

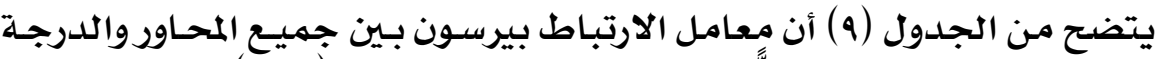

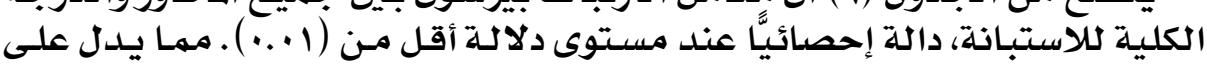
تماسك هذه المحاورووصلاحيتها للتطبيق على عينـة البـحث. \&q1 


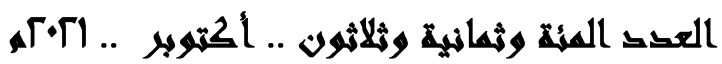

• ثالثًا: ثبات الاستبانة:

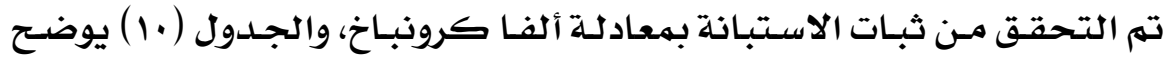

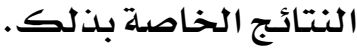

جدول (.1): معامل ثبات الاستبانت بمعادلة ألفا كرونباخ

\begin{tabular}{|c|c|c|c|}
\hline ألفا كروثباخ & عدد العبارات & المحور & الرقم \\
\hline $.97 \%$ & ir & أهميت استخدام التلعيب ـِ تعليم العلوم. & 1 \\
\hline $.9 \mathrm{Vr}$ & 9 & استخدام التلعيب يِّ تعليم العلوم. & $r$ \\
\hline $.91 \%$ & 17 & معوقات تطبيق التلعيب يِ تعليم العلوم. & $r$ \\
\hline .907 & rv & الاستبانت ككل & 0 \\
\hline
\end{tabular}

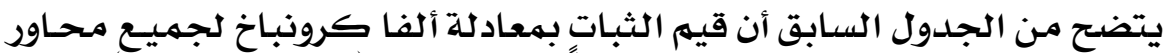

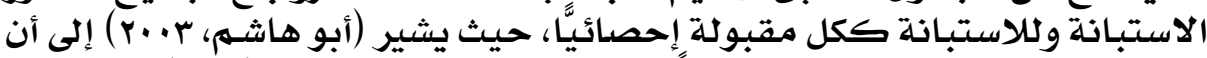

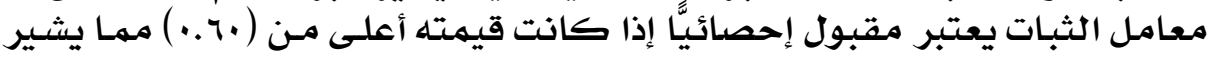

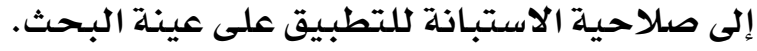

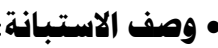

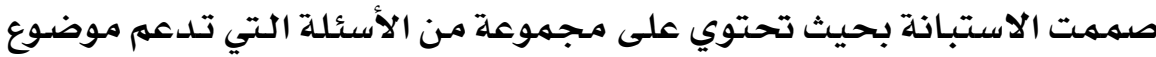

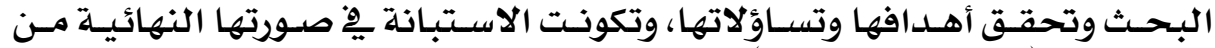

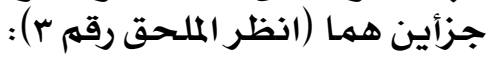

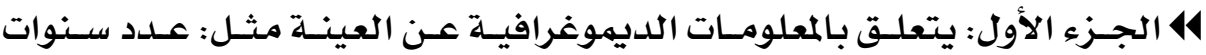

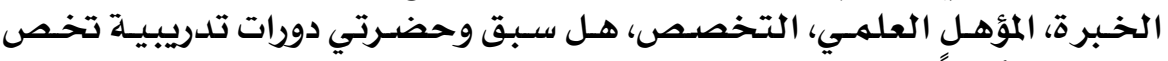

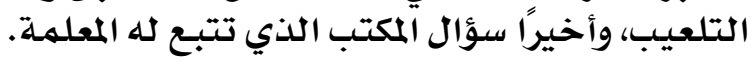

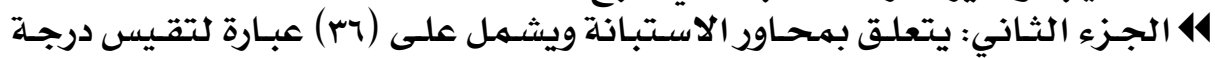

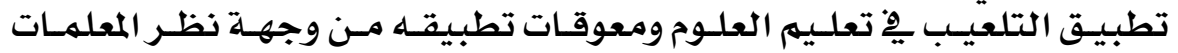

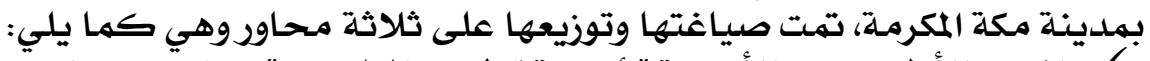

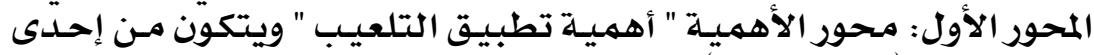

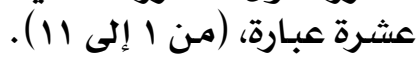

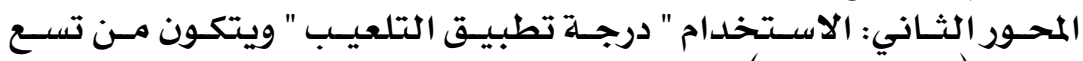

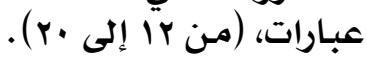

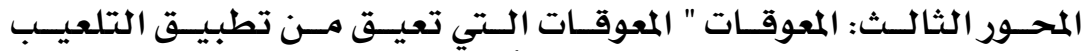

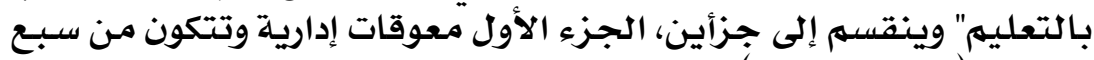

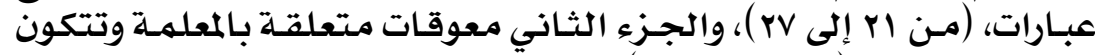

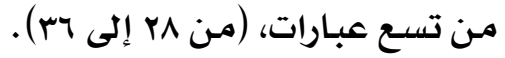

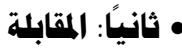

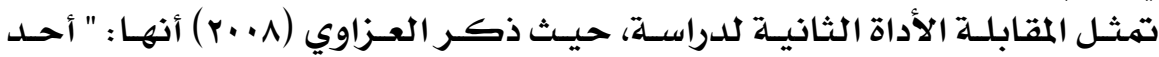

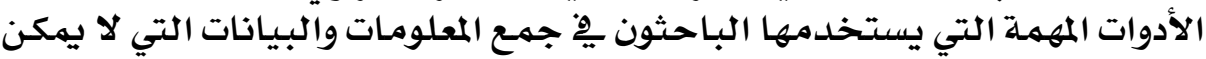

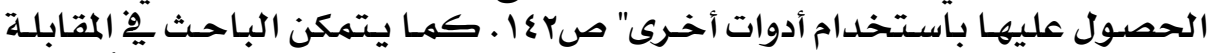

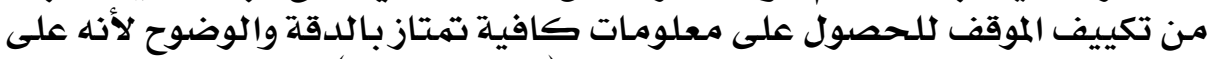

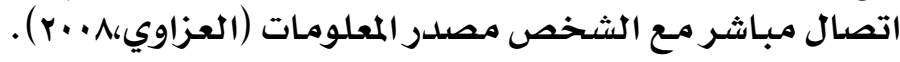




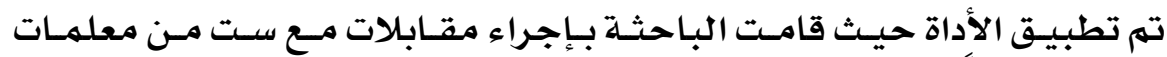

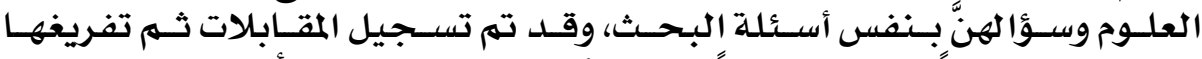

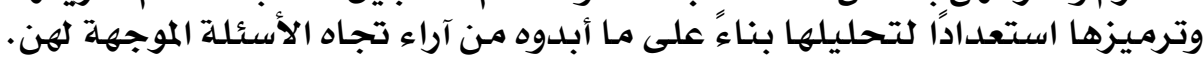
• صدق وثبات أداة البحث (المقابلة):

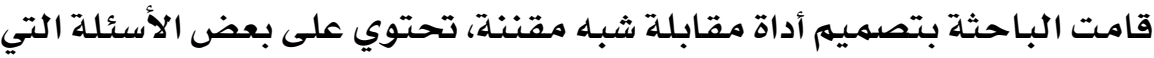

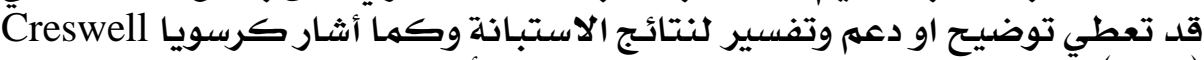

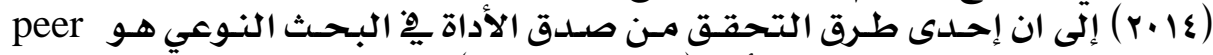
debriefing

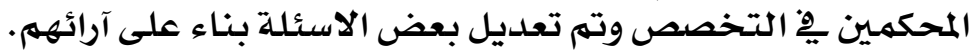

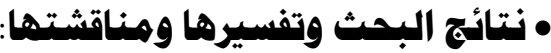

\section{• نتائج الإجابة عن السؤال الأول ومناقشتها وتفسيرها:}

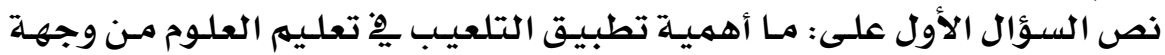

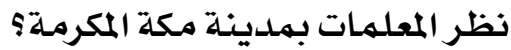

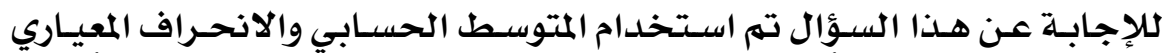

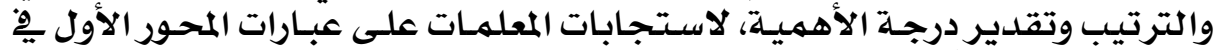

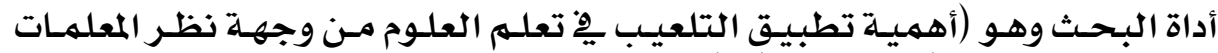

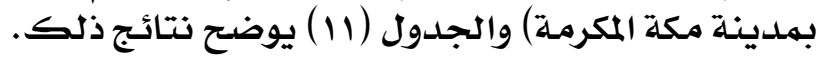

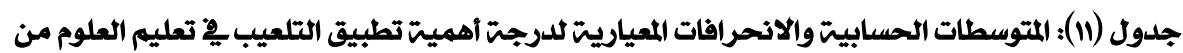

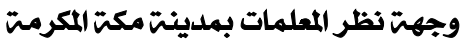

\begin{tabular}{|c|c|c|c|c|c|}
\hline الأهميتً & الترتيب & الالمعياري & المتوسط & استخدام التلعيب مهم من وجهن نظر معلمات العلوم يخّة & p \\
\hline مرتفعتة & $r$ & $\cdot \cdot \cdot \cdot r$ & \&.1r & يزداد تفاعل الطالبات العلمي أثناء الدرس عند تطبيق & 1 \\
\hline مرتفعتة & 1 & 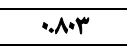 & $\varepsilon .17$ & يحقق آتلعيب المتعت والإثارة فِ تعلم العلوم. & $r$ \\
\hline مرتفعت & 9 & דורטי & r.Av & 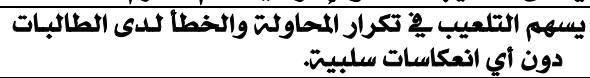 & $r$ \\
\hline مرتفعت & ० & $\cdot \cdot \cdot 0$ & ז.ץ & تزداد المنافاف التلعيب. العلميت الشريفت بين الطالبات من خلال & $\varepsilon$ \\
\hline مرتفعت & 1. & .97 & r.Aई & 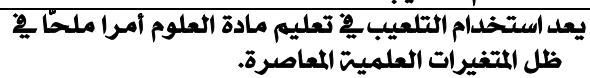 & 。 \\
\hline مرتفعت & $\pi$ & $.9 \% 1$ & r.v & يسهم التلعيب ِِ مراعاة الفروق الفرديت بين الطالبات. & 7 \\
\hline مرتفعتة & 1 & $\cdot 109$ & (.) & يستلعل فيــم الطالبـات لموضـوعات العلوم عند استخدام & $v$ \\
\hline مرتفعت & $r$ &. $\mathrm{VW \varepsilon}$ & $\varepsilon .1 Y$ & ينمي التلعيب الدافعيت لدى الطالبات أثناء التعلم. & $\Lambda$ \\
\hline مرتفعت & $\Lambda$ & • A 14 & r.M & يساعد التلعيب يُ تحقيق أهداف الدرس. & 9 \\
\hline مرتفعت & $\varepsilon$ &. $\mathrm{VV}$ & $\varepsilon \times 1$ & يسهم التلعيب يخ تبسيط المفاهيم العلميت للطالبات. & 1. \\
\hline مرتفعت & $v$ & • & r.৭\& & 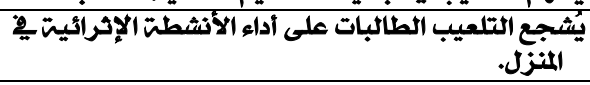 & 11 \\
\hline مرتفعت & & ז797 & r.94 & المحور ككل & \\
\hline
\end{tabular}




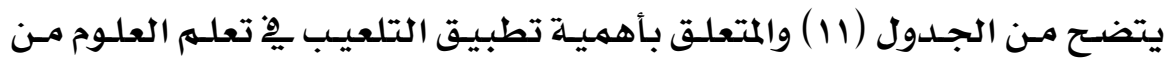

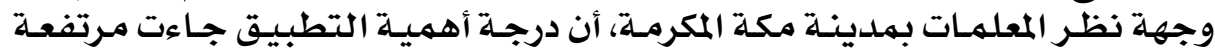

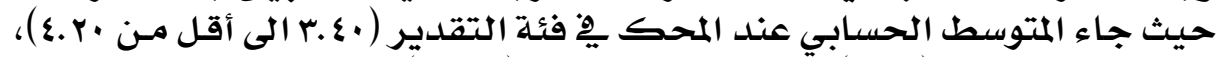

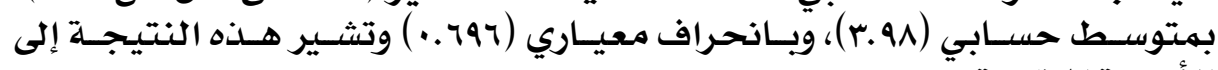
الأهمية المرتفعة.

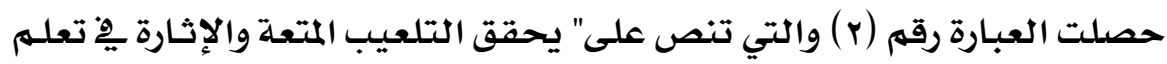

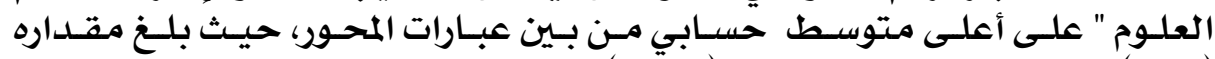

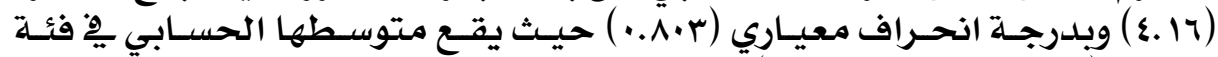

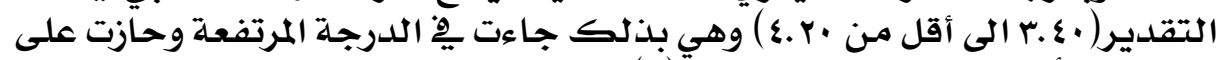

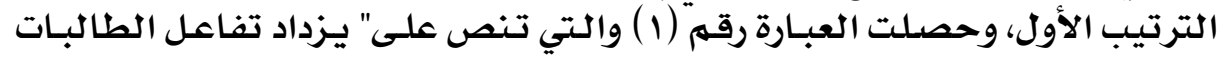

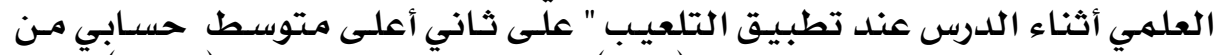

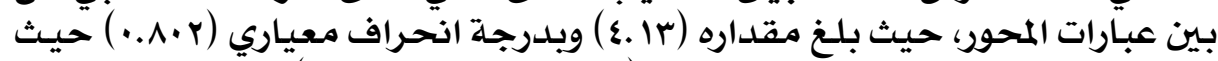

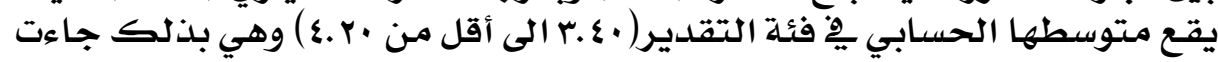

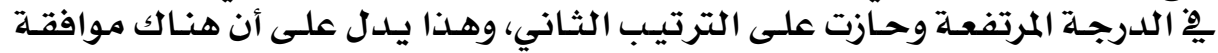

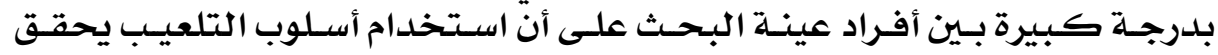

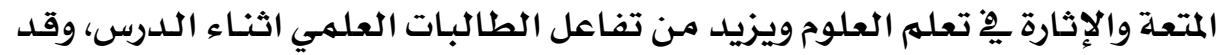

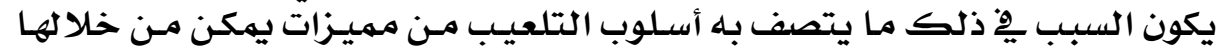

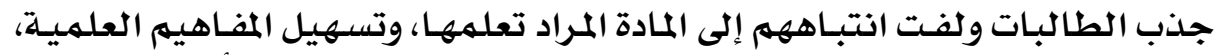

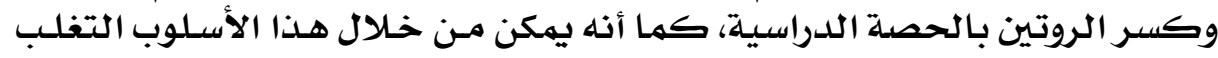

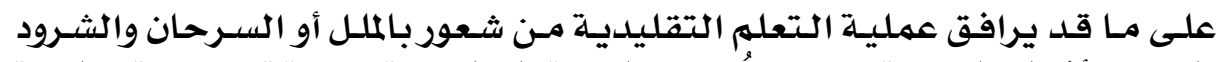

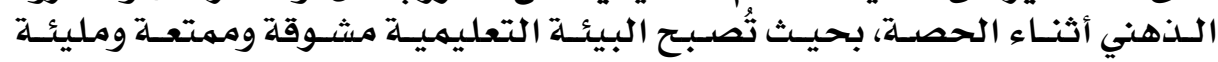

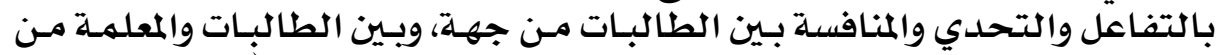

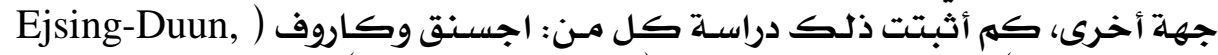

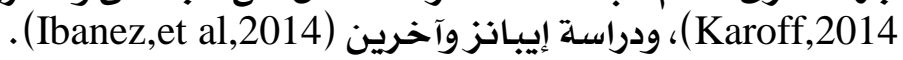

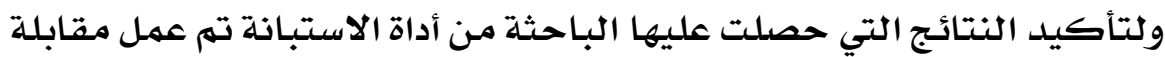

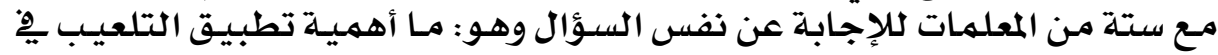

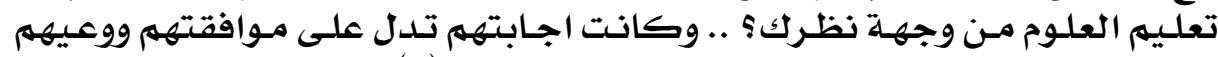

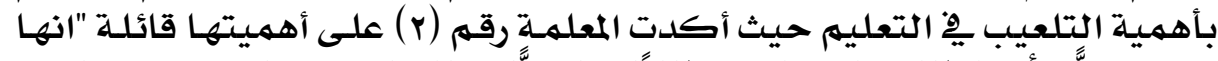

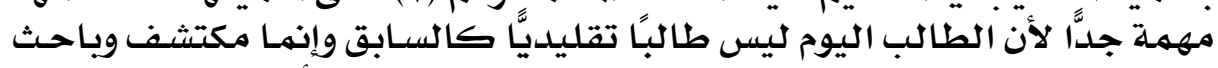

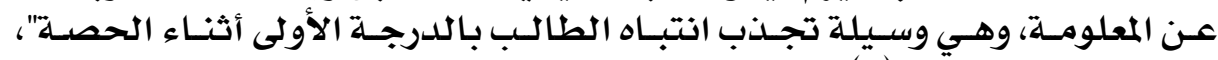

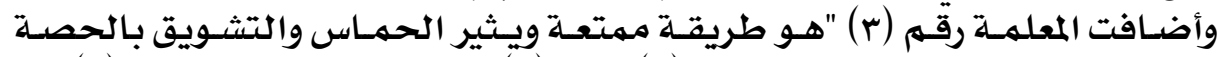

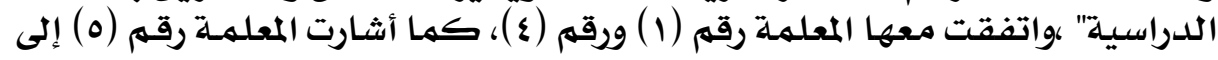

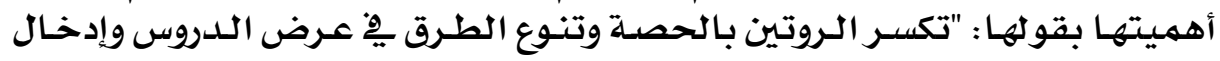

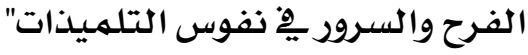

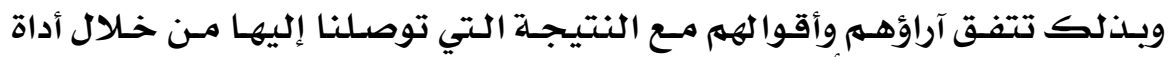

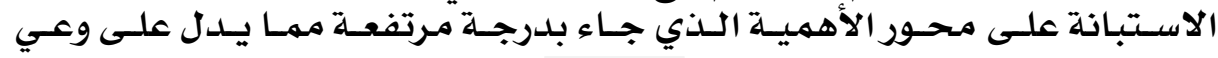

\section{$\varepsilon 9 \varepsilon$}




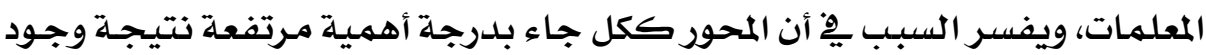

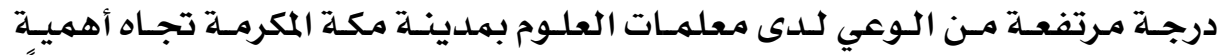

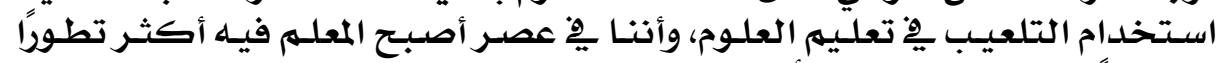

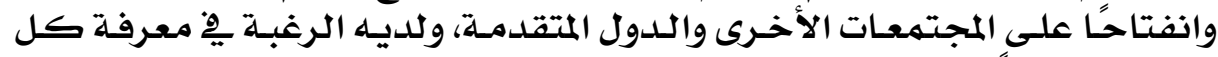

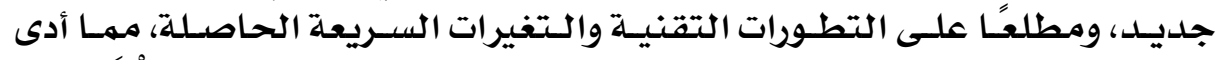

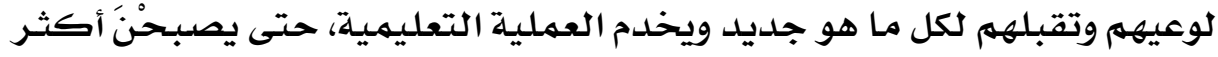

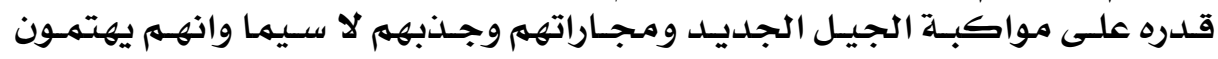

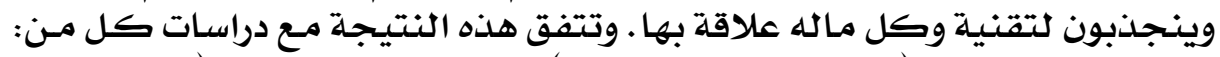

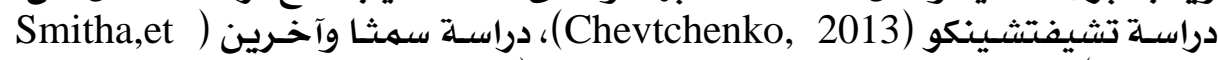

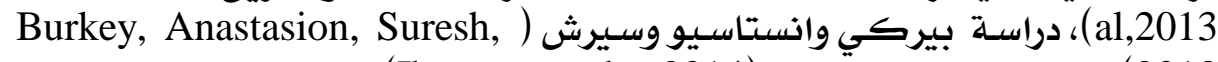

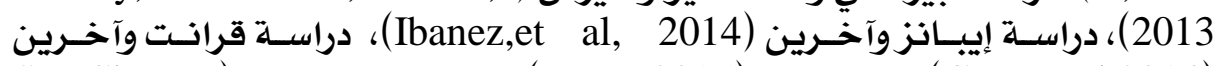

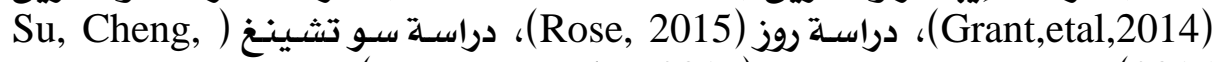

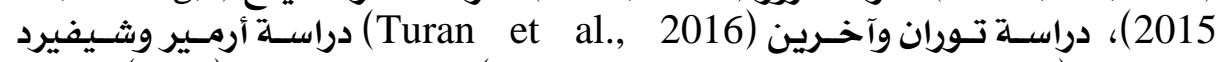

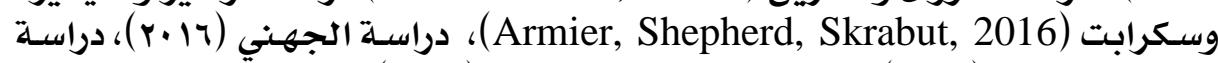

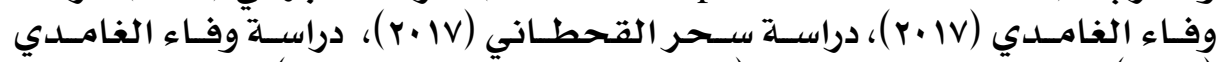

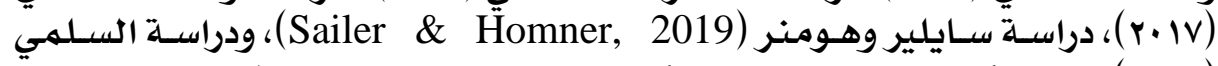

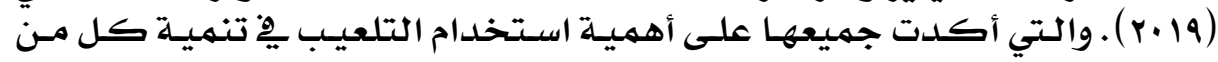

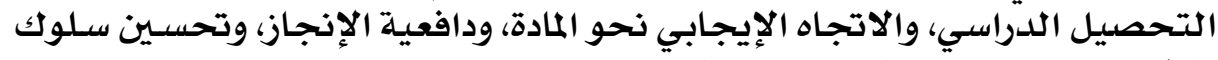

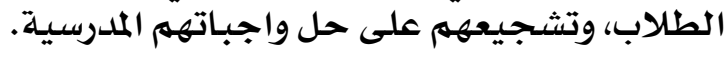

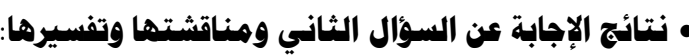

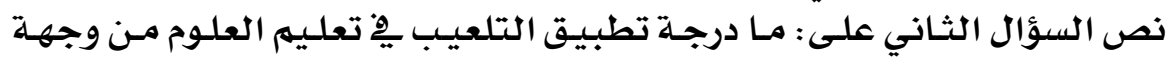

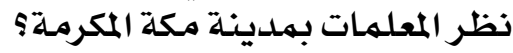

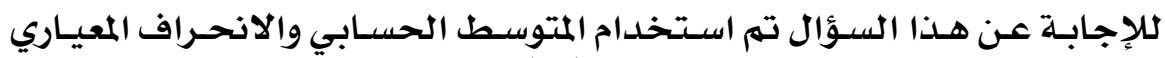

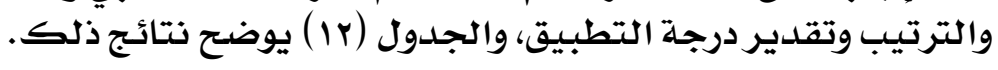

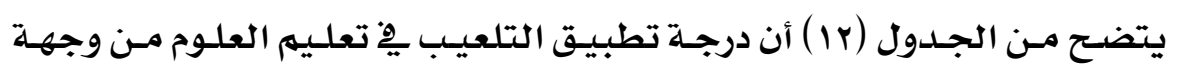

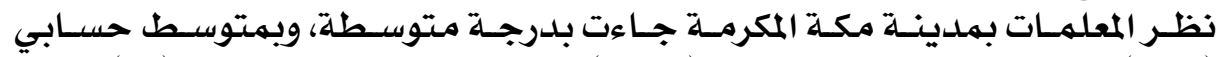

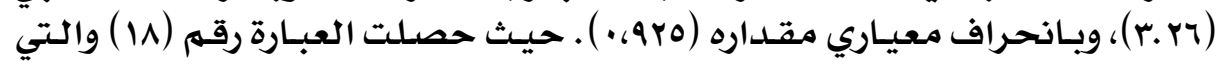

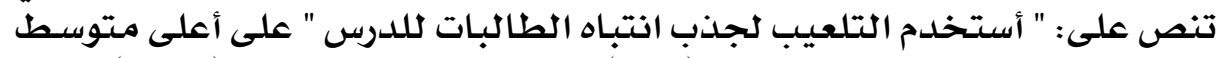

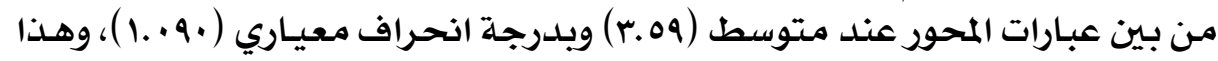

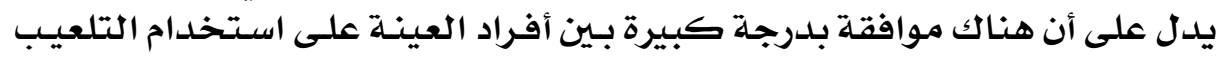

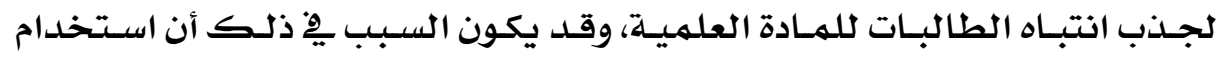

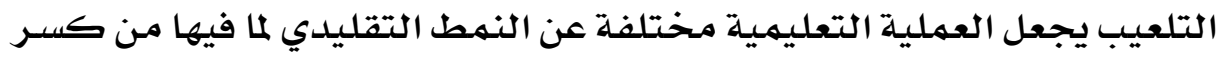

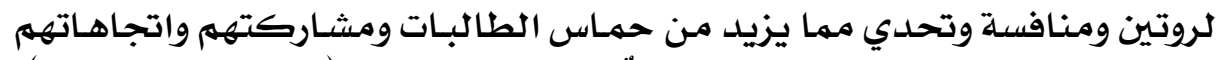

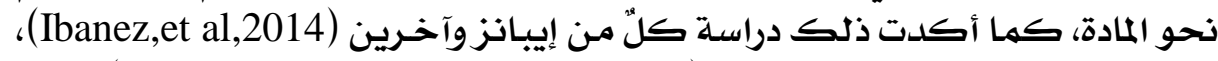
ودراسة بيركي وانستاسيو وسيرش (Burkey, Anastasion, Suresh, 2013).

\section{$\varepsilon 90$}




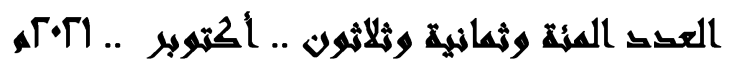

جلدول (1)): المتوسطات الحسابيت والانحرافات المعياريت لدرجت تطبيق التلعيب يِ تعلم العلوم من وجهه نظر معلمات العلوم

\begin{tabular}{|c|c|c|c|c|c|}
\hline 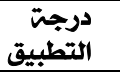 & 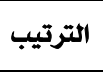 & الانحراف & المتوسط & 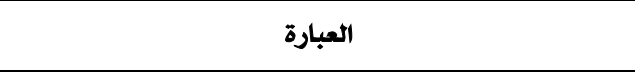 & $p$ \\
\hline متوسطة & 0 & 1.0\% & ד.Y.r & أستخلدم التطبيقات التي تتخذ مبدأ التلعيب لتبسيط تعلم & ir \\
\hline متوسطت & $v$ & 1.10 & r.r & 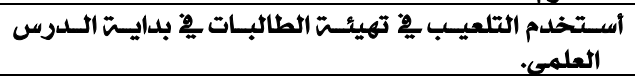 & ir \\
\hline 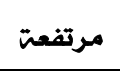 & $r$ & $1.0 \times 0$ & r.\$9 & 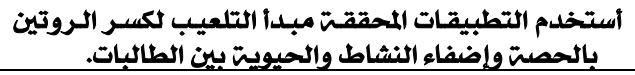 & $1 \varepsilon$ \\
\hline 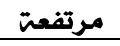 & $r$ & $1 . * 19$ & r.£^ & أستخدم التلعيب لزيادة التنافس الشريف بين الطالبات. & 10 \\
\hline متوسطنة & $\Lambda$ & $1.10 \mathrm{Y}$ & r.৭r & أعطي للطالبات أشطت إثرائيت منزليت قائمت على التلعيب. & 17 \\
\hline متوسطة & 7 & $1.1 \wedge \varepsilon$ & r.Yo & أستخدم التلعيب لمراعاة الفروق الفرديت بين الطالبات. & iv \\
\hline مرتفعت & 1 & 1.9 & r...9 & أستخدم التلعيب لجذب انتباه الطالبات للدرس. & M \\
\hline متوسطت & 9 & $1.10 \mathrm{Y}$ & r.Ar & 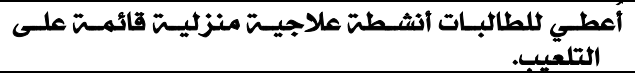 & 19 \\
\hline متوسطة & $\varepsilon$ & $1 . \cdot v r$ & r.ra & أستخدم التلعيب كطريقت جديلدة من طرق تعليم العلوم. & r. \\
\hline متوسطت & & .940 & r.YT & المحور ككل & \\
\hline
\end{tabular}

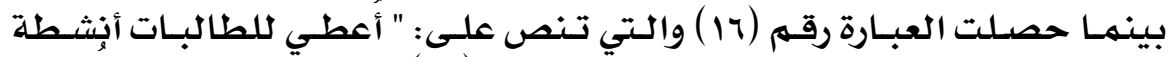

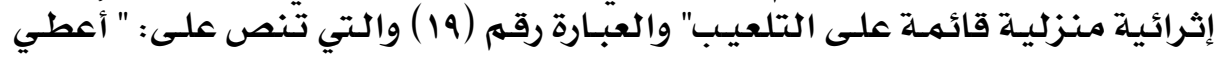

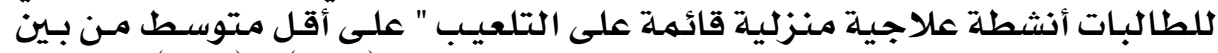

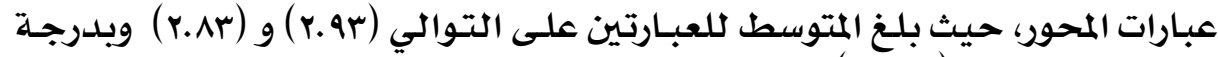

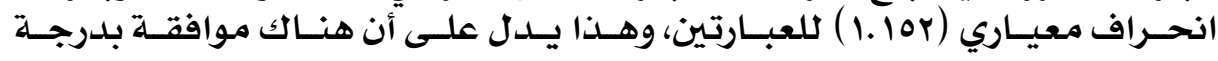

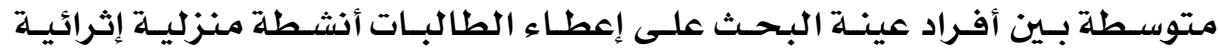

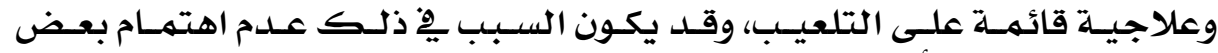

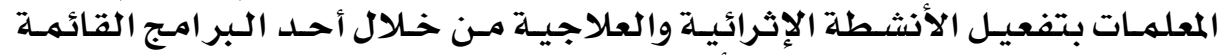

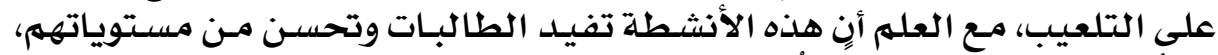

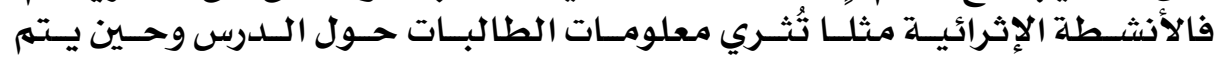

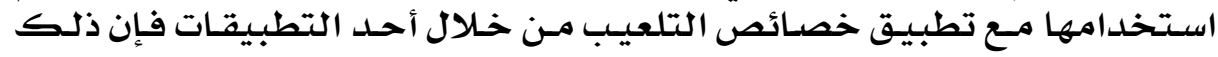

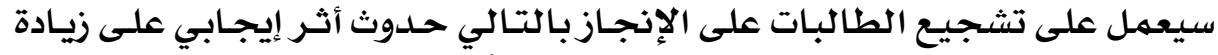

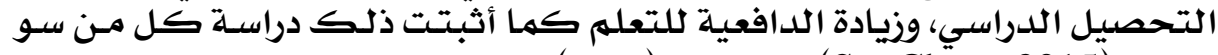

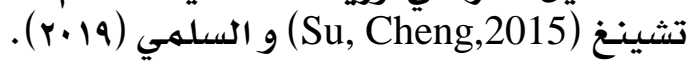

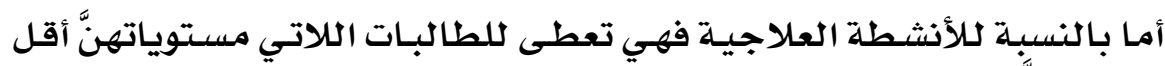

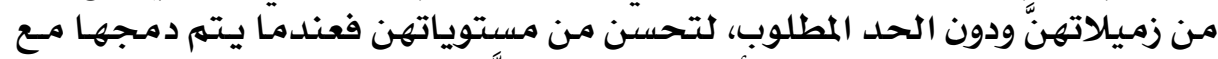

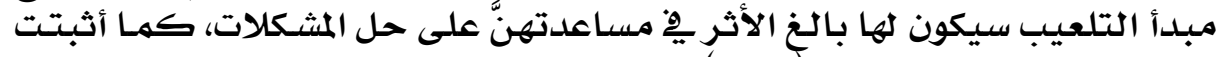

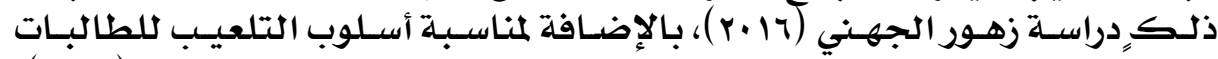

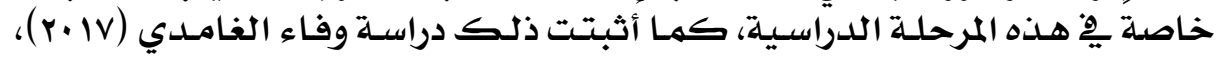

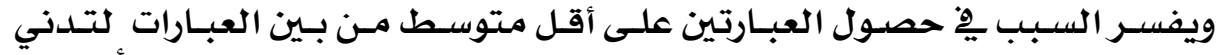

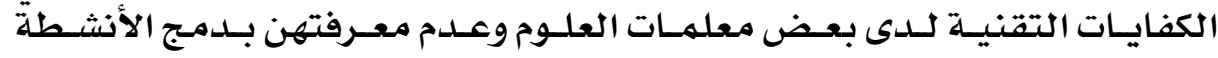

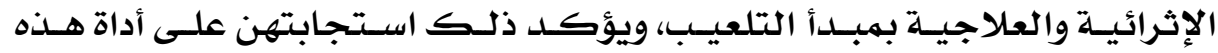




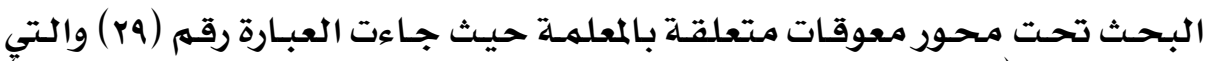

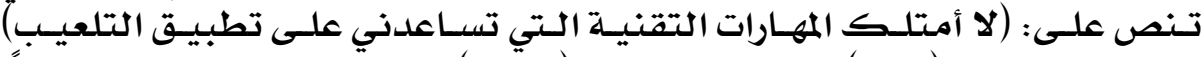

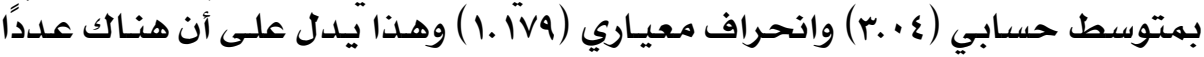

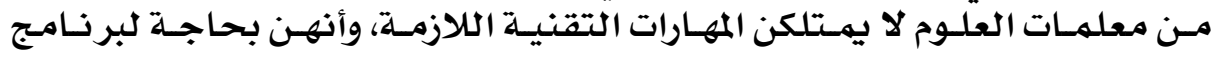

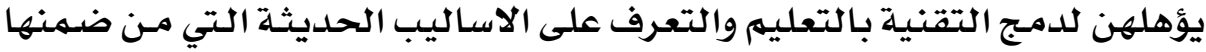

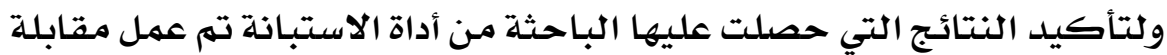

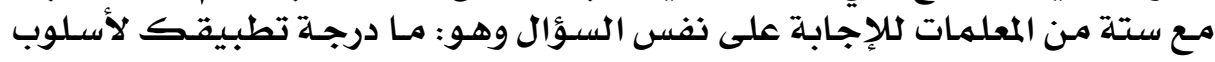

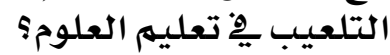

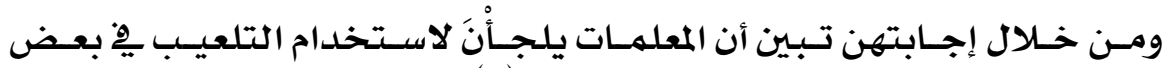

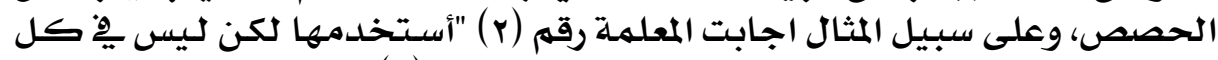

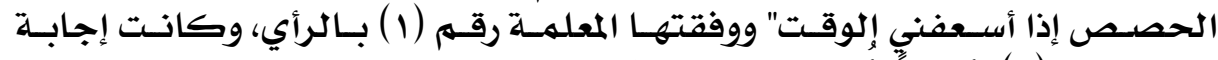

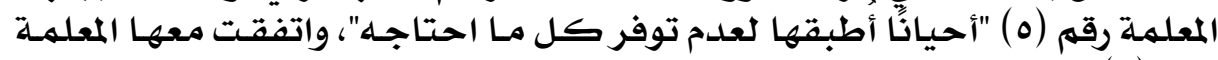

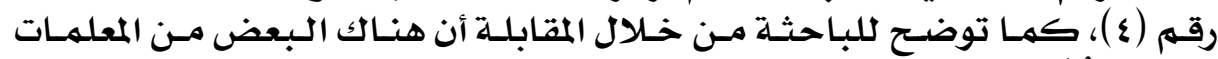

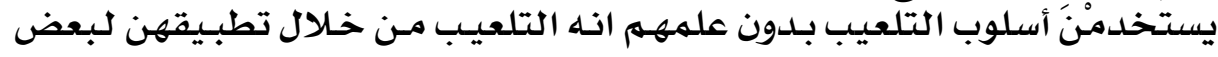

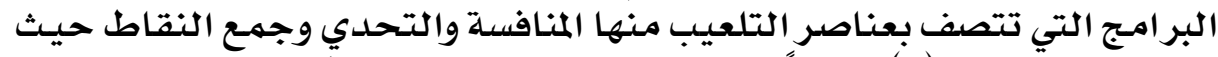

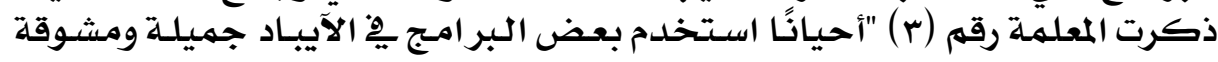

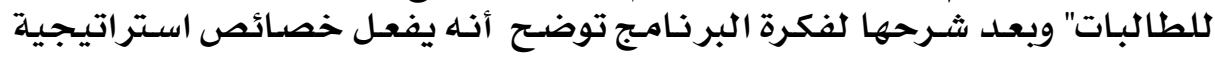

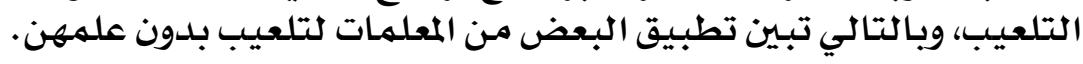

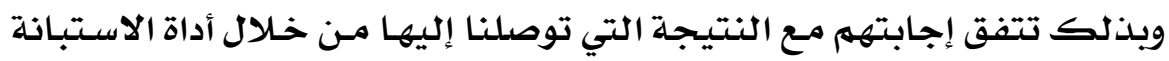

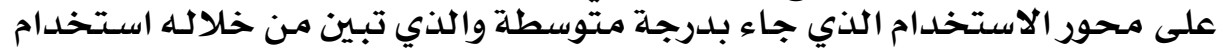

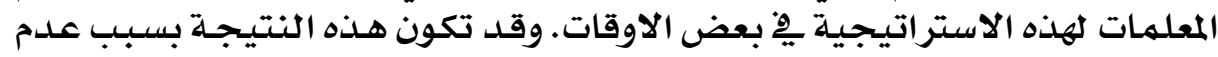

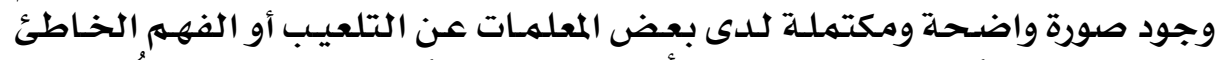

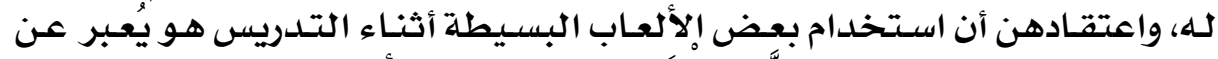

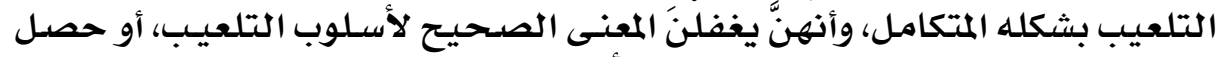

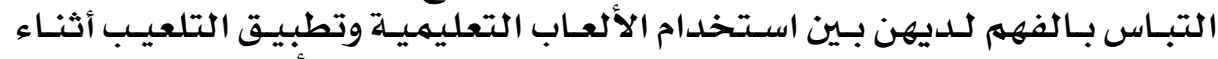

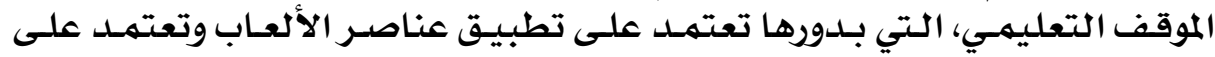

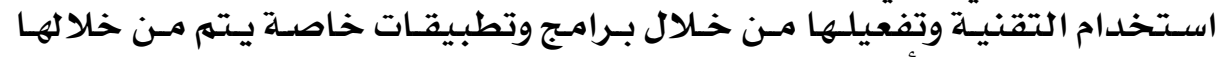

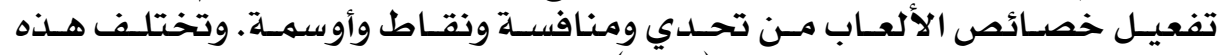

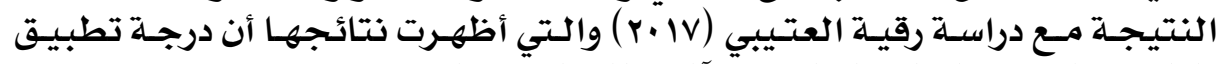

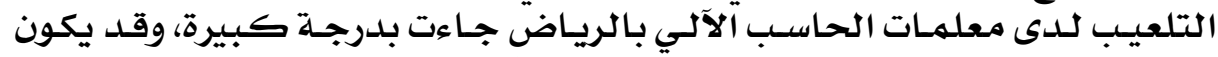

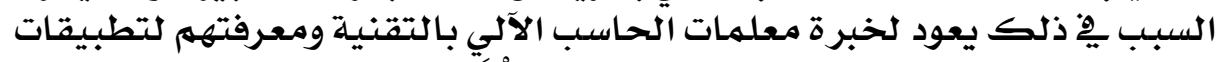

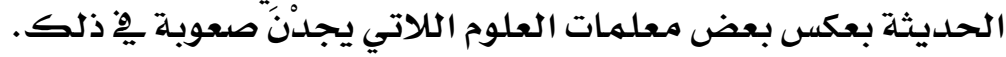

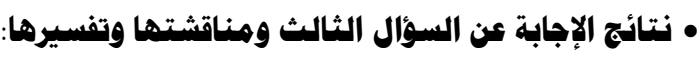

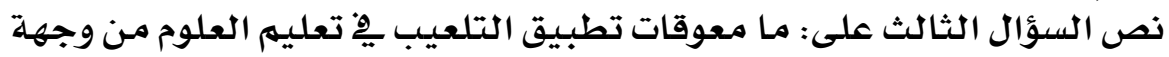

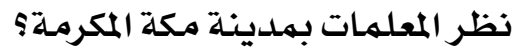




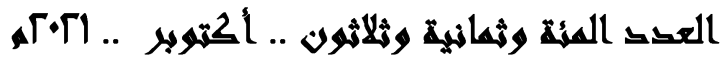

ولإججابـة عن هـذا السؤال تم اسـتخدام المتتوسـط الحســابي والانحـراف المعيـاري

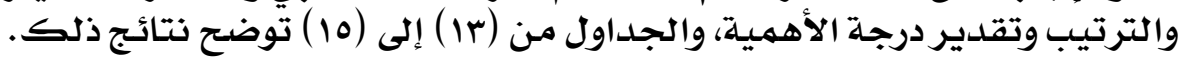

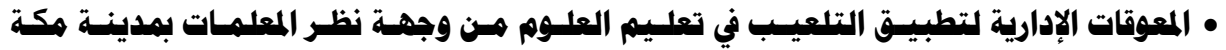

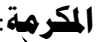

جلدول (r)): المتوسطات الحسابيت والانحرافات المعياريت للمعوقات الإداريت لتطبيق التلعيب يُ تعليم العلوم

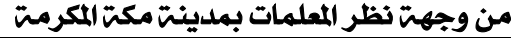

\begin{tabular}{|c|c|c|c|c|c|}
\hline اللا،حمت & التت تس & الانح اف & التمسط & العسا.ة & \\
\hline متوسطة & $v$ & 1.01 & $r+9$ & 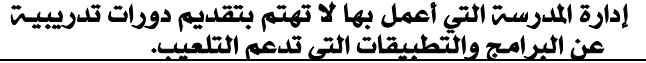 & M \\
\hline متوسطت & 1 & 1.477 & r.r. & 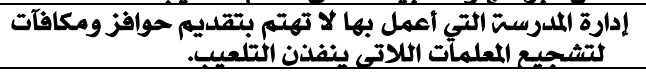 & $r Y$ \\
\hline مرتفعت & $\varepsilon$ & $1 .+1 \varepsilon$ & r.vi & العبء التدريسي والإداري يحد من تطبيقي لأسلوب التلعيب. & rr \\
\hline مرتفعت & ० & 1.99 & r.81 & قلت الدورات التدريبيت التي تهتم بدمج التقنيت ـِ التعليم. & Yq \\
\hline مرتفعت & $r$ & $1 . .+4$ & $\varepsilon .1 \varepsilon$ & 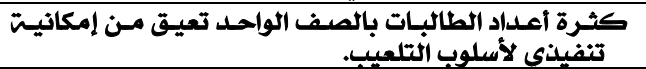 & ro \\
\hline مرتفعت & $r$ & $1.4 Y$ & E.r.r & 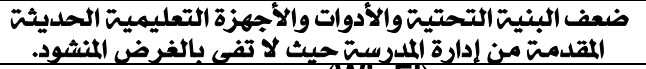 & rT \\
\hline مرتفعة & 1 & •Arr & \&.rr & 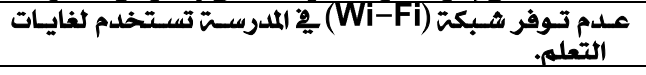 & $r V$ \\
\hline مرتفعت & & $\cdot \mathrm{VII}$ & $r \cdot v$ & المعوقات الإداريت ككل & \\
\hline
\end{tabular}

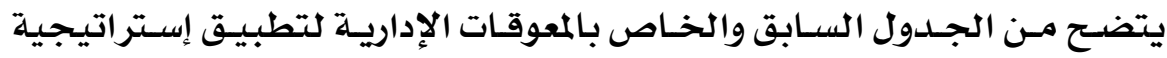

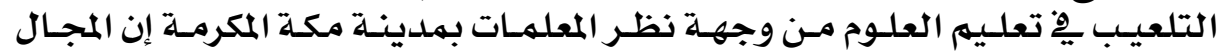

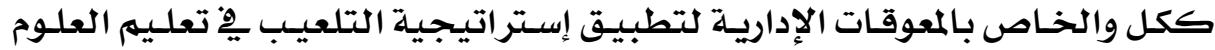

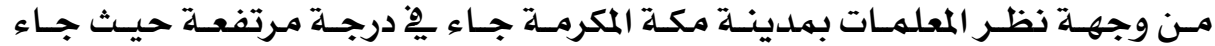

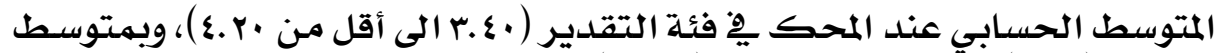

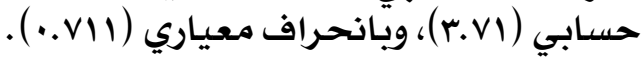

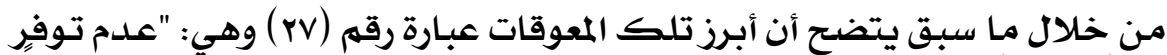

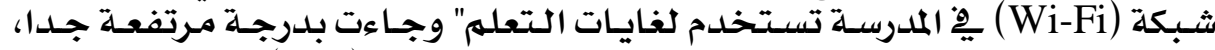

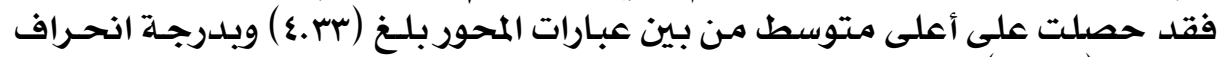

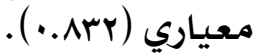

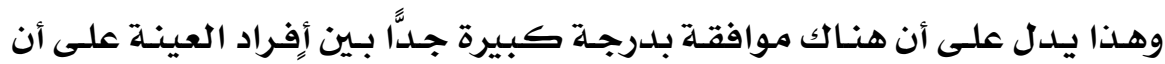

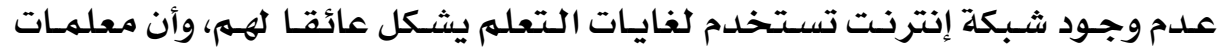

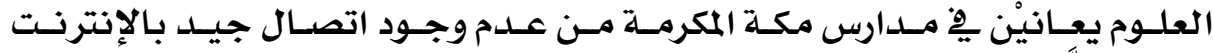

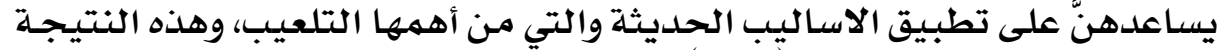

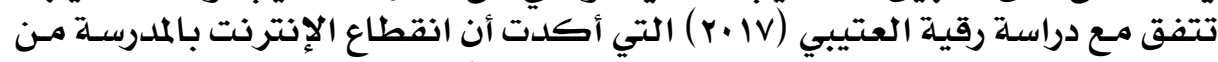

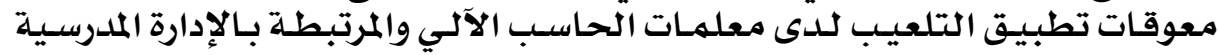
والإمكانات المادية.

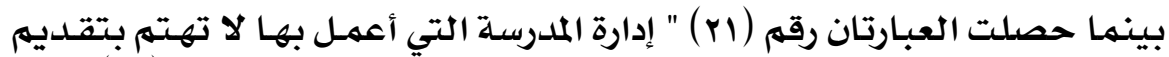

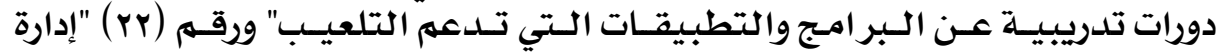




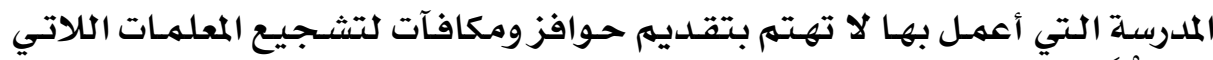

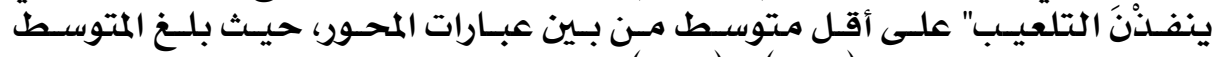

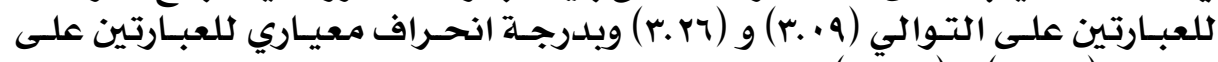

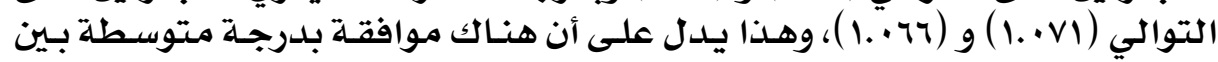

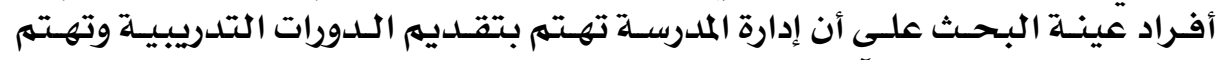

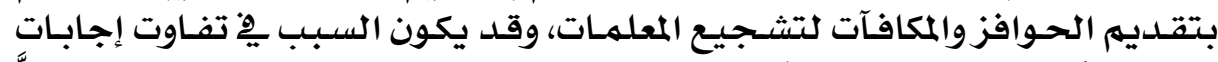

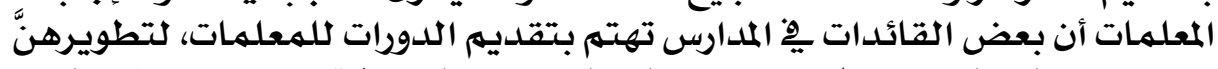

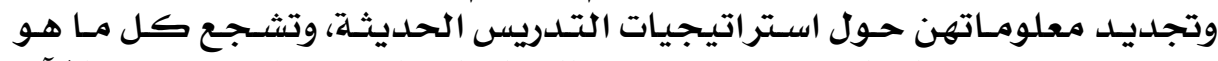

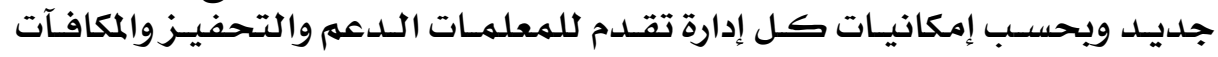

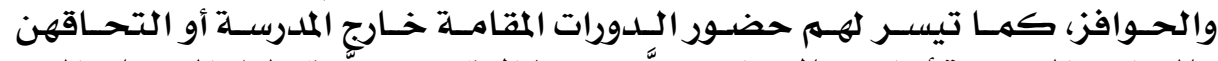

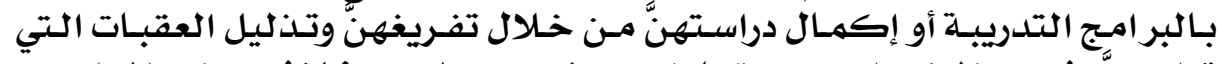

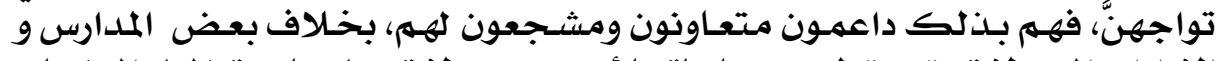

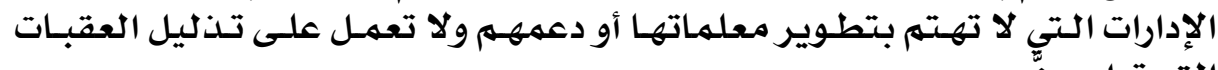
التي تواجهن.

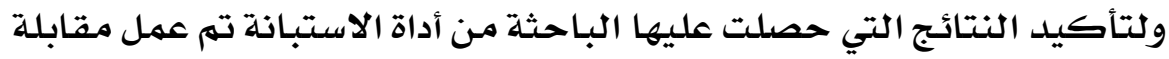

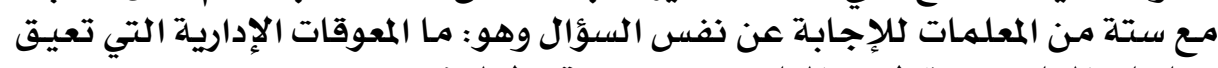

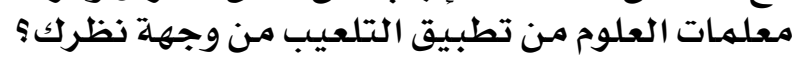

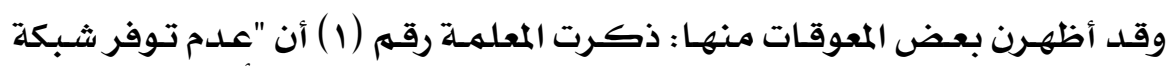

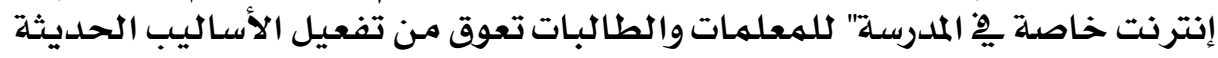

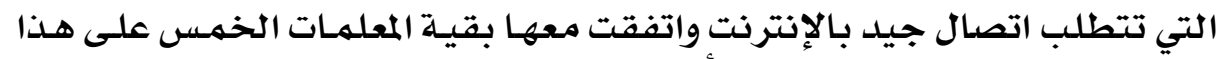

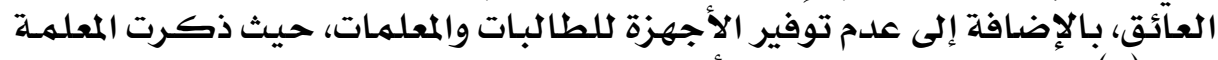

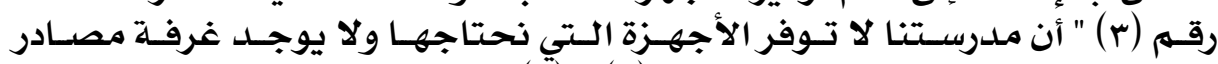

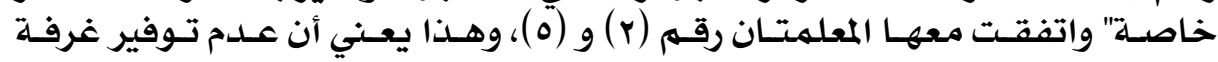

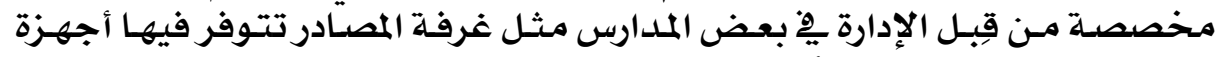

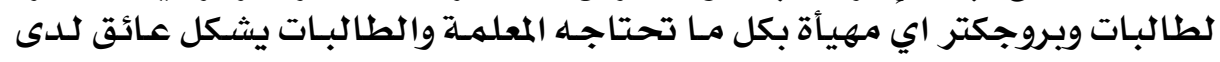
بعض المعلهمات.

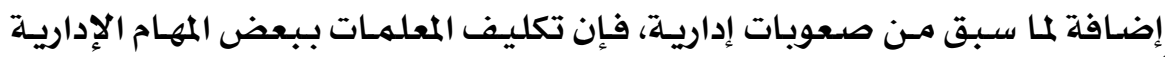

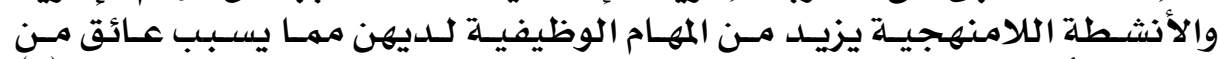

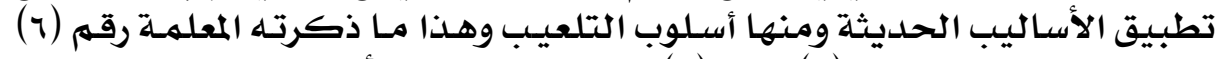

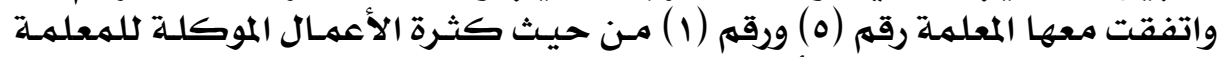

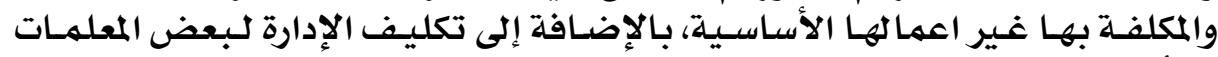

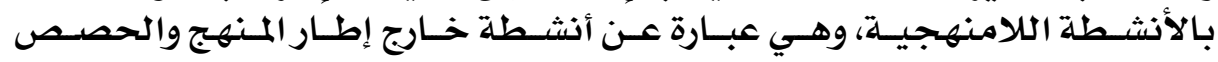

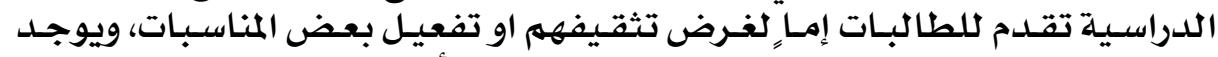

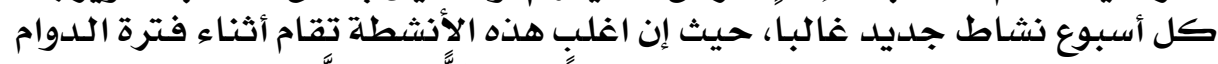

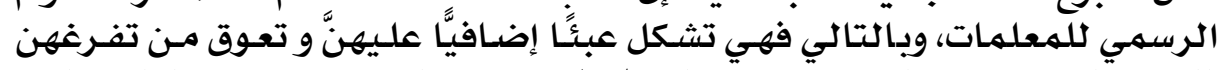

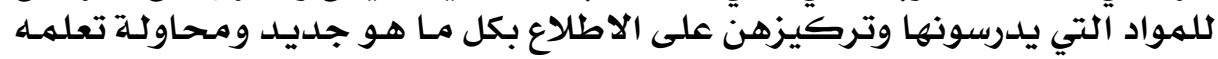

\section{\&99}




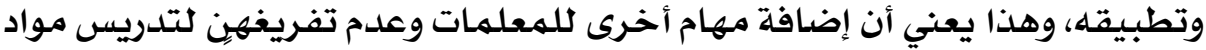

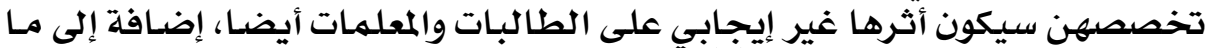

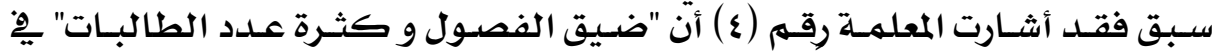

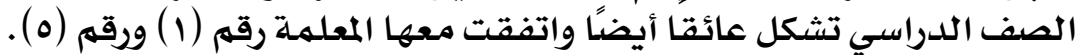

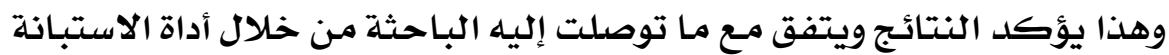

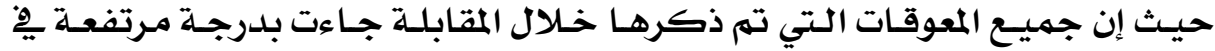

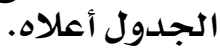

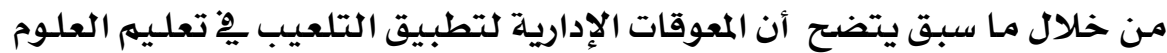

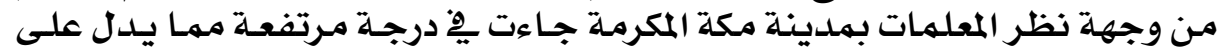

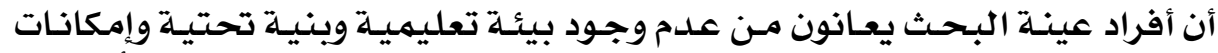

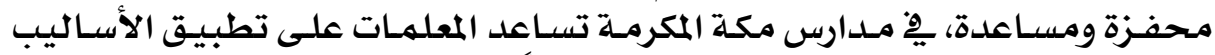

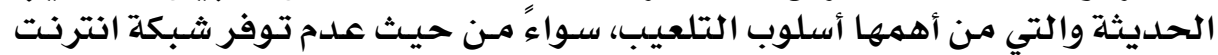

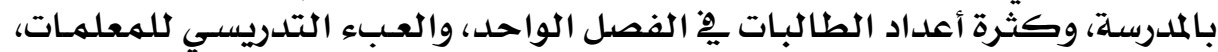

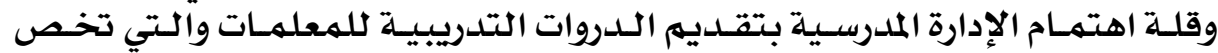

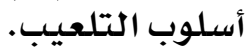

• المعوقات التي تتعلق بالمعلمسة لتطبيسق التلعيسب في تعابـيم العلـوم هـن وجهـة نظـر المعلمسات

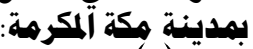

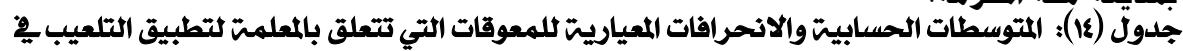
تعليم العلوم من وجهت نظر المعلمات بمدينيت مكتي

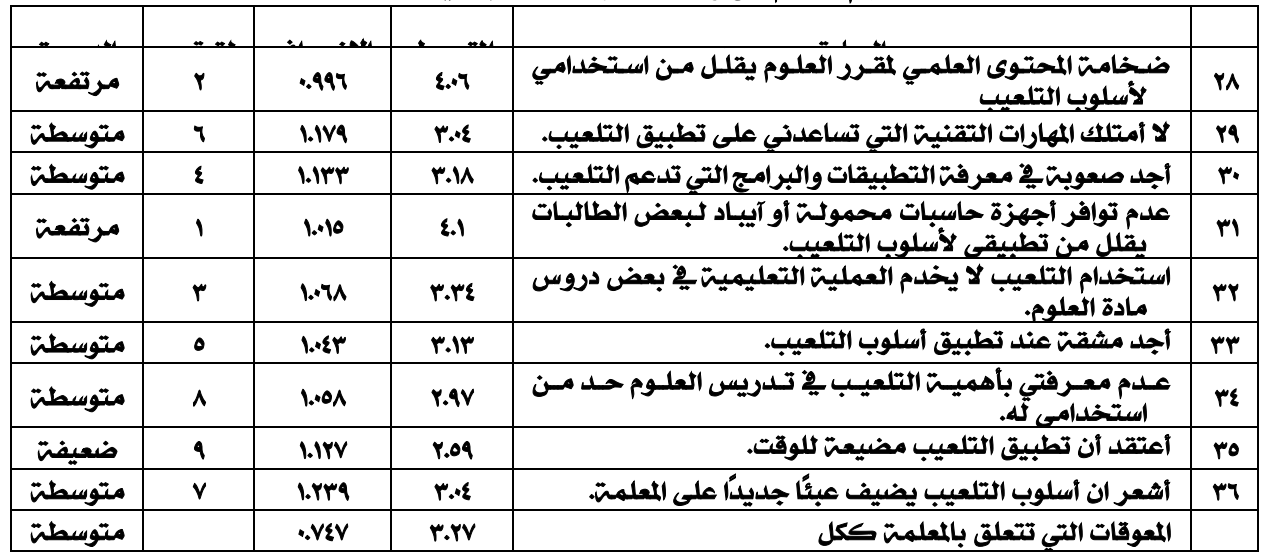

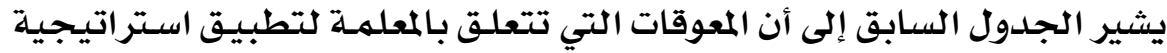

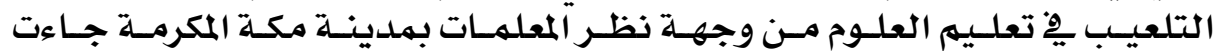

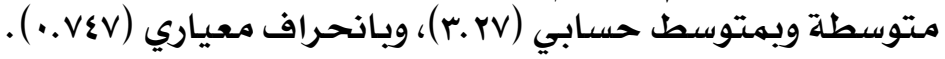

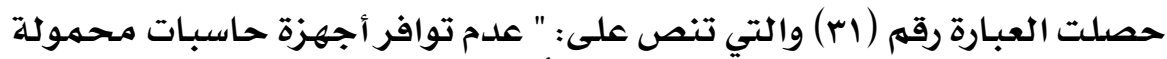

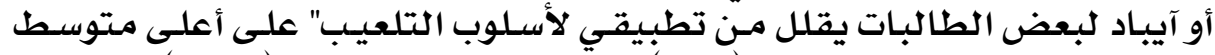

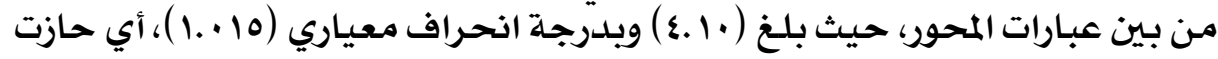




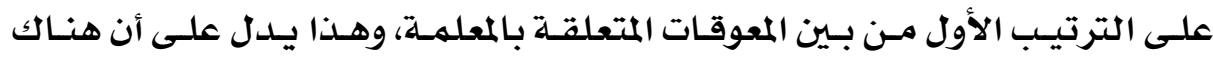

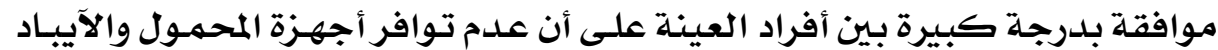

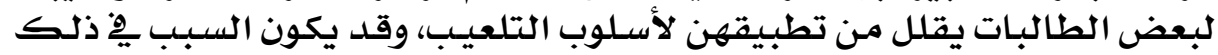

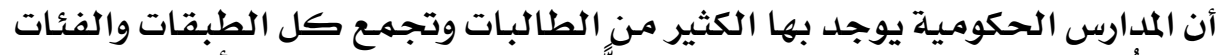

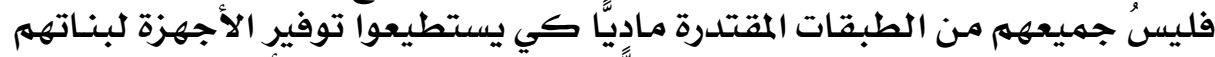

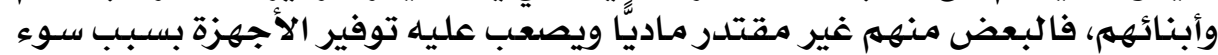

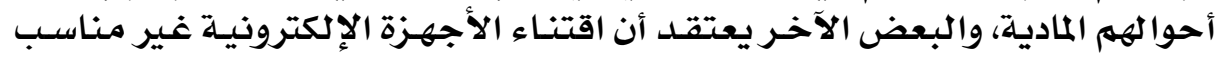

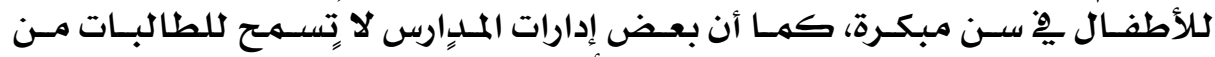

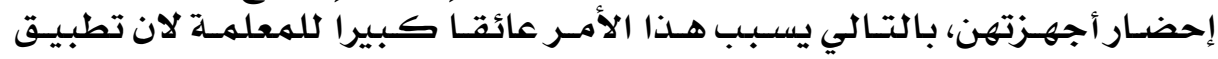

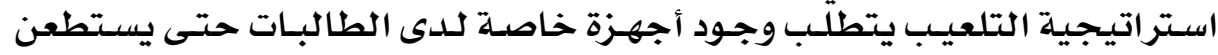

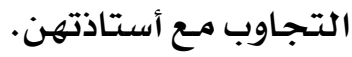

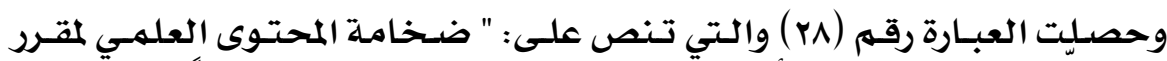

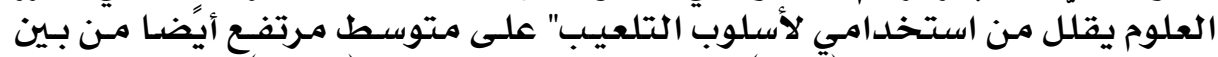

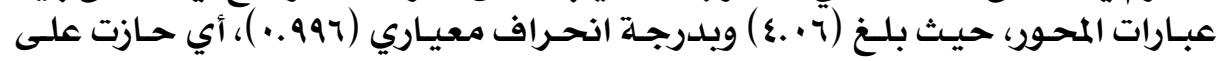

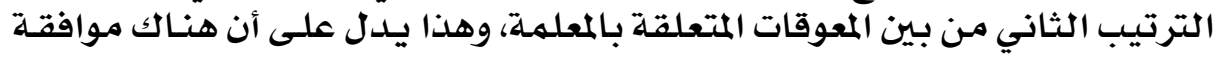

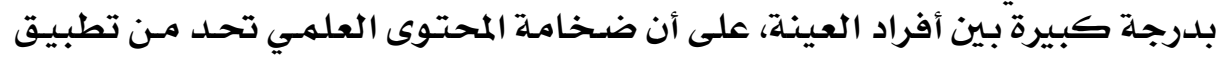

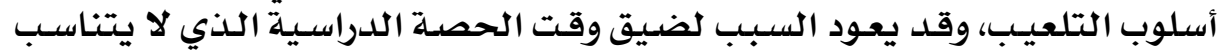

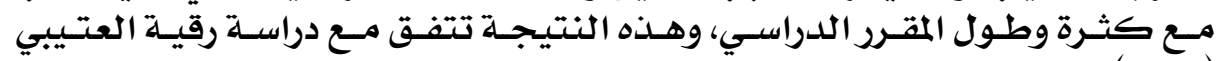

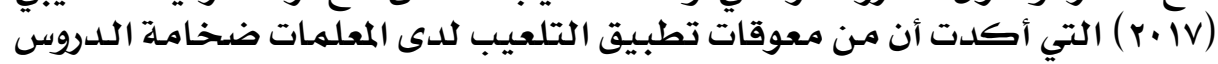

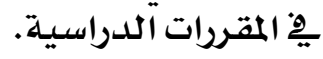

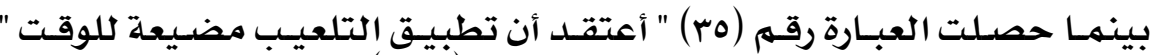

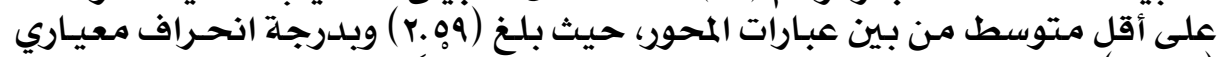

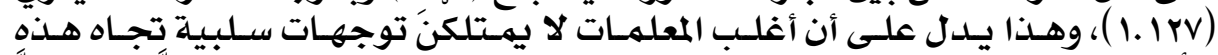

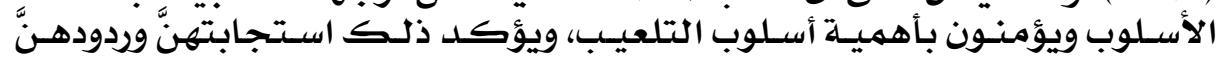

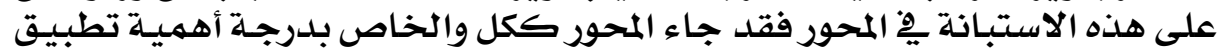

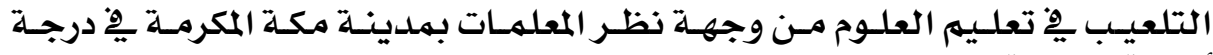
أهميلة مرتفعة.

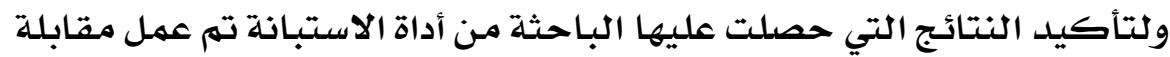

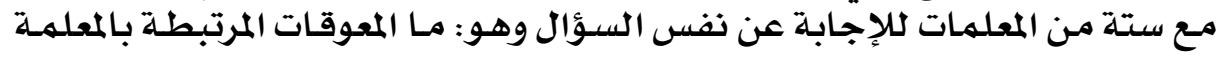

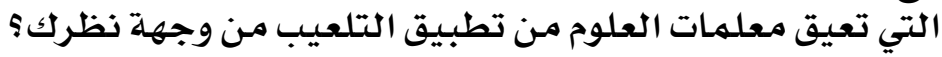

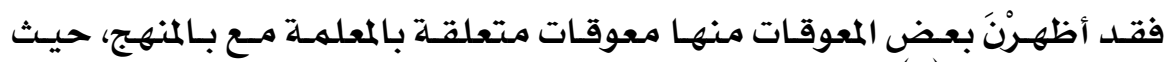

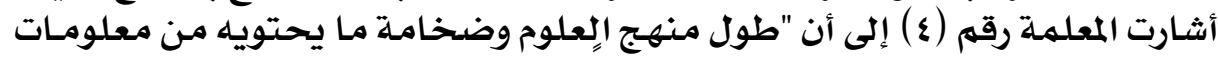

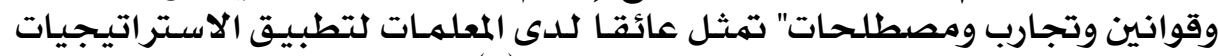

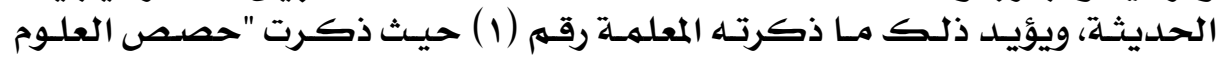

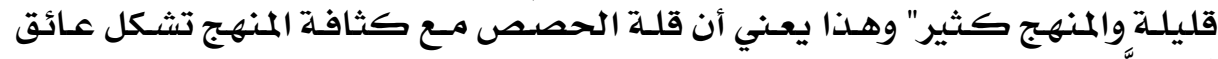
لديهنَّ. 


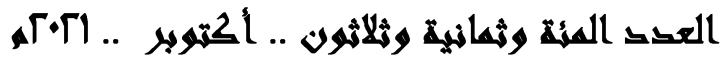

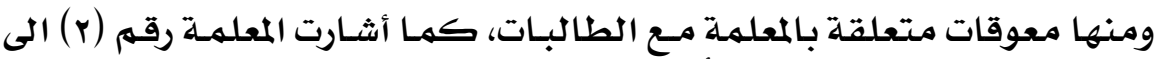

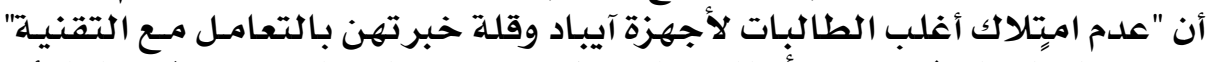

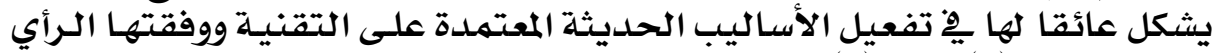

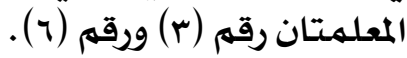

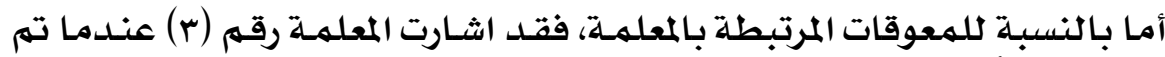

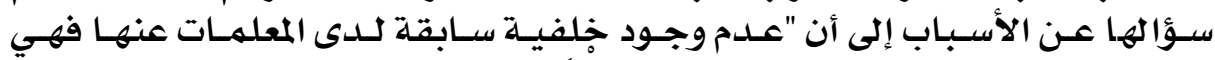

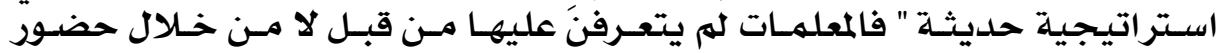

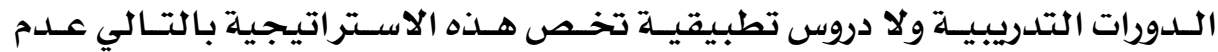

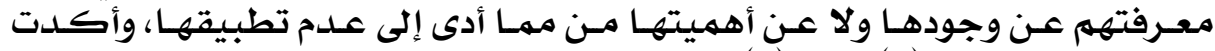

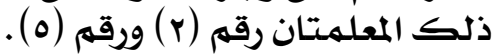

ومن جهة أخرى أوضـحت المعلمهة رقم (r ) أنه يهكن ان يكون أحسد الاسبـاب "عدم ألمام

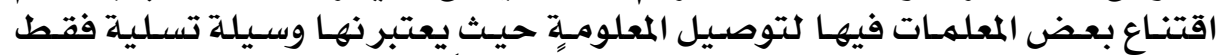

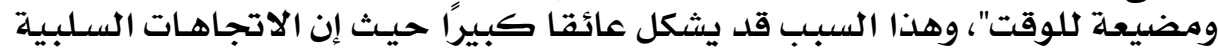

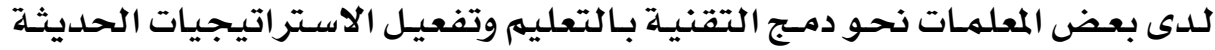

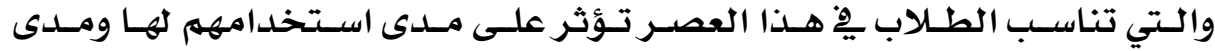

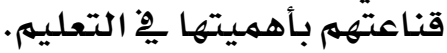

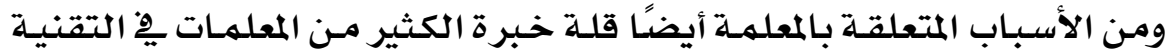

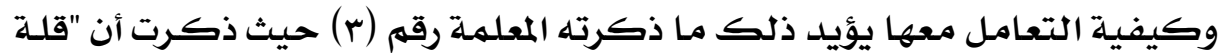

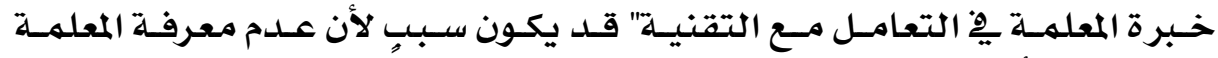
لاستخدام الأجهزة التي تحتاج معرفة تقنية تشكل عائقا واتفقت معها المعلمهة رقهم

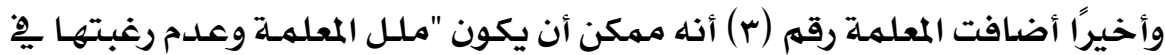

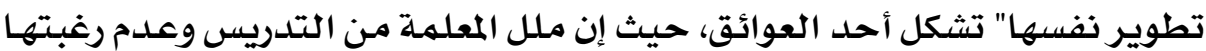

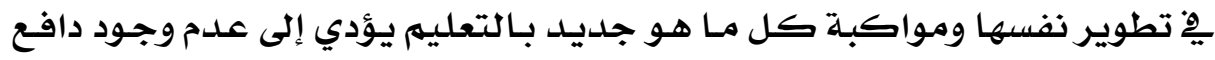

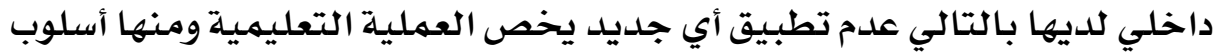
التلعيب.

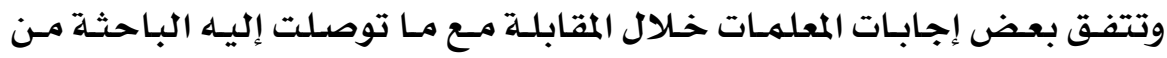

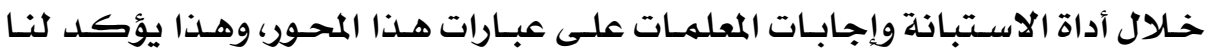
وجود العوائق.

وبـالرجوع لما سبـق، يهكن أن نخله إلى أن معلهـات العلـوم يِّ المرحلـة الابتدائيـة

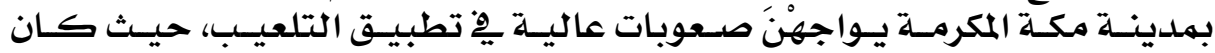

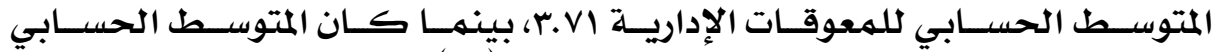

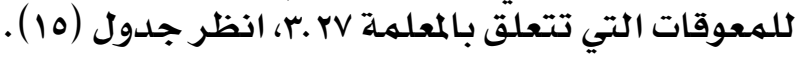

\section{$\odot \cdot Y$}




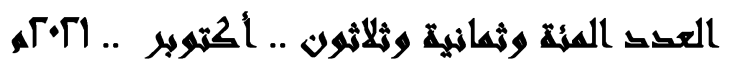

جلدول (10) المتوسطات الحسابيت والانحرافات المعياريت لمعوقات تطبيق التلعيب مِ تعليم العلوم من وجهن نظر المعلمات بملينت مكتة المكرمة ألماتيق

\begin{tabular}{|c|c|c|c|c|}
\hline اللدرجتة & الانحراف & المتوسط & 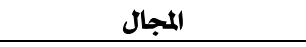 & p \\
\hline مرتفعت & $\cdot V 11$ & $r . v$ & المعوقات الإداريت & 1 \\
\hline متوسطت &.$v \varepsilon \vee$ & r.rv & المعوقات التي تتعلق بالمعلمت & r \\
\hline مرتفعت & $.7 \varepsilon Y$ & r.\$9 & المعوقات ككل & $r$ \\
\hline
\end{tabular}

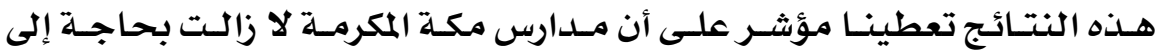

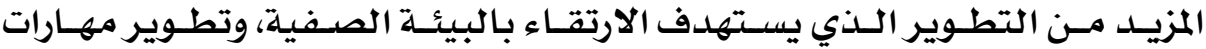

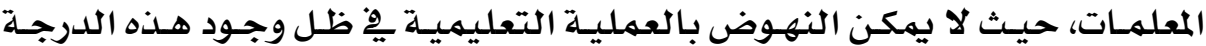

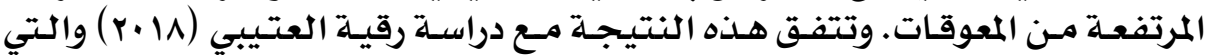

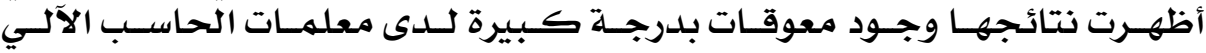
بالرياض لتطبيق التلعيب.

\section{• نتائج الإجابة عن السؤال الرابع وهناقشتها وتفسيرها:}

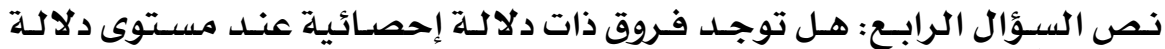
( $\alpha \leq 0,05)$

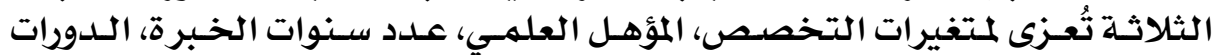

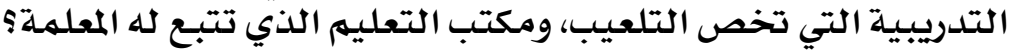

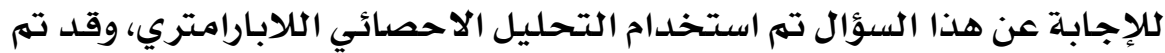

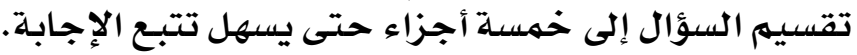
• أولاً: الفروق وفقا لمتغير الدورات التدريبية التي تخص التلعيب:

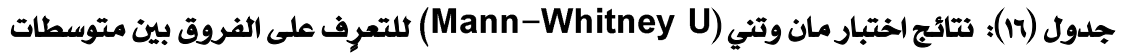

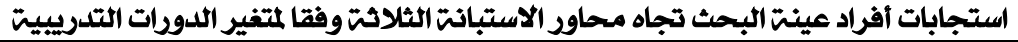

\begin{tabular}{|c|c|c|c|c|c|c|}
\hline مستوى & قيمتً & الانحراف & المتوسط & العدد & التدوراتي & المجال/ المحصور \\
\hline \multirow{2}{*}{$\cdot \wedge 1$} & \multirow{2}{*}{.01} & .VYA & r.qv & VA & نعم & \multirow{2}{*}{ المحوِ تعليم العلوم: أهميت تطبيق التلعيب } \\
\hline & &. IV9 & $r .49$ & IYY & $y$ & \\
\hline \multirow{2}{*}{ r. } & \multirow{2}{*}{1.090} & $\bullet \wedge \leq \varepsilon$ & r.rq & VA & نعم & \multirow{2}{*}{ المحِور تعليم ألعلوم: درجت تطبيق التلعيب } \\
\hline & & $.97 \mathrm{~V}$ & r.IV & IYY & $y$ & \\
\hline \multirow[t]{2}{*}{$\bullet \wedge r \varepsilon$} & \multirow[t]{2}{*}{$\cdot . r I$} & .09 & r.V & VA & نعم & \multirow{2}{*}{ 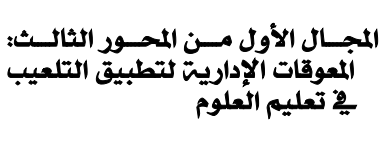 } \\
\hline & & $\because$ VAl & $r . V r$ & Irr & ע & \\
\hline \multirow[b]{2}{*}{.949} & \multirow[b]{2}{*}{$\because v 7$} & .780 & r.rV & VA & نعم & \multirow{2}{*}{ 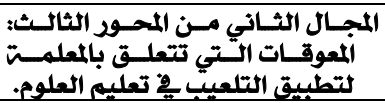 } \\
\hline & & $\bullet \cdot \Lambda \cdot V$ & Y.YV & IYY & ע & \\
\hline \multirow{2}{*}{ •Avr } & \multirow{2}{*}{0.171} & .0 .0Y0 & $r . \varepsilon \Lambda$ & $V \wedge$ & نعم & \multirow{2}{*}{ المحور الثالث: المعوقات ككل } \\
\hline & & $\because V \cdot \Lambda$ & r.o & IYY & $\boldsymbol{y}$ & \\
\hline
\end{tabular}

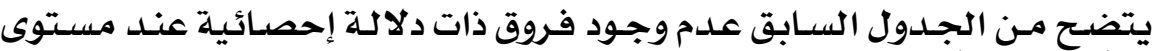

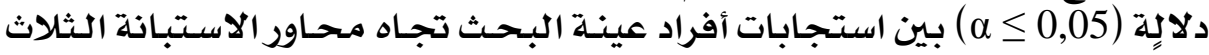

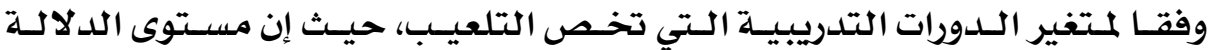

\section{$0, \mu$}




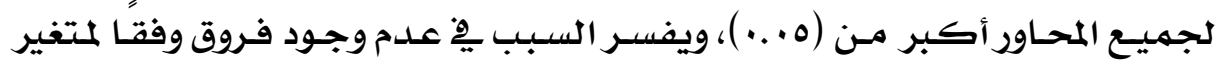

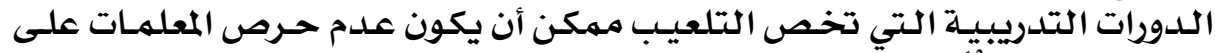

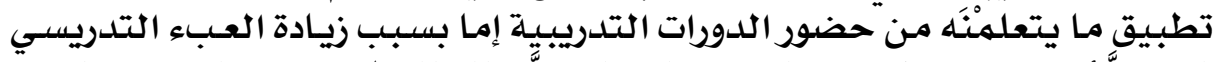

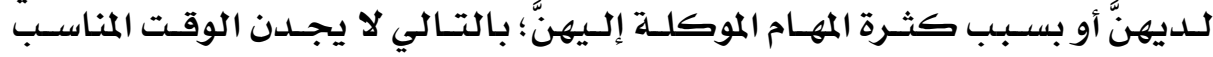

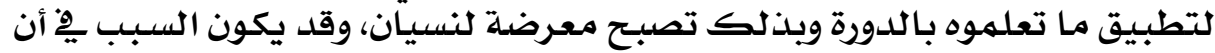

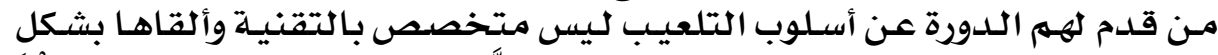

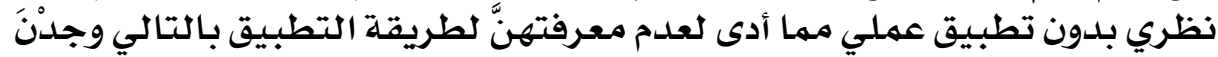

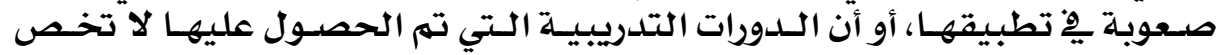

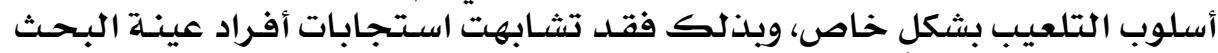

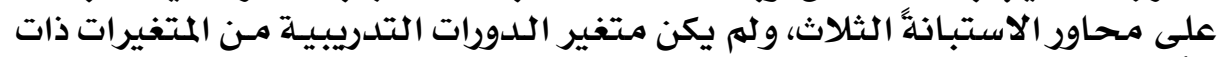

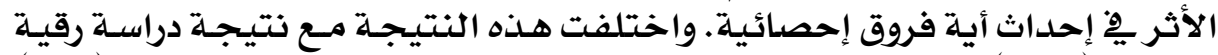

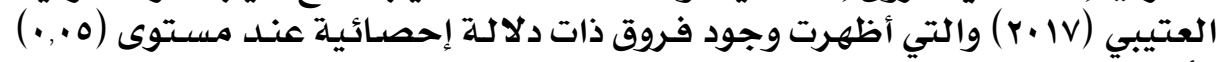

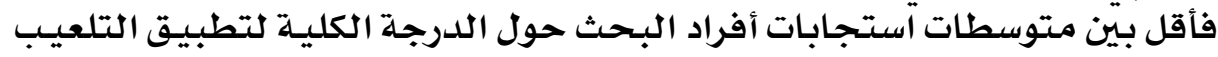

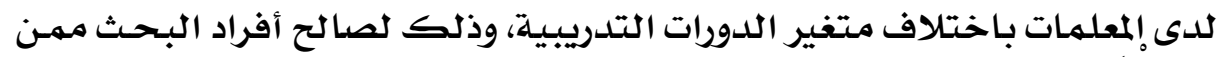

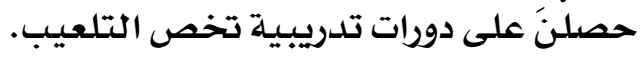

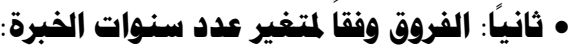

جدول (IV): نتائج اختبار كروسكال ولس (Kruskal Wallis) للتعرف على الفروق بين متوسطات البحات

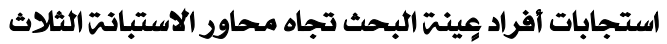

\begin{tabular}{|c|c|c|c|c|c|}
\hline مستوى & $\begin{array}{c}\text { Chi- } \\
\text { Square }\end{array}$ & متوسط & العلدد & الخبرة & المجال/ المحود \\
\hline \multirow{3}{*}{ r.r.r } & \multirow{3}{*}{ r.19Y } & AM.r. & M & أقل من ه سنوات & \multirow{3}{*}{ المِوض تعليم العلوم: أهميت تطبيق التلعيب } \\
\hline & & $9 \varepsilon .4$ & vi & من ه سنوات إلى آقل & \\
\hline & & $1 . V .19$ & 1.7 & . ا سنوات فأكثر & \\
\hline \multirow{3}{*}{ 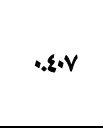 } & \multirow{3}{*}{ I.vav } & 1.1 .11 & M & أقل من ه سنوات & \multirow{3}{*}{ 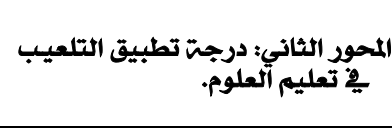 } \\
\hline & & 94.71 & vi & من ه سنوات إلى آقل & \\
\hline & & 1.0.YY & 1.7 & .ا سنوات فاكثر & \\
\hline \multirow{3}{*}{$\bullet \cdot r+\varepsilon$} & \multirow{3}{*}{ Y.rVq } & १Y.Ar & M & آقل من ه سنوات & \multirow{3}{*}{ 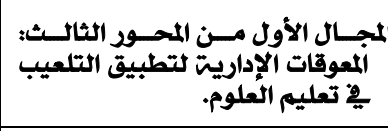 } \\
\hline & & $1 \cdots .27$ & vi & من ه سنوات إلى آقل & \\
\hline & & 97.9 & 1.7 & ما سنوات فاكثر & \\
\hline \multirow{3}{*}{$.0 V \mathrm{VI}$} & \multirow{3}{*}{1.1 .4} & $111.7 \mathrm{~V}$ & $M$ & آلال من 0 سنوات & \multirow{3}{*}{ 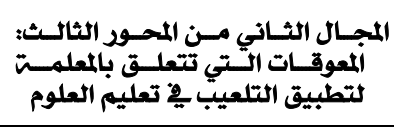 } \\
\hline & & 1.Y.50 & vi & من ه سنوات إلى أقل & \\
\hline & & QV.YI & 1.7 & •ا سنوات فأكثر & \\
\hline \multirow{3}{*}{.7} & \multirow{3}{*}{$1 .+11$} & 1.1 .11 & $M$ & آلال من 0 سنوات & \multirow{3}{*}{ المحور الثالث: المعوقات ككل } \\
\hline & & $1 \cdot 0.00$ & vi & من ه سنوات إلى أقل & \\
\hline & & 97.V $\mathrm{V}$ & 1.7 & •ا سنوات فاكثر & \\
\hline
\end{tabular}

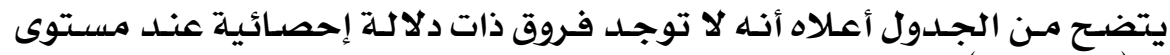

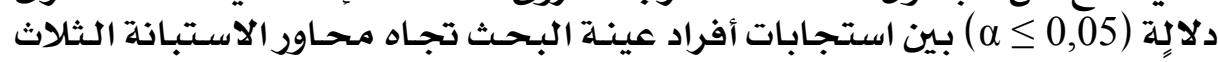

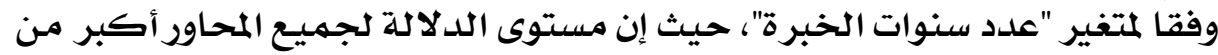




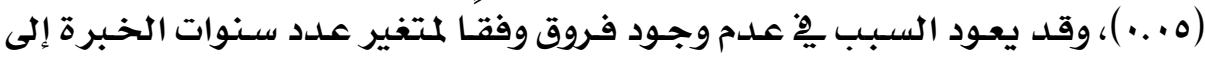

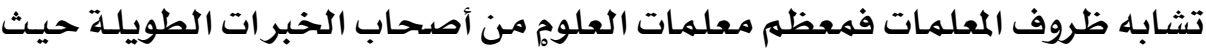

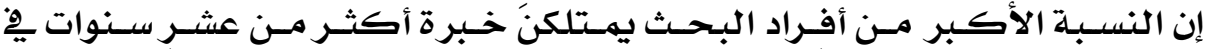

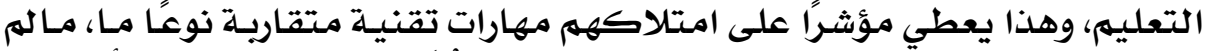

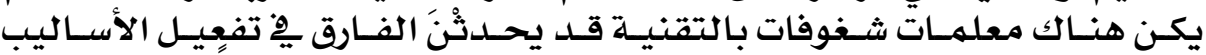

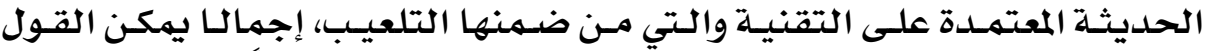

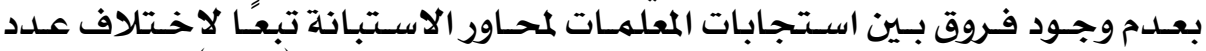

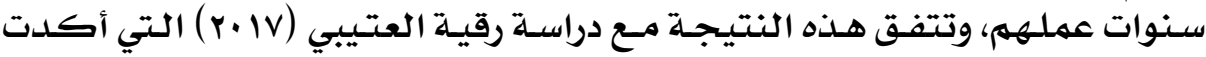

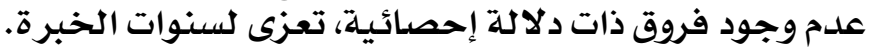
• ثالثًا: الفروق وفقا لمتغير هكتب التعليم الذي تتبع له المعلمة:

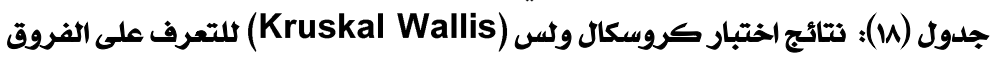

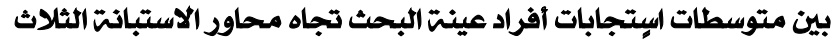

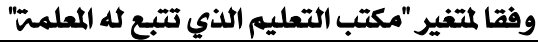

\begin{tabular}{|c|c|c|c|c|c|}
\hline مستوى & $\begin{array}{c}\text { Chi- } \\
\text { Square }\end{array}$ & متوسط الرتب & العدد & مكتب التعليم & المجال/ المحود \\
\hline \multirow{5}{*}{ 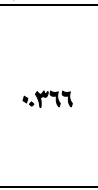 } & \multirow{5}{*}{$\varepsilon . r+\varepsilon$} & $1+1.07$ & \&o & شمال مكتة & \multirow{5}{*}{ المحِور تعليم الأول: أهميت تطبيق التلعيب } \\
\hline & & 9.51 & $\varepsilon r$ & جنوب مكت & \\
\hline & & 1.A.EY & 09 & غرب مكت & \\
\hline & & 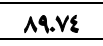 & 19 & ثرق مكت & \\
\hline & & १६.VA & $r \varepsilon$ & وسط مكت & \\
\hline \multirow{5}{*}{. ror } & \multirow{5}{*}{ \&.\&Yr } & 1.V.1A & \&o & شمال مكت & \multirow{5}{*}{ 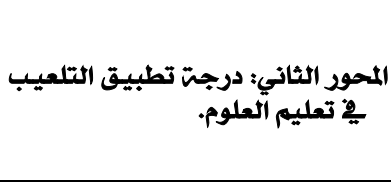 } \\
\hline & & 94.10 & $\varepsilon r$ & جنوب مكتة & \\
\hline & & $1 . r .79$ & $\$ 9$ & غرب مكتة & \\
\hline & & VA.V7 & 19 & شرق مكتة & \\
\hline & & 1.7 .71 & $r \varepsilon$ & وسط مكتة & \\
\hline \multirow{5}{*}{$\cdot A l V$} & \multirow{5}{*}{1.000} & W.Y.YA & so & شمال مكت & \multirow{5}{*}{ 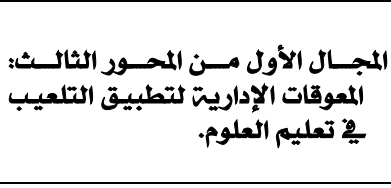 } \\
\hline & & 9V.rY & $\varepsilon r$ & جنوب مكت & \\
\hline & & $9 V . V 1$ & \$9 & غرب مكت & \\
\hline & & 110.20 & 19 & شرق مكت & \\
\hline & & 1.1.rA & $r \varepsilon$ & وسط مكت & \\
\hline \multirow{5}{*}{$.01 \%$} & \multirow{5}{*}{ V.10\& } & $1 . r .19$ & \&o & ثمال مكت & \multirow{5}{*}{ 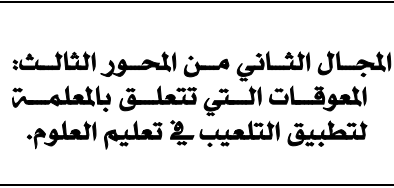 } \\
\hline & & १६.VV & $\varepsilon r$ & جنوب مكت & \\
\hline & & 1.Y.Y9 & \$9 & غرب مكتة & \\
\hline & & IrV.qV & 19 & شرق مكت & \\
\hline & & 10.07 & $r \varepsilon$ & وسط مكت & \\
\hline \multirow{5}{*}{$. Y \leqslant 9$} & \multirow{5}{*}{ 0.raz } & 1.r.IV & so & شمال مكت & \multirow{5}{*}{ المحور الثالث: المعوقات ككل } \\
\hline & & 90.r & $\varepsilon r$ & جنوب مكت & \\
\hline & & w.rr & 09 & غرب مكتة & \\
\hline & & IrT.Ir & 19 & ثرق مكت & \\
\hline & & 19.01 & $r \varepsilon$ & وسط مكت & \\
\hline
\end{tabular}

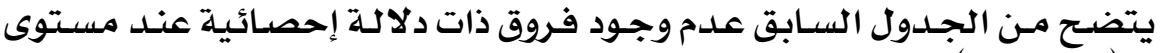

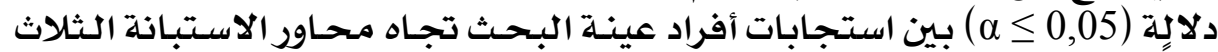

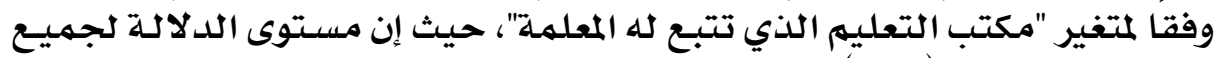

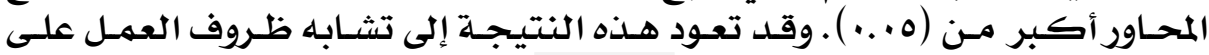

\section{$\theta \cdot \theta$}




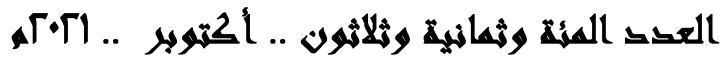

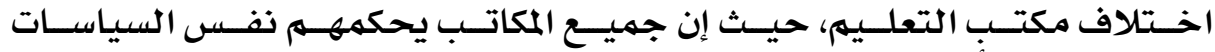

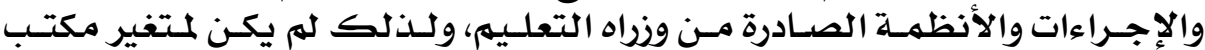

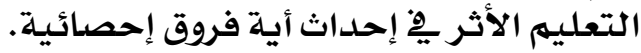

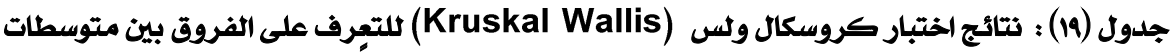
استجابات أفراد عينت البحث تجاه محاور الاستبانت الثلاث وفقا لمتفير "المؤهل العلمي" المئل

\begin{tabular}{|c|c|c|c|c|c|}
\hline مستوى الدلث & $\begin{array}{l}\text { Chi- } \\
\text { Square }\end{array}$ & متوسط & العلدد & المؤهل العلمي & المجال/ المحور \\
\hline \multirow{4}{*}{$.00 \xi$} & \multirow{4}{*}{ Y.*A } & 10.1V & $Y \varepsilon$ & دبلوم - دبلوم & \multirow{4}{*}{ المحور الأول: أهميتيّ تطبيق تعليم العلوم. } \\
\hline & & Q4.rr & $\mathrm{M}$ & بكالوريوس غير تريوي & \\
\hline & & 1.r.Yq & 10. & بكالوريوس تريوي & \\
\hline & & 99 & $\Lambda$ & دراسات عليا & \\
\hline \multirow{4}{*}{ 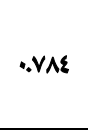 } & \multirow{4}{*}{$1 . \cdot 11$} & A9.VI & $Y \varepsilon$ & دبلوم 2 دبلوم & \multirow{4}{*}{ المحلعيب الثاني: دليم العلوتيق تطبيق } \\
\hline & & 99.V० & M & بكالوريوس فير تريوي & \\
\hline & & 1.1 .9 & 10. & بكالوريوسي تريوي & \\
\hline & & W.A.Yo & $\hat{\Lambda}$ & دراسات عليا & \\
\hline \multirow{4}{*}{ •.val } & \multirow{4}{*}{$1 . \div 21$} & 1. $\{. \$ \varepsilon$ & $Y \varepsilon$ & دبلوم - د د بلوم & \multirow{4}{*}{ 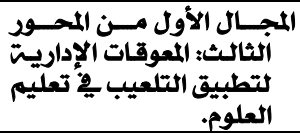 } \\
\hline & & QV.\&v & M & بكالوريوس غير تريوي & \\
\hline & & 99.Y० & 10. & كالوريوسى تريوى & \\
\hline & & IM.An & $\hat{\Lambda}$ & دراسات عليا & \\
\hline \multirow{4}{*}{.017} & \multirow{4}{*}{ 1.VaY } & 1.Y.१1 & $Y \varepsilon$ & دبلوم - د د & \multirow{4}{*}{ 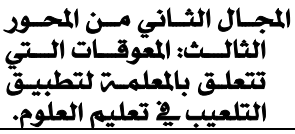 } \\
\hline & & 1...Vo & $\mathrm{M}$ & بكالوريوس غير تريوي & \\
\hline & & 1.1 .0 & 10. & بكالوريوس تريوي & \\
\hline & & Vr.AI & $\Lambda$ & دراسات عليا & \\
\hline \multirow{4}{*}{ •.१६9 } & \multirow{4}{*}{. ro9 } & $1 \cdot 0.11$ & $Y \varepsilon$ & دبلوم - دبلوم & \multirow{4}{*}{ المحكلـور الثاتــث: المعوقـــات } \\
\hline & & Q१.Ar & M & بكالوريوس فير تريوي & \\
\hline & & 1W.YT & 10. & بكالوريوسي تريوي & \\
\hline & & AY.MA & $\Lambda$ & دراسات عليا & \\
\hline
\end{tabular}

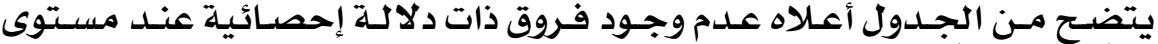

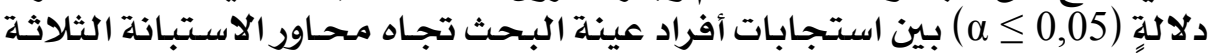

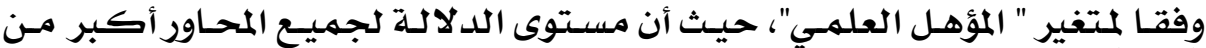

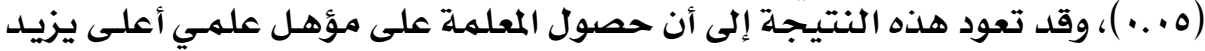

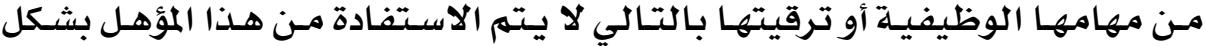

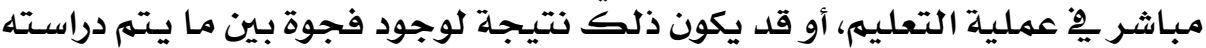

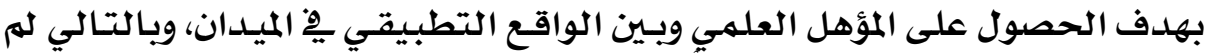

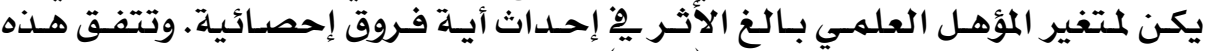

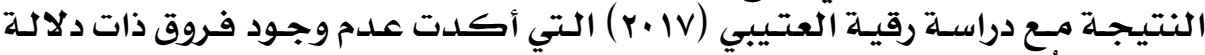

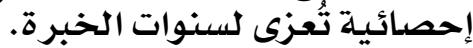

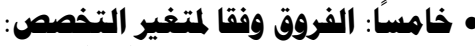

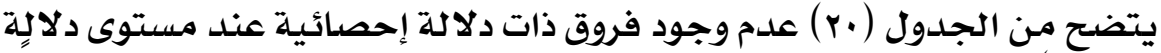
( $\alpha \leq 0,05)$

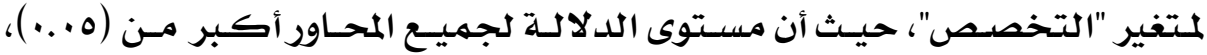

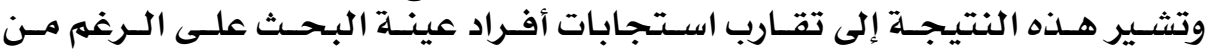




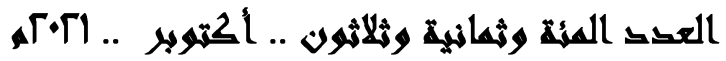

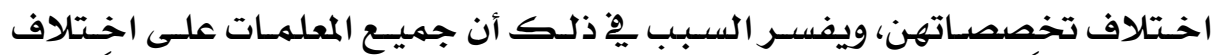

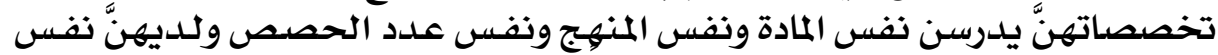

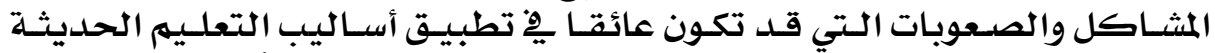

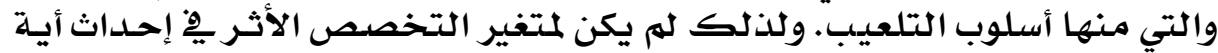
فروق إحصائيـة.

جلدول (†): نتائج اختبار كروسكال ولس (Kruskal Wallis) للتعرف على الفروق بين متوسطات

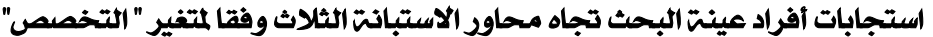

\begin{tabular}{|c|c|c|c|c|c|}
\hline مستوى & $\begin{array}{l}\text { Chi- } \\
\text { Square }\end{array}$ & متوسط & 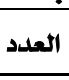 & التخصص & المجال/ المحود \\
\hline \multirow{4}{*}{$.1 . \varepsilon$} & \multirow{4}{*}{$7.10 \varepsilon$} & 1.1 .17 & IrE & علوم ابتدائى & \multirow{4}{*}{ المحور تعليم العلوم: أهميت تطبيق التلعيب } \\
\hline & & $119.9 Y$ & $Y \varepsilon$ & احياء & \\
\hline & & $9 V .50$ & r. & فيزياء & \\
\hline & & VA.0 & YY & كيمياء & \\
\hline \multirow{4}{*}{.790} & \multirow{4}{*}{ 1..$\varepsilon \varepsilon$} & I..r.rY & IrE & علوم ابتدائى & \multirow{4}{*}{ 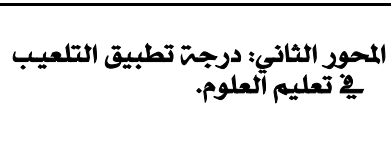 } \\
\hline & & 1.Y & $Y \varepsilon$ & احياء & \\
\hline & & $111 . r \wedge$ & $r$. & فيزياء & \\
\hline & & 90.0 & rr & كيمياء & \\
\hline \multirow{4}{*}{.9 . १^ } & \multirow{4}{*}{ r.roq } & 1.1 .70 & IrE & علوم ابتدائىى & \multirow{4}{*}{ 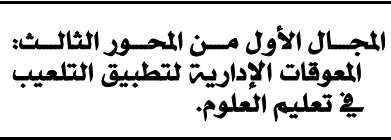 } \\
\hline & & $99 . r r$ & $Y \varepsilon$ & احياء & \\
\hline & & 94.0 & $r$. & فيزياء & \\
\hline & & $1+1.18$ & Yr & كيمياء & \\
\hline \multirow{4}{*}{.911} & \multirow{4}{*}{$0.0 . \varepsilon$} & $1 \cdot 1.2 r$ & Ire & علوم ابتدائى & \multirow{4}{*}{ 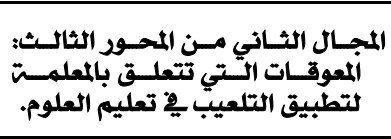 } \\
\hline & & Qצ..Y & $Y \varepsilon$ & احياء & \\
\hline & & 1.5 .91 & $r$. & فيزياء & \\
\hline & & १V.AY & $r Y$ & كيمياء & \\
\hline \multirow{4}{*}{$.9 \vee \wedge$} & \multirow{4}{*}{.0199} & $1+1.7 \mathrm{~V}$ & IrE & علوم ابتدائى & \multirow{4}{*}{ المحور الثالث: المعوقات ككل. } \\
\hline & & 97.28 & $r \varepsilon$ & احياء & \\
\hline & & Q4.Vo & $r$. & فيزياء & \\
\hline & & 99.81 & $r Y$ & كيمياء & \\
\hline
\end{tabular}

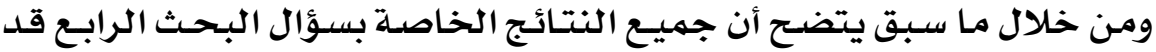

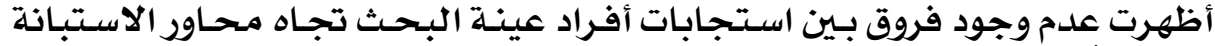

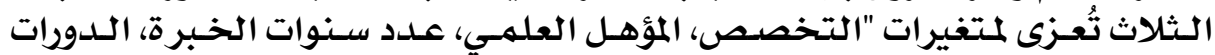

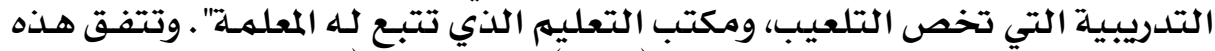

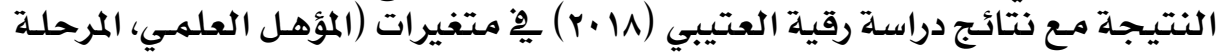

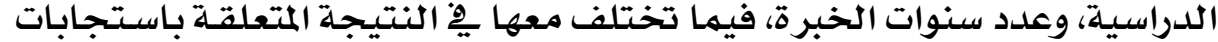

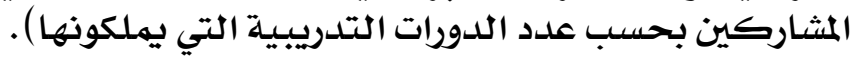

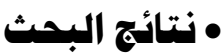

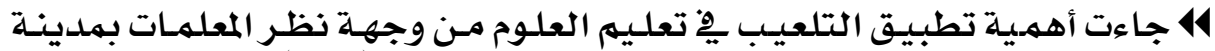

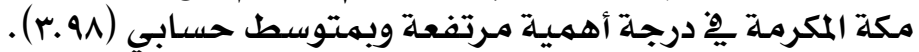

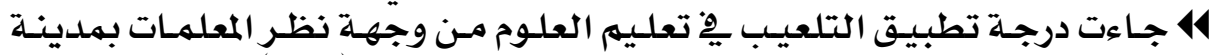

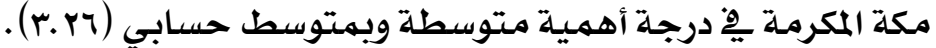

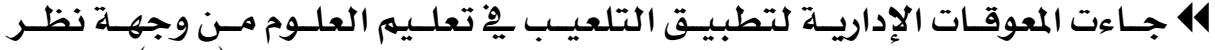

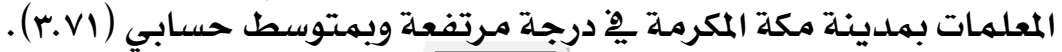




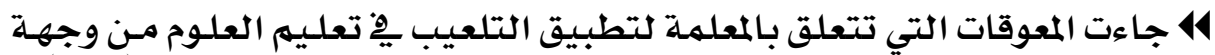

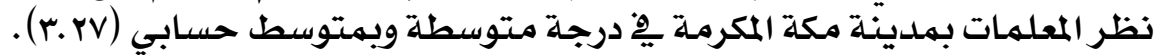

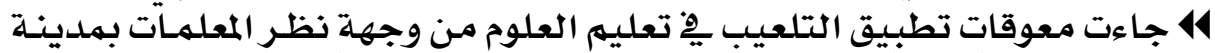

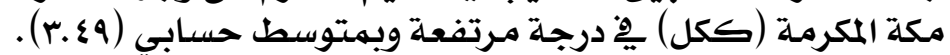

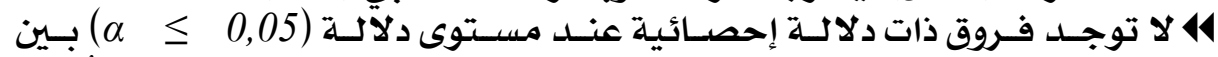

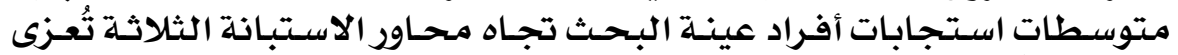

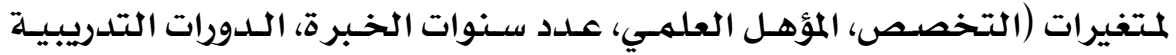

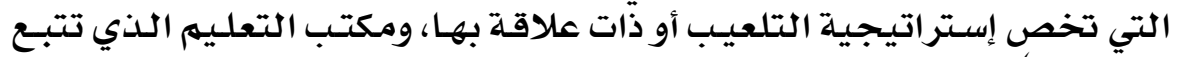
له المعلمهة).

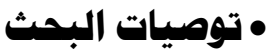

بناءً على نتائج البحث أبحث أعلاه توصي الباحثة بها يلي:

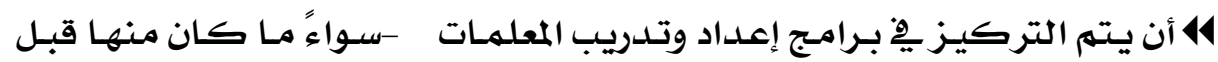

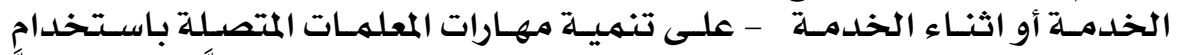

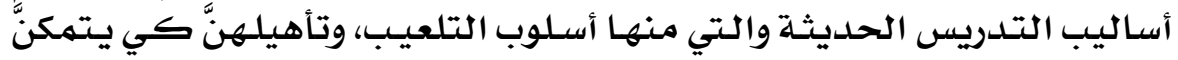

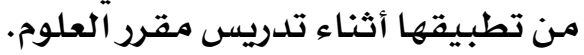

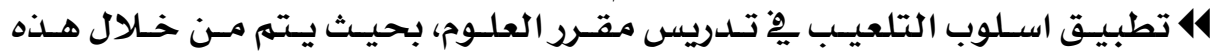

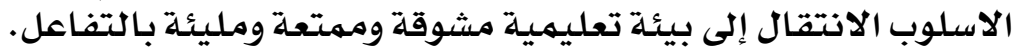

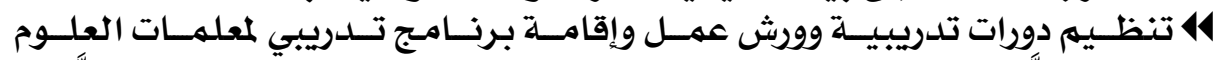

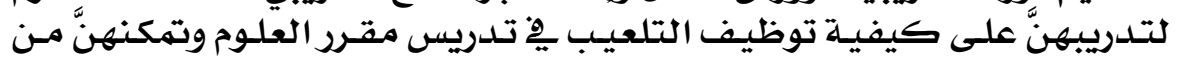
دمجر التقنية بالتعليهم.

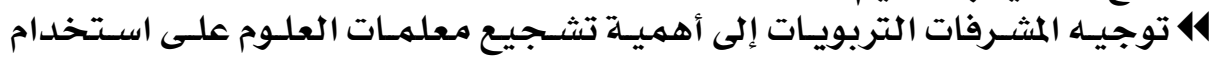

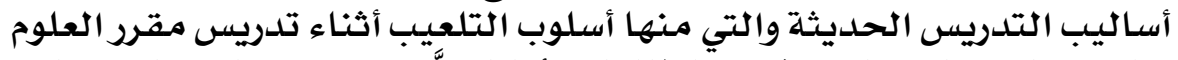

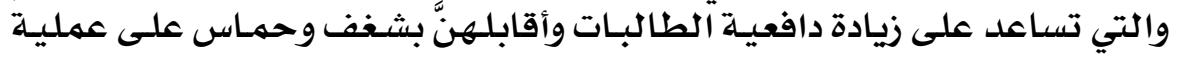

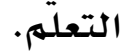

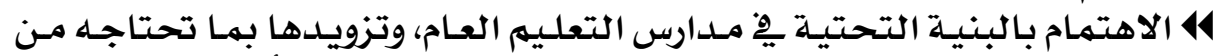

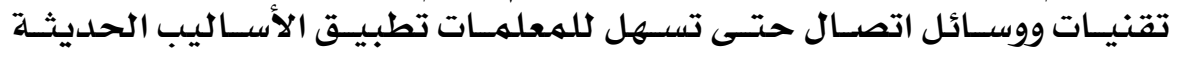

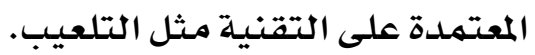

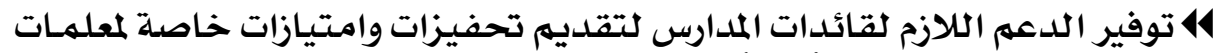

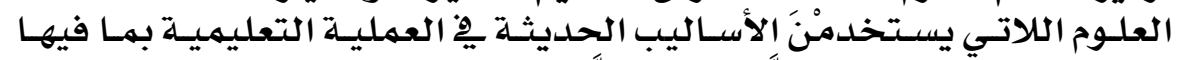

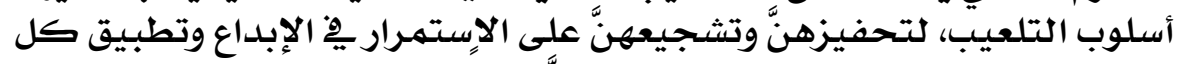

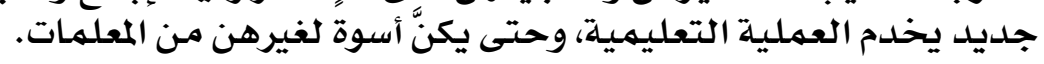

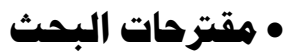

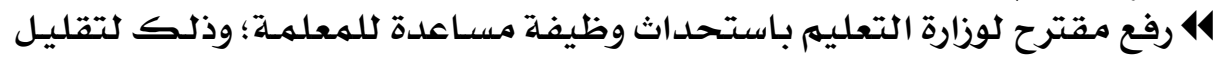

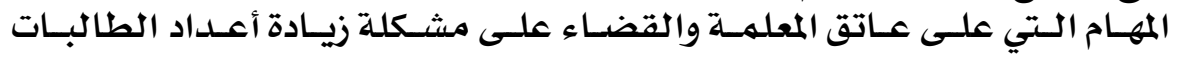

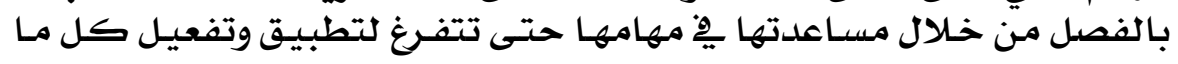
هو جديل ويخدم العملية التعليميلة.

\section{1}


14 دراسـة درجـة استخدام ومعوقات تطبيق التلعيب ِِِ مقررات دراسيلة أخرى.

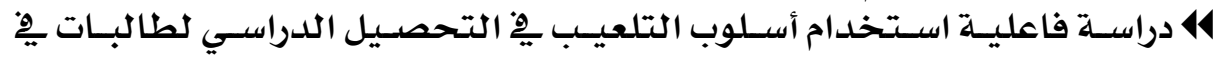
مراحل دراسية مختلفة فاعلة استخاء

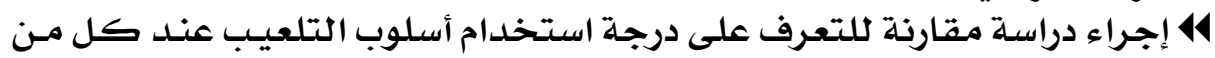

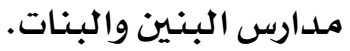

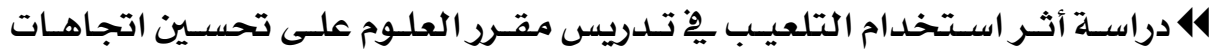

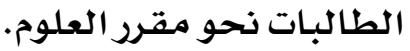

• مالمراجع:

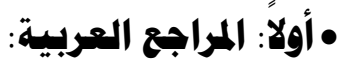

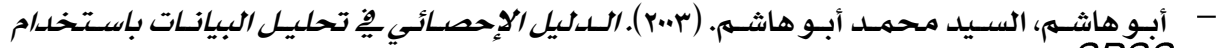
SPSS

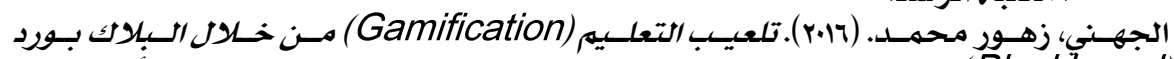
(Blackboard)

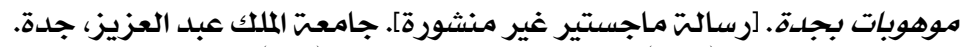

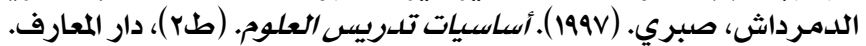

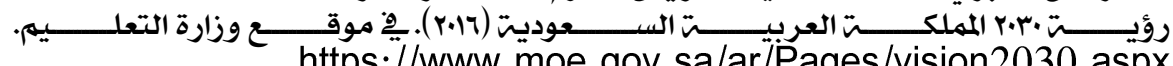
https://www.moe.gov.sa/ar/Pages/vision2030.aspx

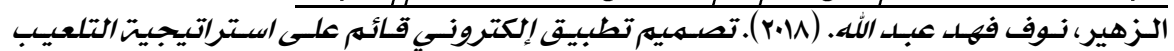

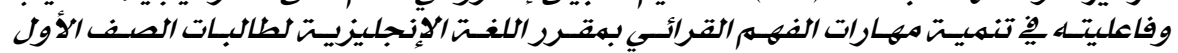

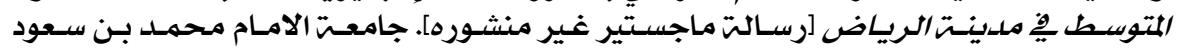
الاسلاميتة.

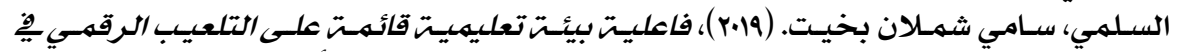

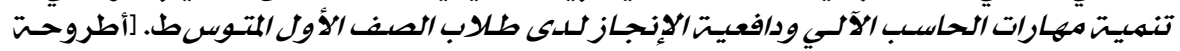

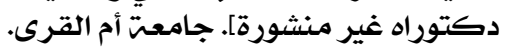

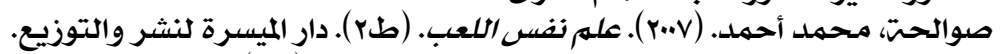

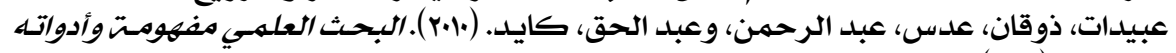

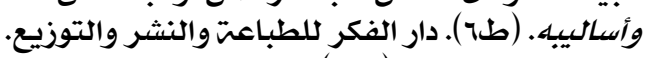

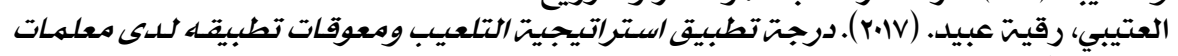

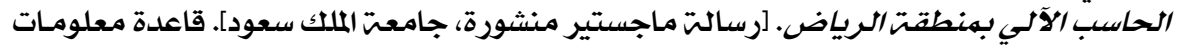
دار المنظومتي،

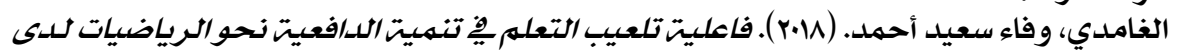

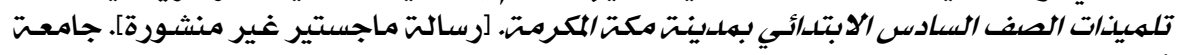

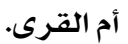

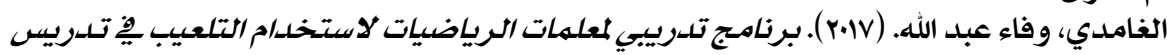

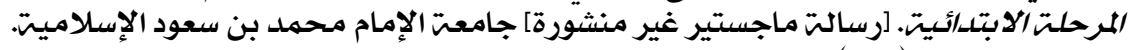

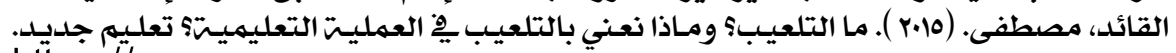

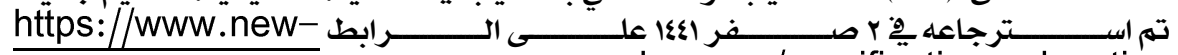
.educ.com/gamification-education

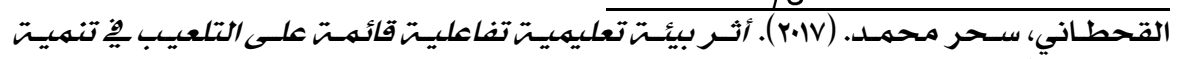

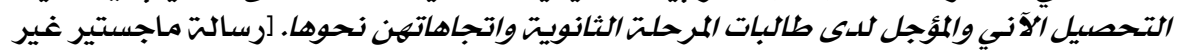
منشورة]. كليتً الثرق العرجي.

\section{9}




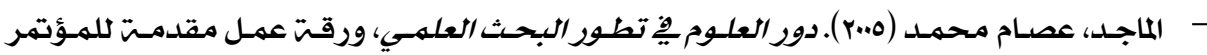

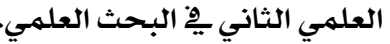

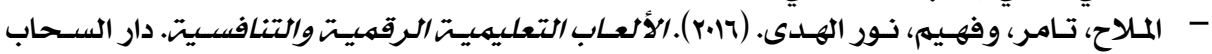

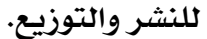

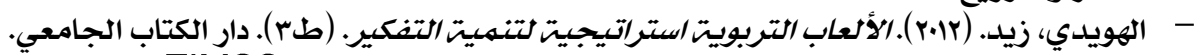

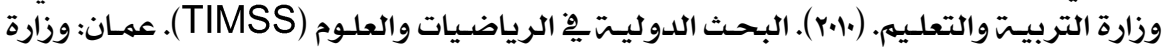
التربيت والتعليه.

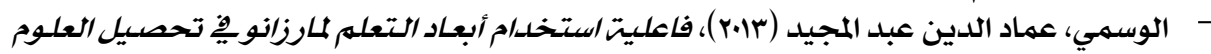

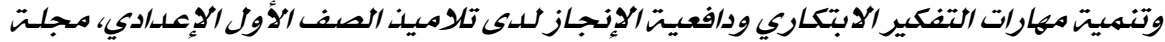

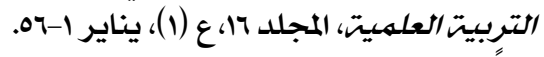

- Armier, D.D.; Jr., Shepherd, C.E., ;Skrabut, S. (2016).Using Game Elements to Increase Student Engagement in Course Assignments. College Teaching, 64,64_72.Retrieved from https://www.tandfonline.com/doi/full/10.1080/87567555.2015.10944 39? scroll=top\&needAccess =true

- Brophy, Keith. (2015). Gamification and Mobile Teaching and Learning. In: Yu Zhang (Editor), Handbook of Mobile Teaching and Learning, (92-105). Springer-Verlag Berlin Heidelberg.

- Burkey, D. D., Anastasio, D. D., \& Suresh, A.(Eds.) 2013. Improving Student Attitudes Toward the Capstone Laboratory Course Using Gamification. Atlanta: American Society for Engineering Education.

- Chevenchnko, A. (2013). Introducing game elements into the school environment to enhance student motivation and performance. Erasmus University Rotterdam.

- Chou, Yu-kai. (2015). Actionable Gamification: Beyond Points, Badges, and Leaderboards. United State of America: Leanpub.

- Creswell, J. W. (2014). Research design: Qualitative, quantitative, and mixed methods approaches. Thousand Oaks, CA: SAGE Publications.

- Creswell, J. W. (2018). Research Design: Qualitative, Quantitative, and Mixed Methods Approaches (5th ed). Thousand Oaks, CA: Sage Publications.

- De Byl, P. (2013). Factors at play in Curriculum Gamification. In the

- Dicheva, D., Dichev, C., Agre, G., \& Angelova, G. (2015). Gamification in education: A systematic mapping study. Journal of Educational Technology \& Society, 18(3), 75-88. 


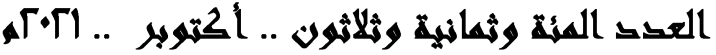

- Ejsing-Duun, S., \& Karoff, H. S. (2014). Gamification of a higher education course: What's the fun in that? European Conference on Games Based Learning, 1, 92.

- Grant, E., Shankararaman, v., \& Loong, J. (2014- December). Experimenting with Gamification in the Classroom. IEEE 6th International Conference on Engineering Education. Kuala Lumpur, Malaysia, 9-10 December 2014.

- Griffin, D. (2014). Gamification in e-learning. United Kingdom: Ashridge Business School.

- Huang, W. H. Y., \& Soman, D. (2013). Gamification of education. Research Report Series: Behavioural Economics in Action, Rotman School of Management, University of Toronto.

- Ibanez, M., Di-Serio, A. \& Delgado-Kloos, C. (2014). Gamification for Engaging Computer Science Students in Learning Activities: A Case Study. IEEE Transactions on Learning Technologies (TLT). 7(3), 291-301.

- IES, National Center for Education Statistics, TIMSS 2015. Retrieved: 14/6/1441H.,11:30am From: https://nces.ed.gov/timss/timss 15.asp

- Jenkins, J. (2016). Top 4 Gamification Problems to Avoid. Retrieved from https://elearningindustry.com/elearning-authors/jayme-jenkins

- Kapp, K. (2012). The gamification of learning and instruction: Game-based methods and strategies for training and education. New York: Wiley.

- Ledda, R. (2014). 6 reasons for the failure of gamification in education. Retrieved from https://rosalieledda.com/2014/03/16/6reasons-for-the-failure-of-gamification-in-education/

- Merrim Webster. (2017). Merriam Webster Dictionary. Retrieved from: https://www.merriam-webster.com/dictionary/gamification .

- O'Donovan, S., Gain, J., \& Marais, P. (2013). A case study in the gamification of a universitylevel games development course. Proceedings of South African Institute for Computer Scientists and Information Technologists Conference, (242-251).ACM.

- Oxford Analytica. (2016). Gamification and the Future of Education. United Kingdom: Oxford Analytica.

- Retrieved from: https://elearninginfographics.com/games-vs-gamebased-learning-vs-gamification-infographic/

- Rose, Jordan. (2015). The Gamification of Physics Education: A Controlled Study of the Effect on Motivation of First Year Life Science Students. University of Guelph, Ontario, Canada. 


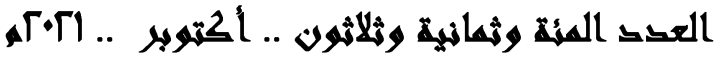

- Sailer, M. \& Homner, L. (2019). The Gamification of Learning: a Meta-analysis. Educational Psychology Review, 1-36.

- Shin, N. (2006). Online learner's "flow" experience: An empirical study. British Journal of Educational Technology, 37(5), 705-720.

- Smitha, E., Herberta, J., Kavanagha, L. \& Reidsema, Ca. (2013). The effects of gamification on student learning through the use of reputation and rewards within community moderated discussion boards. Nathan, Australia: Griffith school of Engineering, Griffith University.

- Su, C-H, \& Cheng, C-H. (2015). A mobile gamification learning system for improving the learning motivation and achievements. Journal of Computer Assisted Learning, 31(3), 268-286.

- Turan, Zeynep, Avinc, Zeynep, Kara, Kadir, \& Goktas, Yuksel. (2016). Gamification and Education: Achievements, Cognitive Loads, and Views of Students. Retrieved: 20/6/1441H.,9:00am From: http://online-journals.org/index.php/i-jet/article/view/5455/0

- Wendy, Hsin, Yuan, Huang, \& Dilip, Soman. (2013). APractitioner's Guide to Gamification of Education. Toronto, University of Toronto

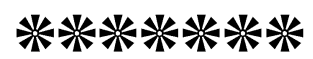

